\title{
ARTICLE
}

\section{Lipophilic prodrugs of nucleoside triphosphates as biochemical probes and potential antivirals}

Tristan Gollnest ${ }^{1}$, Thiago Dinis de Oliveira ${ }^{1}$, Dominique Schols ${ }^{2}$, Jan Balzarini ${ }^{2} \&$ Chris Meier $^{1}$

The antiviral activity of nucleoside reverse transcriptase inhibitors is often limited by ineffective phosphorylation. We report on a nucleoside triphosphate (NTP) prodrug approach in which the $\gamma$-phosphate of NTPs is bioreversibly modified. A series of TriPPPro-compounds bearing two lipophilic masking units at the $\gamma$-phosphate and $\mathrm{d} 4 \mathrm{~T}$ as a nucleoside analogue are synthesized. Successful delivery of d4TTP is demonstrated in human CD4 ${ }^{+}$T-lymphocyte cell extracts by an enzyme-triggered mechanism with high selectivity. In antiviral assays, the compounds are potent inhibitors of HIV-1 and HIV-2 in CD4 ${ }^{+}$T-cell (CEM) cultures. Highly lipophilic acyl residues lead to higher membrane permeability that results in intracellular delivery of phosphorylated metabolites in thymidine kinase-deficient CEM/TK- ${ }^{-}$cells with higher antiviral activity than the parent nucleoside.

\footnotetext{
${ }^{1}$ Institute of Organic Chemistry, Department of Chemistry, Faculty of Sciences, University of Hamburg, Martin-Luther-King-Platz 6, D-20146 Hamburg, Germany. ${ }^{2}$ Department of Microbiology and Immunology, Laboratory of Virology and Chemotherapy, Rega Institute for Medical Research, KU Leuven, Minderbroedersstraat 10, B-3000 Leuven, Belgium. Correspondence and requests for materials should be addressed to C.M. (email: chris.meier@chemie.uni-hamburg.de).
} 
O ver the last decades, a variety of nucleoside analogues were applied in antitumour and antiviral therapy and still play an important role to combat HIV, herpes virus, hepatitis $B$ and hepatitis $C$ virus infections ${ }^{1,2}$. The target of these nucleoside analogue drugs is the inhibition of the virus-encoded DNA polymerases, such as the HIV reverse transcriptase (RT) (3, $^{3,4}$ or the HCV-encoded RNA-dependent RNA-polymerase NS5B (ref. 5), which are the key enzymes in the replication cycle of HIV and $\mathrm{HCV}$, respectively. To date, eight nucleoside analogues have been approved as HIV RT inhibitors (NRTIs) ${ }^{6}$. NRTIs are still used as the backbone of the combined antiretroviral therapy ${ }^{7}$. However, the antiviral efficacy of nucleoside analogues, such as the thymidine analogue $3^{\prime}$-deoxy- $2^{\prime}, 3^{\prime}$-didehydrothymidine $\mathbf{1}$ $(\mathrm{d} 4 \mathrm{~T})$ and $3^{\prime}$-deoxy- $3^{\prime}$-azidothymidine (AZT), is dependent on the activity of host cell kinases metabolizing these nucleoside analogues into their antivirally active triphosphate forms (nucleoside triphosphates, NTPs) $^{8-11}$.

The stepwise transformation via the nucleoside mono- (NMP) and diphosphates (NDP) into the corresponding NTP often occurs insufficiently because of the high substrate specificity of the involved kinases (Supplementary Fig. 1). Furthermore, many nucleoside analogues have limitations such as poor biological half-lives, variable bioavailability after oral administration or selection of drug resistance, which reduce their clinical efficacy ${ }^{12,13}$. To overcome these hurdles, the usage of prodrugs of the phosphorylated metabolites have been explored in the past ${ }^{14,15}$.

In the case of $\mathrm{d} 4 \mathrm{~T} \mathbf{1}$, the first phosphorylation step to yield its monophosphate form $\mathbf{2}$ catalysed by the host cell enzyme thymidine kinase (TK) is metabolism-limiting because of the rather modest affinity of d4T $\mathbf{1}$ to TK as an alternative substrate and because TK activity is S-phase-dependent ${ }^{11,16,17}$. However, to avoid this limitation, it is not possible to apply the charged monophosphorylated metabolite because of the high polarity and thereby extremely poor, if any, membrane permeability. The development of nucleotide prodrugs capable of delivering the monophosphorylated metabolite and thereby bypassing the intracellular activation offered advantages over the use of the corresponding nucleoside analogue ${ }^{18,19}$. Moreover, lipophilicmasked NMPs such as $\mathbf{3}$ are less vulnerable to degradation by unspecific phosphatases present in the blood. This enhanced not only the plasma half-life but also enables the prodrug to be taken up by cells through passive diffusion ${ }^{20,21}$. A number of successful NMP prodrug strategies were reported in the past that efficiently bypass the nucleoside kinase hurdle. These prodrug forms such as phosphoramidates and cycloSal-phosphate triesters of nucleoside analogues were indeed shown to deliver the NMP either by chemical or enzymatic hydrolysis in the target cells ${ }^{22-27}$. In addition to NMPs also the successful delivery of acyclic nucleoside phosphonates such as cidofovir has been reported ${ }^{28}$. However, all these approaches delivered the monophosphor(n)ylated forms of the nucleosides that subsequently needed further phosphorylation into the triphosphate forms by cellular kinases to inhibit their target polymerase.

However, not in all cases such NMP prodrug strategies were successful. For instance, in the case of AZT the metabolism is limited by the second conversion step, the formation of AZT-diphosphate by thymidylate kinase ${ }^{10,29}$. In this case, a lipophilic prodrug that intracellularly releases the NDP would be desirable. At the same time, this would avoid toxicity caused by the parent nucleoside or the accumulation of the monophosphate form ${ }^{30}$. A further example is $2^{\prime}, 3^{\prime}$-dideoxy- $2^{\prime}, 3^{\prime}$-didehydrouridine $(\mathrm{d} 4 \mathrm{U})$. The parent nucleoside proved to be completely inactive against HIV replication in cell cultures. In contrast, the triphosphate form of $\mathrm{d} 4 \mathrm{U}$ is one of the most effective inhibitors of the HIV's RT ${ }^{31}$
We reported on NDP prodrugs (DiPPro-approach), which selectively released NDPs not only in phosphate buffer $(\mathrm{pH} 7.3)$ but for the first time also in CEM cell extracts ${ }^{32-35}$. These compounds showed very good antiviral activity in TK-deficient $\mathrm{CEM} / \mathrm{TK}^{-}$cell cultures infected with HIV, proving the uptake of the compounds and the delivery of at least phosphorylated metabolites, most likely the NDP. The uptake of those compounds was achieved by two acceptor-substituted benzylesters linked to the $\beta$-phosphate group of the NDP. The stability of the compounds correlated with the length of the aliphatic residue of the mask ${ }^{32,33}$. However, we have shown that the delivery of the corresponding mono- or diphosphates from prodrug forms (such as the cycloSal- or DiPPro-compounds) did not improve the antiviral activity ${ }^{34}$. Importantly, in the same study we have proven that $\mathrm{d} 4 \mathrm{U}$ diphosphate was a very poor substrate for the NDP kinase, the enzyme that is generally accepted to be involved in the conversion of NDPs into their triphosphate forms. Thus, this study showed that the phosphorylation of nucleotide analogues by NDP kinase can be also rate-limiting in the activation process of a nucleoside analogue $^{34,36}$. As a consequence, the development of nucleoside triphosphate prodrugs would be highly interesting and desirable because this would bypass all steps of intracellular phosphorylation and would maximize the intracellular concentration of the ultimately bioactive NTP. Although this has been recognized before ${ }^{11}$, it was also claimed that the development of prodrugs of NTP is chemically not feasible because of the low stability of such compounds ${ }^{37}$. For this reason, NTPs were very rarely used as drug platforms because of their expected poor deliverability and their high sensitivity for enzymatic dephosphorylation. Thus, very few reports on potential triphosphate prodrugs have been reported ${ }^{38,39}$. In addition, in the few reported examples the yields in the chemical synthesis were poor, and additionally the compounds proved hydrolytically very unstable. A difficulty that has to be taken into account in the development of NTP prodrugs is related to the energy-rich phosphate anhydride bonds within the triphosphate unit. Under physiological conditions, these linkages are only kinetically stable because of the charges present at that moiety, which prevent nucleophilic reactions that end up in the cleavage of these anhydride bonds but can be enzymatically cleaved. Interestingly, $\gamma$-modification of NTPs by esterification or replacement of the $\gamma$-phosphate group by a phosphonate moiety led to a marked increase in enzymatic stability of the triphosphate unit ${ }^{40,41}$. On the other hand, complete lipophilic modification and thereby neutralization of the charges would significantly increase the reactivity of the triphosphate unit. For completeness, it should be added that the delivery challenge for NTPs has also been addressed by formulating these compounds with cationic nanogels. However, this approach still requires elaboration with respect to their toxicity, immunogenicity and pharmacokinetics ${ }^{42,43}$.

Here we disclose the development of a novel prodrug concept for NTPs that releases directly NTPs with high selectivity by an enzyme-triggered mechanism and thus allows the bypass of all phosphorylation steps normally needed for the activation of a nucleoside analogue (Supplementary Fig. 2). To achieve this goal, the $\gamma$-phosphate group of a NTP was modified by esterification with acyloxybenzyl moieties (TriPPPro-compounds). By fine-tuning the lipophilicity through the use of different acyl esters the chemical stability also proved controllable so that the polarity caused by the remaining charges at the $\alpha$ - and $\beta$-phosphates could be efficiently compensated.

The cleavage of the prodrug moieties is initiated by an enzymatic hydrolysis of the phenolic acyl-ester. This reaction leads to a spontaneous cleavage of the benzyl C-O bond forming 
first a monomasked intermediate of the NTPs. This process is repeated for the second mask so that finally the NTP is formed ${ }^{32}$. Lipophilic aliphatic esters have proven to be suitable for prodrugs to allow entering the cell independently of nucleoside transporters but to enable removal of the lipophilic prodrug moieties by cellular esterases/lipases ${ }^{44}$. Moreover, fatty-acid esters are known to be taken up by the mononuclear phagocyte system. These cells are important in the pathogenesis of AIDS and are considered to be reservoirs for HIV particles ${ }^{45,46}$.

We report on the synthesis of NTP prodrugs 3 bearing two identical 4-alkanoyloxybenzyl- (a-k), 4-alkoxycarbonyloxybenzyl- (1-n) and 4-aminocarbonyloxybenzyl groups (o-q), their hydrolysis properties in different media, the hydrolysis mechanism, primer extension assays and their anti-HIV activity. In addition, the synthesis of the monomasked (4-alkyloxybenzyl)d4TTPs 4a,e,j is reported. As a model nucleoside analogue, d4T 1 was used to allow a comparison of the TriPPPro-compounds $\mathbf{3}$ with the DiPPro-compounds.

\section{Results}

Synthesis of TriPPPro-d4T triphosphate prodrugs 4 . For the synthesis of TriPPPros-d4TTP prodrugs 3 a convergent strategy using a dicyanoimidazol (DCI)-mediated coupling of an appropriate phosphoramidite $\mathbf{5}$ and d4TDP $\mathbf{6}$ to form the energetically rich pyrophosphate moiety in the last step was performed (Fig. 1). First, d4T 1 was prepared in good overall yields according to a three-step protocol reported by Horwitz $z^{47}$. From that compound, d4TDP $\mathbf{6}$ was prepared by applying the cycloSal technique (55\% yield) because it has been reported that acceptor-substituted cycloSal nucleotides gave access to diphosphorylated compounds by using tetra- $n$-butylammonium phosphate as a nucleophile ${ }^{48}$. Therefore, the 5-chloro-substituted cycloSal-phosphate triester 7 was synthesized starting from $\mathrm{d} 4 \mathrm{~T} \mathbf{1}$ with 5-chlorosaligenylchlorophosphite $\mathbf{8}$ followed by oxidation with tert-butylhydroperoxide to give the product 7 as a mixture of two diastereomers in high yields.

Despite its very difficult chromatographic properties, the resulting crude $(n-\mathrm{Bu})_{4} \mathrm{~N}^{+}$-salt 6 was purified by automatic RP-18 flash chromatography without additional ion exchange.
The hygroscopic tetra- $n$-butylammonium salt form of d4TDP 6 was co-evaporated in dimethylformamide (DMF) and dried in high vacuum before the coupling reaction to ensure dry reaction conditions. The use of tetra- $n$-butylammonium counterions afforded a higher reactivity and better solubility in organic solvents. D4TDP 6 was then reacted with a series of phosphoramidites $\mathbf{5}$ in a very fast DCI-mediated coupling reaction and was oxidized $^{32,33}$.

Inspired by recently published biodegradable linear polymers that were degraded by an acid-induced cascade reaction, we also synthesized carbamate derivatives 3o-q (ref. 49). In this case, 4-hydroxybenzyl alcohol $\mathbf{1 0}$ was first protected with tert-butyldimethylsilyl chloride to give compound $\mathbf{1 1}$ followed by an esterification using 4-nitrophenyl chloroformiate. To trap the excess of the chloroformiate, triethylene glycol monomethyl ether was added ${ }^{49}$. The obtained carbonate 12 was then converted with $t$-Boc-protected dimethylethylenediamine 13 and after acid-catalysed cleavage of both protecting groups the methylcarbamate $\mathbf{1 4}$ was isolated in $98 \%$ yield. Finally, phenylcarbamates 15 were synthesized starting from 14 in an one-pot reaction including tetramethylsilane (TMS) protection, coupling with the corresponding acyl chloroformiates 16 and desilylation in a yield of up to $59 \%$ (Fig. 2).

The 4-hydroxybenzyl alcohols bearing acyl-ester groups at the phenol and the carbamates were converted into phosphoramidites 5 in high yields as published before ${ }^{32,33}$. Finally, d4TDP 6 was mixed with 1.7 equivalents (eq.) of a corresponding phosphoramidite $\mathbf{5}$ and co-evaporated with acetonitrile. Then, the mixture was dissolved in a minimum of acetonitrile because achieving a high concentration was crucial for the success of the coupling reaction. In case of compounds with long acyl residues $\left(\mathrm{R} \geq \mathrm{C}_{11} \mathrm{H}_{23}\right)$, tetrahydrofurane (THF) was added to accomplish complete solubility of the reagents. In some cases, the conversion of d4TDP 6 was not complete. In these cases, all volatile components were removed in vacuum, the residue was redissolved and further $1.0 \mathrm{eq}$. of the phosphoramidite 5 and 0.8 eq. of DCI were added. After another minute of stirring, the reaction mixture was oxidized. After oxidation the quantitative consumption of d4TDP 6 was confirmed using high-performance
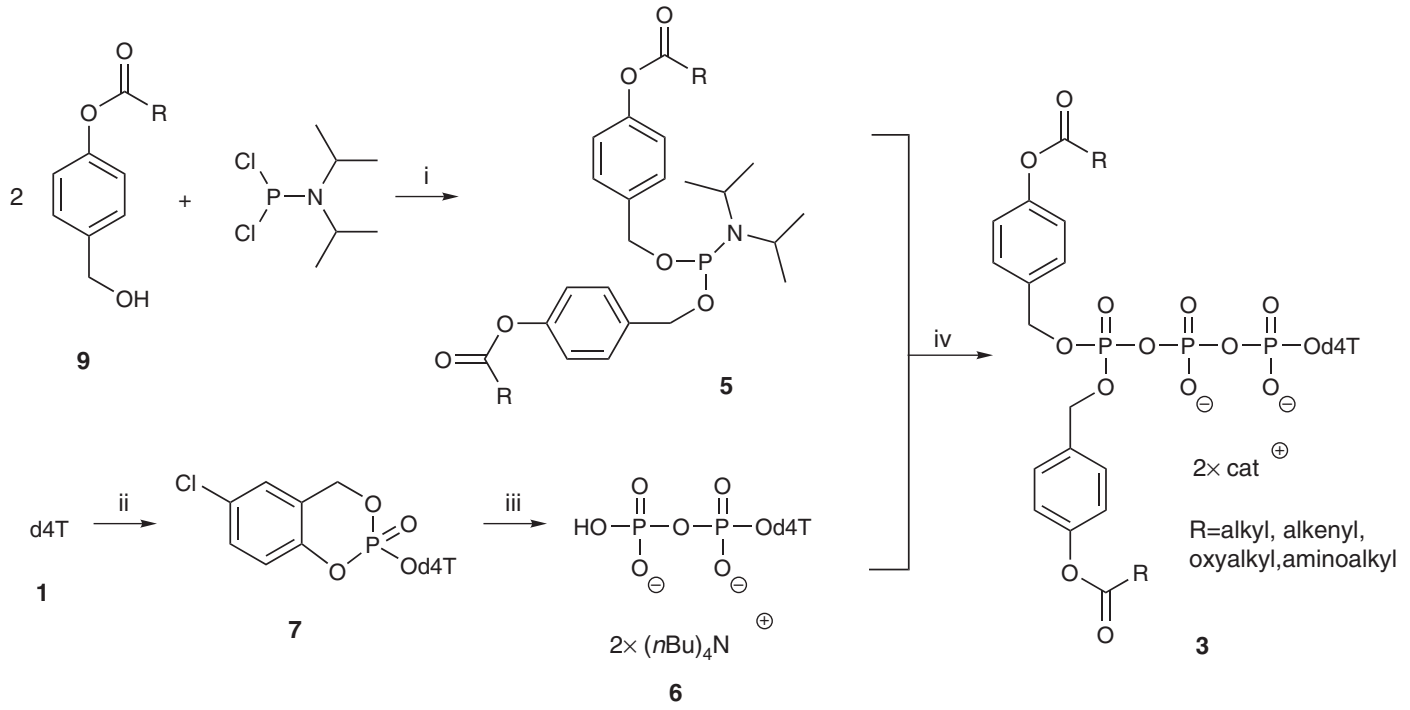

Figure 1 | Reagents and conditions. (i) Triethylamine, $\mathrm{THF}, \mathrm{O}^{\circ} \mathrm{C}-\mathrm{rt}, 2 \mathrm{Oh}$; (ii) 1. 5-chlorosaligenylchlorophosphite 8, $\mathrm{N}, \mathrm{N}$-diisopropylethylamine, $\mathrm{CH}{ }_{3} \mathrm{CN}$, $-20^{\circ} \mathrm{C}$-rt, $3 \mathrm{~h}$, 2. $t$ - $\mathrm{BuOOH}$ in $n$-decane, $0{ }^{\circ} \mathrm{C}$-rt, $30 \mathrm{~min}$; (iii) $\left(\mathrm{H}_{2} \mathrm{PO}_{4}\right) \mathrm{Bu}_{4} \mathrm{~N}, \mathrm{DMF}, \mathrm{rt}, 20 \mathrm{~h}$; (iv) 1. $\mathrm{DCl}, \mathrm{CH}_{3} \mathrm{CN}, \mathrm{rt}, 1 \mathrm{~min}, 2 \mathrm{2} t-\mathrm{BuOOH}$ in $n$-decane, $0{ }^{\circ} \mathrm{C}$-rt, $15 \mathrm{~min}$. 


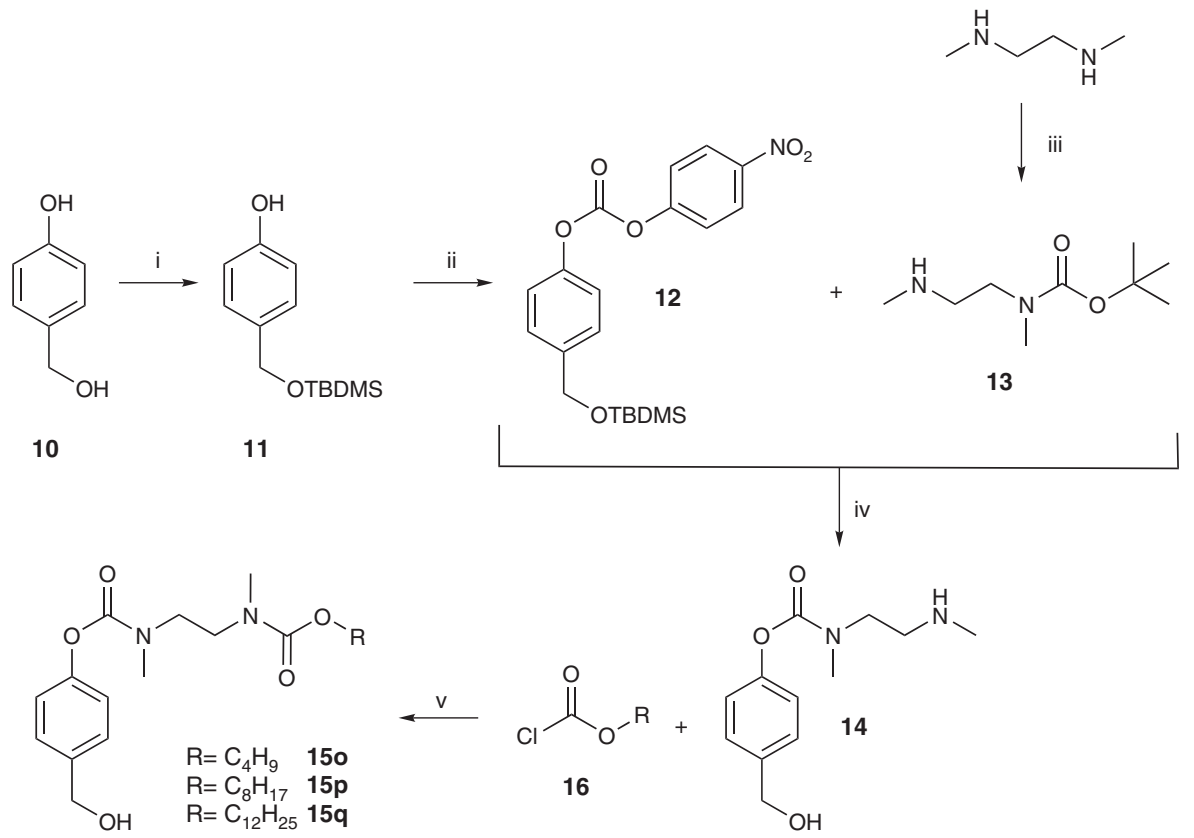

Figure 2 | Reagents and conditions. (i) TBDMSCl, imidazole, $\mathrm{CH}_{2} \mathrm{Cl}_{2}, \mathrm{rt}, 2 \mathrm{~h}$; (ii) 1. 4-nitrophenyl chloroformiate, triethylamine, $\mathrm{CH}_{2} \mathrm{Cl}_{2}, \mathrm{rt}, 16 \mathrm{~h}, \mathbf{2}$. triethylene glycol monomethyl ether, rt, $20 \mathrm{~min}$; (iii) $\mathrm{Boc}_{2} \mathrm{O}, \mathrm{O}^{\circ} \mathrm{C}-\mathrm{rt}, 2 \mathrm{O}$; (iv) 1. 4-DMAP, diisopropylethylamine, toluene, $\mathrm{rt}, 16 \mathrm{~h}, \mathbf{2} . \mathrm{TFA} / \mathrm{CH}_{2} \mathrm{Cl}{ }_{2}, \mathrm{rt}, 0.5 \mathrm{~h}$; (v) 1. $\mathrm{TMSCl}$, imidazole, $\mathrm{THF}, 0^{\circ} \mathrm{C}-\mathrm{rt}, 2 \mathrm{~h}$, 2. triethylamine, $0{ }^{\circ} \mathrm{C}-\mathrm{rt}, 1.5 \mathrm{~h}, 3.1 \% \mathrm{HCl}(12 \mathrm{M})$ in $\mathrm{EtOH}, \mathrm{rt}, 1 \mathrm{~h}$.
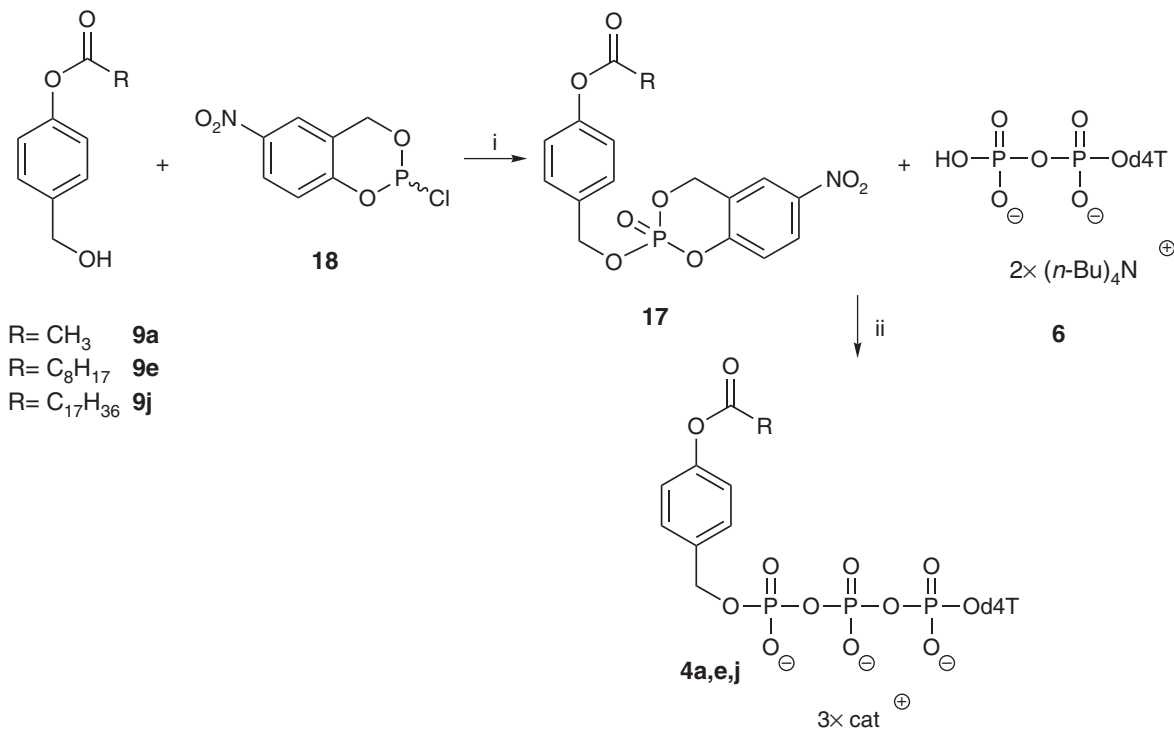

Figure 3 | Reagents and conditions. (i) 1. diisopropylethylamine, $\mathrm{CH}_{3} \mathrm{CN},-20^{\circ} \mathrm{C}-\mathrm{rt}, 1 \mathrm{~h}, \mathbf{2}$. oxone, $\mathrm{H}_{2} \mathrm{O} / \mathrm{CH}_{3} \mathrm{CN}$, rt, 30 min; (ii) bis(tetra-nbutyl)ammonium-d4TDP 6, DMF, rt, $3 \mathrm{~h}$.

liquid chromatography (HPLC; Supplementary Fig. 3). Next, the solvent was removed in vacuum and the crude product was purified with RP-18 chromatography using gradients of water/ acetonitrile or water/THF as eluents. For compounds $\mathbf{3 a}-\mathbf{f}, \mathbf{1}-\mathbf{n}$, $\mathbf{o - q}$ the tetra- $n$-butylammonium ions were exchanged by ammonium ions using Dowex 50WX8 and the chromatography was repeated.

Synthesis of monomasked triphosphate prodrugs 4 . In addition to the TriPPPro-compounds $\mathbf{3}$, the monomasked acyloxybenzylNTP derivatives 4 were synthesized as well (Fig. 3). Such monoesterified substances were described by others as potential triphosphate prodrugs ${ }^{38,39,50}$. Several synthesis routes mainly based on DCC-activated coupling were published. In our recent studies with DiPPro-prodrugs, we isolated such monoesterified compounds by simple hydrolysis ${ }^{33}$.

An efficient access to such compounds was developed in this study. The monoesterified NTPs were prepared starting from 4-acyloxybenzyl alcohol 9 and its conversion into the 5-nitro-cycloSal-triester 17. Despite the high reactivity of this compound, the purification by preparative thin-layer chromatography (TLC) was successful. The benzyl-(5-nitro-cycloSal)phosphate triesters $\mathbf{1 7}$ were obtained in high yields (up to 
89\%). Next, triesters 17 gave the monomasked acyloxybenzyld4TTPs 4 in yields of $26-30 \%$ by the addition of d4TDP 6 .

Stability studies. The TriPPPros-d4TTP prodrugs 3 and the intermediates 4 were incubated in PBS $(25 \mathrm{mM}, \mathrm{pH} 7.3)$, or were exposed to pig liver esterase (PLE) in PBS and to human $\mathrm{CD}_{4}^{+}$ T-lymphocyte cell extracts to study their stability and the product distribution. The hydrolysis mixtures were analysed by means of analytical RP-18-HPLC. The calculated half-lives (Table 1$)$ were determined for the first removal of one masking unit $\left(t_{1 / 2}(1)\right)$ to yield the intermediate $\mathbf{4}$ and the second hydrolysis step $\left(t_{1 / 2}(2)\right)$ to give the triphosphate 19.

Chemical stability in PBS at $\mathbf{p H}$ 7.3. In PBS, the stability of TriPPPro-d4TTP prodrugs $\mathbf{3 a}-\mathbf{h}, \mathbf{l}-\mathbf{n}$ increased with increasing alkyl chain lengths (Table 1). However, the half-lives of more lipophilic compounds $\mathbf{3 i}-\mathbf{k}$ decreased because of altered solubility behaviour or micelle formation. The half-lives of the intermediates $\mathbf{4}$ were always considerably higher than those of their precursors 3 because of the increase in charges leading to repulsive interaction with an incoming nucleophile. Moreover, formation of the three nucleotide forms 2, 6 and 19 were observed (Supplementary Fig. 4).

Hydrolysis study using esterase. Next, we examined the enzymatic stability of prodrugs $\mathbf{3 a}-\mathbf{n}$ by incubation with PLE in PBS, $\mathrm{pH}$ 7.3. The cleavage of the masking units for $\mathbf{3 b}-\mathbf{g}$ occurred much faster than that in PBS, demonstrating a significant contribution of the enzymatic cleavage (Table 1). As observed in the chemical hydrolysis studies, the cleavage of the second masking group proceeded much slower. According to the substrate specificity of PLE we determined the lowest half-lives for $\mathbf{3 c}-\mathbf{f}$ and $\mathbf{3 m}$. Shorter as well as longer alkyl residues in the ester moiety of the masking group led to increased half-lives. In addition, d4TTP Table 1 | Hydrolysis half-lives of TriPPPro-d4TTPs 3 and
monoesterified d4TTPs 4 in different media.

\begin{tabular}{|c|c|c|c|c|c|c|}
\hline \multirow[t]{2}{*}{ Compd } & \multirow[t]{2}{*}{$\mathbf{R}$} & \multicolumn{2}{|c|}{ PBS, $\mathrm{pH}=7.3(\mathrm{~h})$} & \multicolumn{2}{|c|}{ PLE (h) } & \multirow{2}{*}{$\begin{array}{l}\text { CEM } \\
\text { (h) } \\
t_{1 / 2}(1)^{\star}\end{array}$} \\
\hline & & $\overline{t_{1 / 2}(1)^{\star}}$ & $t_{1 / 2}(2)^{\dagger}$ & $t_{1 / 2}(1)^{\star}$ & $t_{1 / 2}(2) \dagger$ & \\
\hline $3 a$ & $\mathrm{CH}_{3}$ & 18 & 75 & 1.9 & 71 & 0.050 \\
\hline $\mathbf{3 b}$ & $\mathrm{C}_{2} \mathrm{H}_{5}$ & 17 & 150 & 0.42 & 33 & 0.12 \\
\hline $3 c$ & $\mathrm{C}_{4} \mathrm{H}_{9}$ & 22 & 270 & 0.063 & 7.7 & 0.43 \\
\hline 3d & $\mathrm{C}_{6} \mathrm{H}_{13}$ & 26 & 350 & 0.013 & 1.6 & 0.98 \\
\hline $3 e$ & $\mathrm{C}_{8} \mathrm{H}_{17}$ & 52 & 390 & 0.013 & 1.6 & 2.5 \\
\hline $3 f$ & $\mathrm{C}_{9} \mathrm{H}_{19}$ & 44 & 350 & 0.082 & 3.0 & 2.8 \\
\hline $3 g$ & $\mathrm{C}_{11} \mathrm{H}_{23}$ & 68 & 410 & 0.95 & 8.3 & 2.2 \\
\hline $3 \mathrm{~h}$ & $\mathrm{C}_{13} \mathrm{H}_{27}$ & 90 & 355 & 30 & n.d. $\ddagger$ & 4.6 \\
\hline $3 \mathbf{i}$ & $\mathrm{C}_{15} \mathrm{H}_{31}$ & 73 & 462 & 33 & n.d..$^{\ddagger}$ & 5.3 \\
\hline $3 \mathbf{j}$ & $\mathrm{C}_{17} \mathrm{H}_{35}$ & 50 & 583 & 37 & n.d..$^{\ddagger}$ & 13 \\
\hline $3 k$ & $\mathrm{C}_{17} \mathrm{H}_{33}(8 \mathrm{Z})$ & 27 & 92 & 42 & n.d..$^{\ddagger}$ & 4.3 \\
\hline 31 & $\mathrm{OCH}_{3}$ & 24 & 200 & 3.8 & 177 & 0.97 \\
\hline $3 m$ & $\mathrm{OC}_{8} \mathrm{H}_{17}$ & 82 & 590 & 0.12 & 17 & 2.6 \\
\hline $3 n$ & $\mathrm{OC}_{11} \mathrm{H}_{23}$ & 99 & 631 & 44 & n.d. $\ddagger$ & 3.0 \\
\hline 30 & $\mathrm{NCH}_{3}\left(\mathrm{C}_{9} \mathrm{H}_{19} \mathrm{NO}_{2}\right)$ & 27 & n.d. $\ddagger$ & n.d. ${ }^{\S}$ & n.d. ${ }^{\S}$ & n.d..$^{\ddagger}$ \\
\hline $3 p$ & $\mathrm{NCH}_{3}\left(\mathrm{C}_{13} \mathrm{H}_{27} \mathrm{NO}_{2}\right)$ & 48 & n.d. $\ddagger$ & n.d. ${ }^{\S}$ & n.d. $\$$ & 5.6 \\
\hline $3 q$ & $\mathrm{NCH}_{3}\left(\mathrm{C}_{17} \mathrm{H}_{35} \mathrm{NO}_{2}\right)$ & 48 & n.d. ${ }^{\ddagger}$ & n.d. ${ }^{\S}$ & n.d. ${ }^{\S}$ & n.d. ${ }^{\ddagger}$ \\
\hline $4 a$ & $\mathrm{CH}_{3}$ & n.a.ll & 95 & n.a.ll & 108 & 0.040 \\
\hline $4 e$ & $\mathrm{C}_{8} \mathrm{H}_{17}$ & n.a.ll & 237 & n.a.ll & 1.5 & 1.8 \\
\hline $4 \mathbf{j}$ & $\mathrm{C}_{17} \mathrm{H}_{35}$ & n.a."l & 637 & n.a."l & 57 & 4.6 \\
\hline \multicolumn{7}{|c|}{ 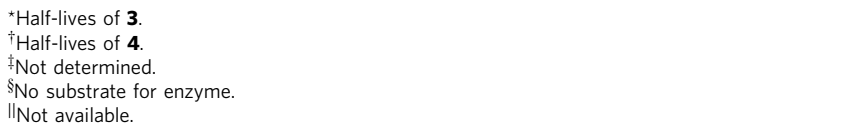 } \\
\hline
\end{tabular}

19 was delivered by enzymatic activation of $\mathbf{3 a}-\mathbf{n}$ but was also found to be the sole metabolite from $\mathbf{4 a}, \mathbf{e}, \mathbf{j}$ as long as the enzymatic cleavage occurred rapidly (Supplementary Fig. 5). The

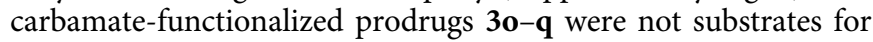
PLE, as expected.

To confirm the prodrug concept and thus the direct successful release of the biologically active triphosphate metabolite, the prodrug 3e was exposed to PLE and the hydrolysis monitored with RP-18-HPLC. After complete consumption of $\mathbf{3 e}$ as well as its intermediate $4 \mathbf{e}$ the solvents were removed. For the template/ primer extension assay (Fig. 4a), HIV RT was incubated with the PLE hydrolysate as such $\left(T^{*}\right)$ or with the PLE hydrolysate in the additional presence of dCTP $\left(T^{*}, C\right)$, or dCTP + dGTP $\left(T^{*}, C, G\right)$ or all natural $2^{\prime}$-deoxynucleotides $\left(\mathrm{N}^{*}\right)$. Interestingly, an immediate DNA chain termination was observed after incorporation of d4TMP 2 (derived from the incoming d4TTP 19 that was released from the prodrug by PLE), while the control reaction containing all four natural NTPs in the absence of the PLE hydrolysate (N) showed full extension of the primer (Fig. 4a). In addition, TriPPPro-TTP 3r was synthesized (Fig. 5) and also investigated in the same way. As expected, the template/ primer extension assay showed efficient DNA elongation (Fig. 4b). The $\mathrm{T}^{*}$ lysate resulted in termination of the polymerization because of the lack of the next complementary nucleotide (dCTP; position 26nt), whereas the reaction proceeded till position $28 \mathrm{nt}$ in the presence of both $\mathrm{T}^{*}$ and dCTP $\left(T^{*}, C\right)$. The primer could be fully extended till $30 \mathrm{nt}$ when $\mathrm{T}^{*}$ was added in the presence of dCTP and dGTP, as also the $\mathrm{N}^{\star}$ and $\mathrm{N}$ samples could.

Hydrolysis in cell extracts. The hydrolysis of the TriPPProcompounds 3 was further investigated in human $\mathrm{CD}_{4}^{+} \mathrm{T}$-lymphocyte CEM cell extracts. Again, the half-lives of the prodrugs 3a-n correlated well with chain length and were significantly lower than the half-lives in PBS buffer (Table 1). Thus, an enzymatic cleavage reaction took place as described above for the PLE studies. Furthermore, we observed the formation of the corresponding intermediates $\mathbf{4 a}-\mathbf{n}$ that had lower half-lives than their parent prodrugs. This assumption was proven by hydrolysis of the synthesized intermediates $\mathbf{4 a}, \mathbf{e}, \mathbf{j}$. In contrast to hydrolysis studies with PLE, in addition to d4TTP 19 d4TDP 6 was also detected as a major component in the CEM cell extracts most probably because of the presence of hydrolytic enzymes such as phosphatases and esterases (Supplementary Fig. 6).

The formation of d4TDP $\mathbf{6}$ was clearly not a result of unselective cleavage of the prodrug 3 . Investigations in cell
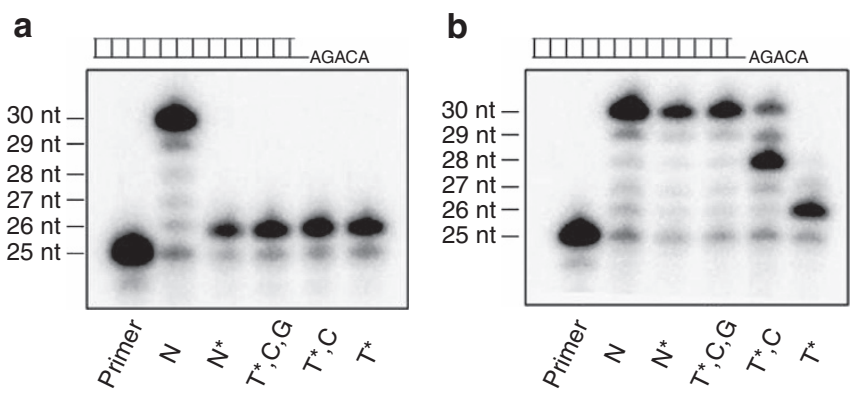

Figure 4 | Primer extension assays with HIV reverse transcriptase. (a) PLE hydrolysate based on TriPPPro-d4TTP $3 \mathbf{e}\left(T^{\star}\right)$; dCTP; dGTP; all natural triphosphates $(\mathrm{N})$; dATP, dCTP, dGTP and the hydrolysate of 3e $\left(\mathrm{N}^{\star}\right)$. (b) PLE hydrolysate based on TriPPPro-compound $\mathbf{3 r}\left(\mathrm{T}^{*}\right)$; dCTP; dGTP; all natural triphosphates (N); dATP, dCTP, dGTP and the hydrolysate of $3 \mathbf{r}\left(N^{\star}\right)$. nt: nucleotide, length of primer. 


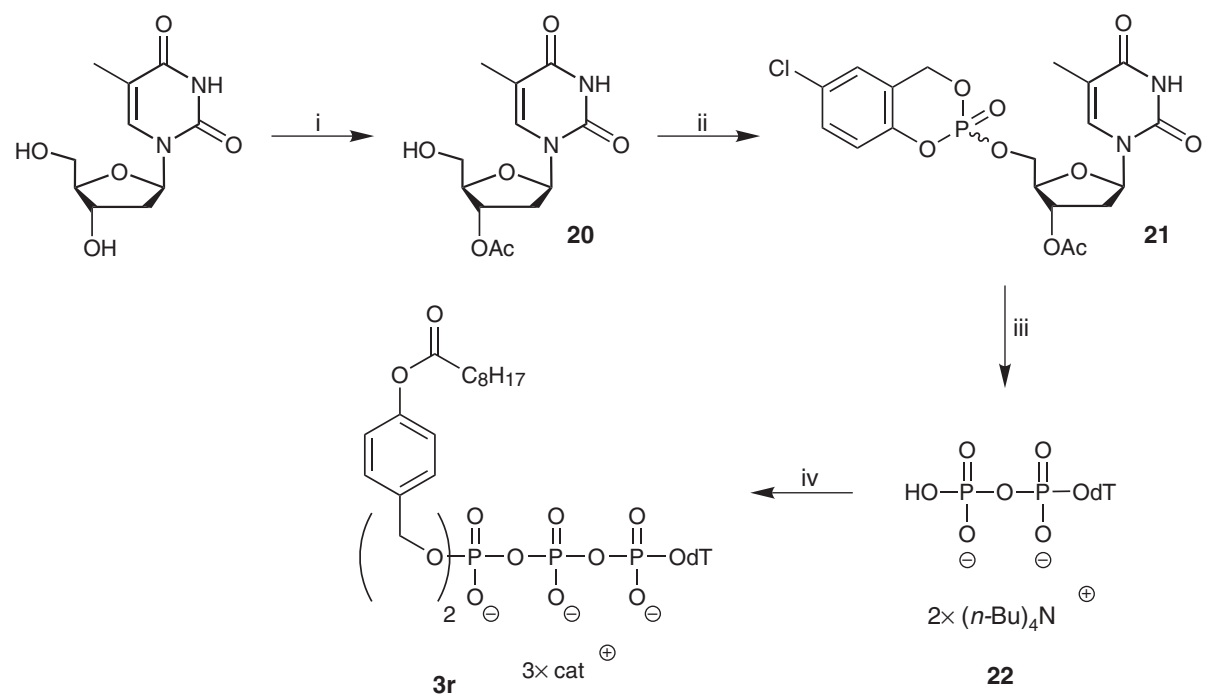

Figure 5 | Reagents and conditions. (i) 1. TBDMSCl, pyridine, rt, $20 \mathrm{~h}, \mathbf{2} . \mathrm{Ac}_{2} \mathrm{O}, \mathrm{rt}, 5 \mathrm{~h}, \mathbf{3} . \mathrm{TBAF}, \mathrm{THF}, \mathrm{O}^{\circ} \mathrm{C}, 1.5 \mathrm{~h}$; (ii) 1. 5-chlorosaligenylchlorophosphite 8, $\mathrm{N}, \mathrm{N}$-diisopropylethylamine, $\mathrm{CH}_{3} \mathrm{CN}, \mathrm{O}^{\circ} \mathrm{C}$-rt, $3 \mathrm{~h}, \mathbf{2} . \mathrm{t}-\mathrm{BuOOH}$ in $n$-decane, $\mathrm{O}^{\circ} \mathrm{C}, 2 \mathrm{O}$ min; (iii) 1. $\left(\mathrm{H}_{2} \mathrm{PO}_{4}\right) \mathrm{Bu}_{4} \mathrm{~N}, \mathrm{DMF}, \mathrm{rt}, 2 \mathrm{Oh}, \mathbf{2} . \mathrm{MeOH} / \mathrm{H}_{2} \mathrm{O} / \mathrm{Bu}_{4} \mathrm{NOH}(7: 3: 1)$, rt, $17 \mathrm{~h}$; (iv) 1. 5e, $\mathrm{DCl}, \mathrm{CH}_{3} \mathrm{CN}, \mathrm{rt}, 1 \mathrm{~min} ; \mathbf{2} . \mathrm{t}-\mathrm{BuOOH}$ in $n$-decane, $0^{\circ} \mathrm{C}-\mathrm{rt}, 15 \mathrm{~min}$.

Table 2 | Antiviral activity and cytotoxicity of TriPPPro-d4TTPs 3 in comparison with the parent nucleoside d4T 1.

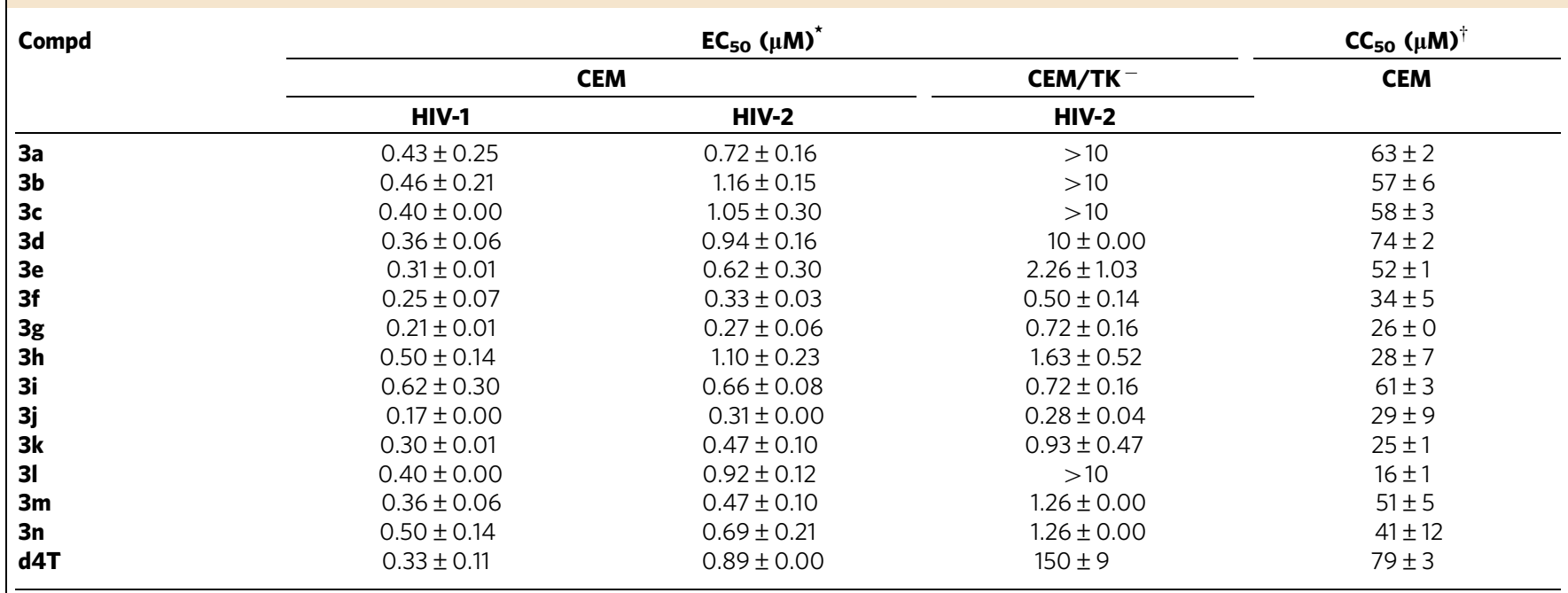

${ }^{\star}$ Antiviral activity in $\mathrm{CD} 4+$ T-lymphocytes: $50 \%$ effective concentration; values are the mean \pm s.d. of $n=2-3$ independent experiments.

${ }^{\dagger}$ Cytotoxicity: $50 \%$ cytostatic concentration or compound concentration required to inhibit CD4 ${ }^{+}$T-cell (CEM) proliferation by $50 \%$; values are the mean \pm s.d. of $n=2-3$ independent experiments.

extracts starting from d4TTP 19 led to a rapid degradation $\left(t_{1 / 2}=0.63 \mathrm{~h}\right)$. For this reason d4TDP $6\left(t_{1 / 2}=59 \mathrm{~h}\right)$ accumulated under these conditions. On the other hand, only very small amounts of d4TMP 2 were formed. Nevertheless, it was proven that the triphosphate of $\mathrm{d} 4 \mathrm{~T} \mathbf{1 9}$ was successfully released in biological media such as $\mathrm{CD} 4^{+}$T-lymphocyte extracts.

Antiviral evaluation. TriPPPro-compounds $\mathbf{3 a}-\mathbf{n}$ were evaluated for their ability to inhibit the replication of HIV. For this purpose, HIV-1- or HIV-2-infected wild-type CEM/0 as well as mutant TK-deficient CEM cell cultures $\left(\mathrm{CEM} / \mathrm{TK}^{-}\right)$were treated with the prodrugs 3. As can be seen in Table 1, all compounds showed virtually similar activities against HIV-1 and HIV-2 as the parent nucleoside $\mathrm{d} 4 \mathrm{~T}$ 1. A somewhat increased antiviral activity with increasing lipophilicity resulting from their advantageous permeability was observed. In addition, all prodrugs with $\mathrm{R} \geq \mathrm{C}_{8} \mathrm{H}_{17}$ were also highly potent in $\mathrm{CEM} \mathrm{TK}^{-}$cells, whereas $\mathrm{d} 4 \mathrm{~T} 1$ lacked relevant anti-HIV activity as expected in this TK-deficient cell model $\left(\mathrm{EC}_{50}: 150 \mu \mathrm{M}\right)$. It should also be noticed that none of the prodrugs 3 were endowed with a significantly higher cytotoxicity than the parent d4T 1 compound (Table 2).

\section{Discussion}

We reported on the first successful direct intracellular delivery of NTPs using prodrug technology. D4T triphosphate prodrugs 3a-q were prepared via a convergent route using phosphoramidite chemistry (Fig. 1). Despite complete and selective conversion, TriPPPro-NTP prodrugs 3 were obtained in yields between 27 and $66 \%$. We assumed that the loss in yield may be the result of a cleavage of the $\beta$ - and $\gamma$-phosphate anhydride bond of the prodrugs during work-up. This assumption was supported by the detection of d4TDP 6 and the bis(benzyl)phosphate diester after chromatography. Alternative purification methods such as extraction and precipitation were investigated but proved to be 
inefficient. Nevertheless, by this method a large number of TriPPPro-d4TTPs 3 bearing various acyloxybenzyl-masking units were obtained. Moreover, this synthesis strategy also showed to be applicable to the synthesis of TriPPPro-compounds bearing other pyrimidine or purine nucleoside analogues. In addition, the intermediates $\mathbf{4 a}, \mathbf{e}, \mathbf{j}$ were synthesized using the cycloSal method and were obtained in moderate chemical yields. This method, which is based on the cycloSal strategy, is a reliable method for the synthesis of polyphosphate diesters comprising esters at both ends of the polyphosphate group (Fig. 3) $48,51,52$.

In general, three reactions should be considered in the hydrolysis pathways of TriPPPro-nucleotide prodrugs 3. First, the designed pathway yielding the NTP; second, a concurrent reaction that involved a nucleophilic reaction at the $\gamma$-phosphate leading to the formation of d4TDP 6; and third, a nucleophilic reaction at the $\beta$-phosphate that would lead to d4TMP 2. Figure 6 summarizes all three possible hydrolysis pathways leading to the different phosphorylated nucleotide species. As shown in Fig. 6, to release d4TTP 19 two successive cleavage processes were necessary (path A). Thus, in addition to hydrolysis pathway $\mathbf{A}$, also a reaction at the $\gamma$ - and $\beta$-phosphate groups took place as side-reactions. Owing to the presence of a second energetically rich pyrophosphate bond, but despite its additional negative charge, the half-lives were found to be lower than those published recently for the DiPPro-d4TDPs ${ }^{33}$. However, the triphosphate 19 was the predominant product formed (Supplementary Fig. 4). Moreover, after the starting material $3 \mathbf{e}$ was completely consumed, there was no further increase in the amounts of d4TMP 2 and d4TDP 6, which again points to the fact that the intermediate selectively delivers the triphosphate while the mono- and the diphosphate are formed from the starting

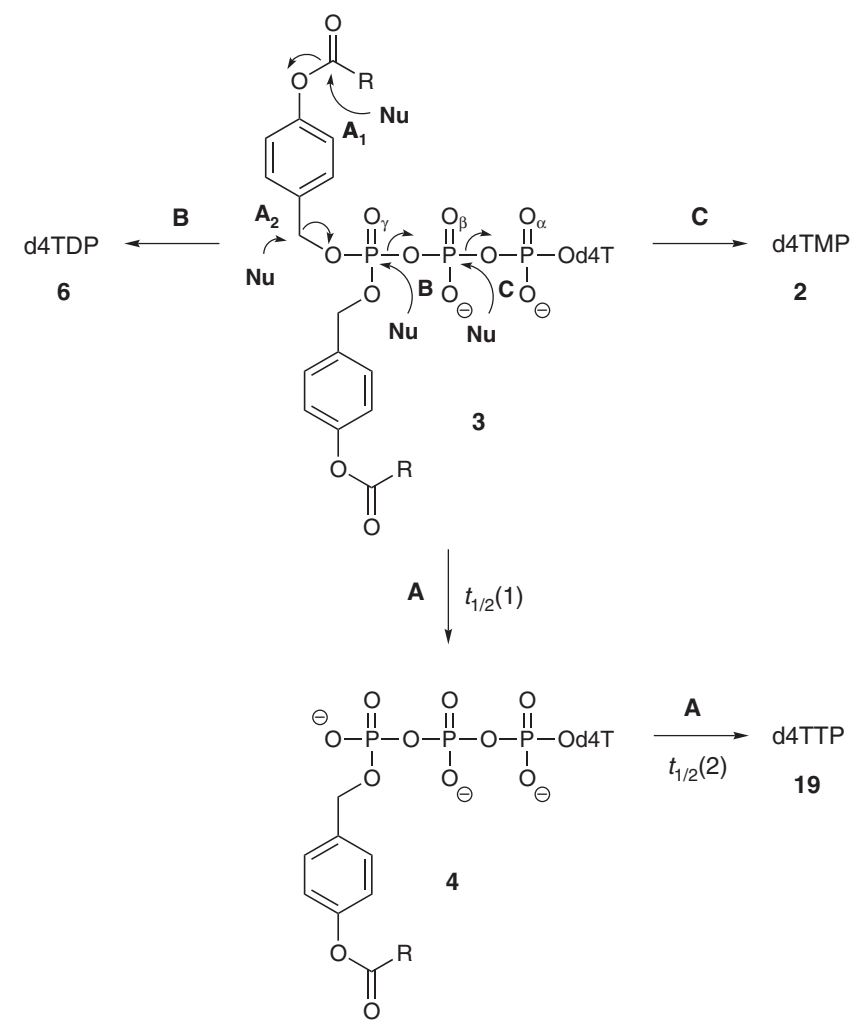

Figure 6 | Chemical hydrolysis pathways for TriPPPro-d4TTPs 3.

$A_{1+2}$ delivery of d4TTP 19; $B$ release of d4TDP 6 by cleavage of the phosphoanhydride bond between $\beta$ - and $\gamma$-phosphate; $C$ release of d4TMP $\mathbf{2}$ by cleavage of phosphoanhydride bond between $\alpha$ - and $\beta$-phosphate.
TriPPPro-compounds only. A comparable behaviour has also been observed for the DiPPro-compounds ${ }^{33}$.

In contrast, for the carbamate derivatives $\mathbf{3 0}-\mathbf{q}$ the cleavage of the masking groups occurred only once leading to the intermediates $\mathbf{4 0}-\mathbf{q}$. Therefore, it was concluded that the delivery mechanism should be different as compared with the ester-bearing masking groups. Owing to the highly stable carbamate functions present in the masking group, the first masking group cannot be cleaved by the original mechanism that involves a cleavage within the ester/carbamate residue. To gain more insights into this, a hydrolysis experiment of derivative 30 was conducted in ${ }^{18} \mathrm{O}$-labelled water to yield 4o. Surprisingly, the ${ }^{18} \mathrm{O}$-label was found in the cleaved benzyl-alcohol and not at the phosphate, which was convincingly confirmed using mass spectrometry (Supplementary Fig. 7). Two different interpretations are possible for this result: (i) a $\mathrm{S}_{\mathrm{N}} 1$-type reaction took place forming a benzyl cation and the monomasked NTP intermediate 4. The cation is then trapped by addition of water or (ii) a $\mathrm{S}_{\mathrm{N}}$ 2-type reaction took place instead in which the labelled water displaces the monomasked NTP intermediate 4 (Fig. 6, hydrolysis pathway $\mathbf{A}_{2}$ ). In addition to hydrolysis in PBS, pH 7.3, 4p was hydrolysed under slightly acidic conditions ( $\mathrm{pH}$ 6.0), although in comparison with the physiological $\mathrm{pH}$ conditions no difference in its hydrolysis behaviour was observed. Because of the very long hydrolysis time periods, a cleavage of the glycosidic bond in $\mathrm{d} 4 \mathrm{~T}$ 1 resulted in the appearance of the nucleobase thymine. The amount doubles every $63 \mathrm{~h}$; however, this aspect has not been further considered in these investigations because it was irrelevant in the enzyme or cell extract incubations and in the case of other nucleoside analogues.

Finally, a very important result from the studies conducted with the monomasked intermediates $\mathbf{4 a}, \mathbf{e}, \mathbf{j}$ was the finding that exclusively d4TTP 19 was formed from these compounds. In addition, the hydrolysis studies conducted in the presence of PLE clearly led to the selective formation of two different NTPs (d4TTP and TTP) from the corresponding prodrug forms.

In conclusion, because of a successful cell membrane passage of the TriPPPro-compounds 3 and subsequent intracellular enzymatic hydrolysis, which led to the direct intracellular formation of phosphorylated $\mathrm{d} 4 \mathrm{~T}$ metabolites such as $\mathrm{d} 4 \mathrm{TTP} 19$ or at least d4TDP 6, marked anti-HIV activity in CEM/TK ${ }^{-}$cell cultures was observed while the parent nucleoside $\mathrm{d} 4 \mathrm{~T} \mathbf{1}$ lacked significant activity in this cell assay. Thus, although the TriPPPro-compounds are still charged at the phosphate groups, obviously the modification at the $\gamma$-phosphate group by lipophilic, bioreversible moieties gives the molecule sufficient lipophilicity to penetrate the cell membrane. To the best of our knowledge, we provided the first direct proof of the successful application of masked triphosphates that obviously are able to efficiently enter the cells and to directly deliver a higher phosphate derivative, most likely d4TTP 19. Because the concept should be generally applicable to natural nucleosides and a broad variety of nucleoside analogues, a novel way to deliver the corresponding bioactive triphosphate form of these nucleosides without any need for further enzymatically catalysed phosphorylation has been discovered. This concept seems to be very interesting for application with nucleoside analogues that show severe limitations in their activation to give the corresponding NTPs. Moreover, we are convinced that this approach is not limited to HIV treatment but can also be used for other viral targets and cancer and can also be used as a delivery for non-natural NTPs as biochemical tools in Chemical Biology approaches.

\section{Methods}

General. All reactions were carried out under dry conditions and at room temperature. Solvents and reagents: Acetonitrile, THF and DMF were purchased from Acros Organics (Extra Dry over molecular sieves) and dried with activated 
molecular sieves. Triethylamine and $\mathrm{N}, \mathrm{N}$-diisopropylethylamine were refluxed over $\mathrm{CaH}_{2}$ for 3 days and distilled under nitrogen. 5-Chlorosaligenylchlorophosphite $\mathbf{8}$ and 5-nitrosaligenylchlorophosphite $\mathbf{1 8}$ were synthesized according to the literature and $\mathbf{8}$ freshly distilled before use ${ }^{48}$. All further reagents commercially available were used as received. Thin-layer chromatography: For TLC Macherey-Nagel precoated TLC sheets Alugram Xtra SIL G/UV254 were used; sugar-containing compounds were visualized with sugar spray reagent (4-methoxybenzaldehyde/ EtOH/concentrated sulphuric acid/glacial acetic acid in ratio 5/90/5/0.1 v/v) and phosphate-containing compounds with ammonium molybdate solution $(1 \mathrm{~g}$ $\left(\mathrm{NH}_{4}\right)_{6} \mathrm{Mo}_{7} \mathrm{O}_{24} 4 \mathrm{H}_{2} \mathrm{O}$ in $7 \mathrm{ml}$ semiconcentrated nitric acid and $13 \mathrm{ml}$ water) followed by tin(II)chloride solution $\left(0.1 \mathrm{~g} \mathrm{SnCl}_{2} 2 \mathrm{H}_{2} \mathrm{O}\right.$ in $20 \mathrm{ml}_{0.5 \mathrm{moll}^{-1}}$ hydrochloric acid). Preparative chromatography: The preparative TLCs were accomplished with a chromatotron (Harrison Research, Model 7,924T) using glass plates coated with 2 or $4 \mathrm{~mm}$ layers of Merck $60 \mathrm{PF}_{254}$ silica gel. Column chromatography: Normal phase column chromatography was performed with Macherey-Nagel silica gel $60 \mathrm{M}(0.04-0.063 \mathrm{~mm})$. Automatic RP-18 chromatography: For reverse-phase chromatography, an Intershim Puriflash 430 in combination with Chromabond Flash RS40 $\mathrm{C}_{18} \mathrm{ec}$ was used. High-performance liquid chromatography: HPLC was required for analytical studies and monitoring reactions. It was performed using a VWR-Hitachi LaChromElite HPLC system (L-2130, L-2200, L-2455) and EzChromElite software, equipped with a Nucleodur $100-5 \mathrm{C}_{18} \mathrm{ec}$ or Nucleodur 100-5 $\mathrm{C}_{8} \mathrm{ec}$ (Macherey-Nagel). Acetonitrile for HPLC was obtained from VWR (HPLC grade) and ultrapure water using Sartorius Aurium pro (Sartopore $0.2 \mu \mathrm{m}$, UV detector). Tetra- $n$-butylammonium acetate solution ( $2 \mathrm{mM}$; TBAA, $\mathrm{pH} 6.3$ ) or $10 \mathrm{mM}$ triethylammonium acetate (TEAA, $\mathrm{pH}$ 6.2) were used for buffering. Method A: Nucleodur 100-5 $\mathrm{C}_{18} \mathrm{ec} ; 0-20 \mathrm{~min}$ : TBAA buffer/acetonitrile gradient (5-80\%); 20-30 min: buffer/acetonitrile (80\%); 3033 min: buffer/acetonitrile (80-5\%); 33-38 min: buffer/acetonitrile (5\%); flow: $1 \mathrm{ml} \mathrm{min}{ }^{-1}$. Method B: Nucleodur $100-5 \mathrm{C}_{18} \mathrm{ec} ; 0-20 \mathrm{~min}$ : TEAA buffer/ acetonitrile gradient (5-90\%); 20-30 min: buffer/acetonitrile (90\%); 30-33 min: buffer/acetonitrile (90-5\%); 33-38 min: buffer/acetonitrile (5\%); flow: $1 \mathrm{ml} \mathrm{min}^{-}$ Method C: Nucleodur 100-5 $\mathrm{C}_{8} \mathrm{ec}$; 0-25 min: TBAA buffer/acetonitrile gradient (5-80\%); 25-30 min: buffer/acetonitrile (80\%); 30-33 min: buffer/acetonitrile (80-5\%); 33-38 min: buffer/acetonitrile (5\%); flow: $1 \mathrm{ml} \mathrm{min}^{-1}$.

Nuclear Magnetic Resonance: NMR spectra were recorded at room temperature in an automation mode with a Varian Gemini 2000BB, Bruker Fourier 300, Bruker AMX 400, Bruker DRX 500 or Bruker AVIII 600. All ${ }^{1} \mathrm{H}$ - and ${ }^{13} \mathrm{C}-\mathrm{NMR}$ chemical shifts $(\delta)$ are quoted in parts per million (p.p.m.) downfield from TMS and calibrated on solvent signal. The ${ }^{31} \mathrm{P}-\mathrm{NMR}$ chemical shifts (proton decoupled) are also quoted in p.p.m. using phosphoric acid as the external standard. Mass spectrometry: high resolution mass spectrometry (HRMS and electrospray ionization (ESI) mass spectra were acquired with a VG Analytical Finnigan ThermoQuest MAT 95 XL spectrometer. MALDI measurements (matrix: 9aminoacridine (9AA)) were performed with a Bruker UltrafleXtreme spectrometer. Infrared spectroscopy: IR spectra were recorded on a Bruker Alpha P FT-IR at room temperature in the range of $400-4,000 \mathrm{~cm}^{-1}$.

General procedure A: preparation of 4-acyloxybenzyl alcohols 9. 4-Hydroxybenzyl alcohol 10 (1.1 eq.) and triethylamine (1.0 eq.) in THF were cooled down to $0{ }^{\circ} \mathrm{C}$. The corresponding acyl chloride $(1.0 \mathrm{eq}$.) in THF was added dropwise and the mixture stirred for $1-2 \mathrm{~h}$. The precipitate was removed by filtration and the solvent evaporated in vacuum. The residue was diluted with $\mathrm{CH}_{2} \mathrm{Cl}_{2}$ and washed once with saturated sodium bicarbonate solution and once with water. The organic layer was dried with $\mathrm{Na}_{2} \mathrm{SO}_{4}$ and the solvent was removed in vaccum. The crude material was purified using column chromatography to give compound $\mathbf{9}$.

The syntheses and characterization of 4-(hydroxymethyl)phenylalkanoates $9 \mathbf{a}-\mathbf{k}$ were described previously ${ }^{33}$.

4-(Hydroxymethyl)phenylmethylcarbonate 91. General procedure A with $4.0 \mathrm{~g}$ 4-hydroxybenzyl alcohol 10 (33 mmol, $1.1 \mathrm{eq}$.), $4.1 \mathrm{ml}$ triethylamine $(3.0 \mathrm{~g}, 30 \mathrm{mmol}$, 1.0 eq.) dissolved in $35 \mathrm{ml}$ THF and dropwise addition of $2.3 \mathrm{ml}$ methyl chloroformate $\left(2.8 \mathrm{~g}, 30 \mathrm{mmol}, 1.0 \mathrm{eq}\right.$.) in $20 \mathrm{ml} \mathrm{THF}$ at $0{ }^{\circ} \mathrm{C}$. Reaction time was $1.5 \mathrm{~h}$ at room temperature (rt). Column chromatography (petroleum ether 50-70/ethyl acetate $4: 3 \mathrm{v} / \mathrm{v})$. Yield: $4.6 \mathrm{~g}(25 \mathrm{mmol}, 85 \%)$ colourless oil. TLC (petroleum ether 50-70/ethyl acetate $3: 2 \mathrm{v} / \mathrm{v}): R_{\mathrm{f}}=0.35 ;{ }^{1} \mathrm{H}-\mathrm{NMR}(400 \mathrm{MHz}$, dimethylsulphoxide (DMSO) $\left.-d_{6}\right): \delta 7.39-7.31(m, 2 \mathrm{H}), 7.20-7.13(m, 2 \mathrm{H}), 5.22(t, J=5.7 \mathrm{~Hz}, 1 \mathrm{H}), 4.50$ $(d, J=5.8 \mathrm{~Hz}, 2 \mathrm{H}), 3.82(s, 3 \mathrm{H}) ;{ }^{13} \mathrm{C}-\mathrm{NMR}\left(101 \mathrm{MHz}, \mathrm{DMSO}-d_{6}\right): \delta 153.7,149.5$, 140.5, 127.5, 121.4, 62.3, 55.4; infrared red (IR): 3,375, 2,959, 2,873, 1,758, 1,254, $1,210 \mathrm{~cm}^{-1}$; HRMS $\left(\mathrm{ESI}^{+}, \mathrm{m} / \mathrm{z}\right.$ ): $[\mathrm{M}+\mathrm{Na}]^{+}$calcd. for $\mathrm{C}_{9} \mathrm{H}_{10} \mathrm{O}_{4}, 205.0471$; found, 205.0337 .

4-(Hydroxymethyl)phenyloctylcarbonate $9 \mathrm{~m}$. General procedure A with $3.1 \mathrm{~g}$ 4-hydroxybenzyl alcohol 10 ( $25 \mathrm{mmol}, 1.1 \mathrm{eq}$.), $3.1 \mathrm{ml}$ triethylamine $(2.3 \mathrm{~g}$, $23 \mathrm{mmol}, 1.0$ eq.) dissolved in $35 \mathrm{ml}$ THF and dropwise addition of $4.4 \mathrm{ml}$ octyl chloroformate ( $4.4 \mathrm{~g}, 23 \mathrm{mmol}, 1.0 \mathrm{eq}$.) in $20 \mathrm{ml} \mathrm{THF}$ at $0^{\circ} \mathrm{C}$. Reaction time was $1.5 \mathrm{~h}$ at rt. Column chromatography (petroleum ether 50-70/ethyl acetate $4: 3 \mathrm{v} / \mathrm{v}$ ). Yield: $5.3 \mathrm{~g}(19 \mathrm{mmol}, 84 \%)$ colourless oil. TLC (PE/EE 3:1 v/v): $R_{\mathrm{f}}=0.45 ;{ }^{1} \mathrm{H}-\mathrm{NMR}$ $\left(300 \mathrm{MHz}\right.$, DMSO- $\left.d_{6}\right): \delta 7.39-7.31(m, 2 \mathrm{H}), 7.21-7.12(m, 2 \mathrm{H}), 5.22(t, J=5.7 \mathrm{~Hz}$, $1 \mathrm{H}), 4.49(d, J=5.7 \mathrm{~Hz}, 2 \mathrm{H}), 4.18\left(t,{ }^{3} J_{\mathrm{HH}}=6.6 \mathrm{~Hz}, 2 \mathrm{H}\right), 1.72-1.58(m, 2 \mathrm{H})$ $1.41-1.18(m, 10 \mathrm{H}), 0.87(t, J=6.7 \mathrm{~Hz}, 3 \mathrm{H}) ;{ }^{13} \mathrm{C}-\mathrm{NMR}\left(75 \mathrm{MHz}, \mathrm{DMSO}-d_{6}\right)$ : $\delta 153.2,149.5,140.4,127.5,120.8,68.5,62.3,31.2,28.6,28.0,25.2,22.1,28.6,14.0$;

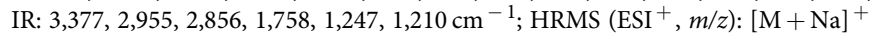
calcd. for $\mathrm{C}_{16} \mathrm{H}_{24} \mathrm{O}_{4}, 303.1567$; found, 303.1568 .

4-(Hydroxymethyl)phenyldodecylcarbonate 9n. General procedure A with $4.1 \mathrm{~g}$ 4-hydroxybenzyl alcohol 10 (33 mmol, 1.1 eq.), $4.0 \mathrm{ml}$ triethylamine $(2.9 \mathrm{~g}$, $30 \mathrm{mmol}, 1.0 \mathrm{eq}$.) dissolved in $40 \mathrm{ml}$ THF and dropwise addition of $8.1 \mathrm{ml}$ dodecyl chloroformate ( $7.5 \mathrm{~g}, 30 \mathrm{mmol}, 1.0 \mathrm{eq}$.) in $20 \mathrm{ml} \mathrm{THF}$ at $0^{\circ} \mathrm{C}$. Reaction time was $1.5 \mathrm{~h}$ at rt. Column chromatography (petroleum ether (PE) 50-70/ethyl acetate (EE) 4:1 v/v). Yield: $7.7 \mathrm{~g}(23 \mathrm{mmol}, 76 \%)$ colourless oil. TLC (PE/EE 3:1 v/v): $R_{\mathrm{f}}=0.48 ;{ }^{1} \mathrm{H}-\mathrm{NMR}\left(300 \mathrm{MHz}, \mathrm{CDCl}_{3}\right): \delta 7.42-7.33(m, 2 \mathrm{H}), 7.21-7.12(m, 2 \mathrm{H})$, $4.68(s, 2 \mathrm{H}), 4.24(t, J=6.7 \mathrm{~Hz}, 2 \mathrm{H}), 1.81-1.69(m, 2 \mathrm{H}), 1.47-1.19(m, 18 \mathrm{H}), 0.88(t$ $J=6.7 \mathrm{~Hz}, 3 \mathrm{H}) ;{ }^{13} \mathrm{C}-\mathrm{NMR}\left(75 \mathrm{MHz}, \mathrm{CDCl}_{3}\right): \delta 153.9,150.7,138.8,128.2,121.1$, 69.2, 64.8, 32.1, 29.8, 29.7, 29.6, 29.5, 29.3, 28.7, 25.8, 22.8, 28.6, 14.3; IR: 3,355, 2,917, 2,848,1,747,1,273 $\mathrm{cm}^{-1}$; HRMS $\left(\mathrm{ESI}^{+}, \mathrm{m} / \mathrm{z}\right):[\mathrm{M}+\mathrm{Na}]^{+}$calcd. for $\mathrm{C}_{20} \mathrm{H}_{34} \mathrm{O}_{4}, 359.2193$; found, 359.2195.

4-(((tert-Butyldimethylsilyl)oxy)methyl)phenol 11. 4-Hydroxybenzyl alcohol 10 ( $5.1 \mathrm{~g} ; 41 \mathrm{mmol}, 1.0$ eq.), dissolved in $40 \mathrm{ml}$ DMF, was converted with $6.8 \mathrm{~g}$ tert-butyldimethylsilyl chloride $(45 \mathrm{mmol}, 1.1 \mathrm{eq}$.$) and 6.1 \mathrm{~g}$ imidazole $(89 \mathrm{mmol}$, 2.2 eq.). After $17 \mathrm{~h}$ the solvent was removed by evaporation. The crude product was dissolved in $\mathrm{CH}_{2} \mathrm{Cl}_{2}$ and washed with $0.1 \mathrm{M} \mathrm{HCl}$. The organic phase was dried over $\mathrm{Na}_{2} \mathrm{SO}_{4}$, filtered and the solvent was removed by evaporation. Column chromatography (petroleum ether 50-70/ethyl acetate 6:1 v/v). Yield: $7.9 \mathrm{~g}(33 \mathrm{mmol}, 81 \%)$ colourless oil. TLC (PE/EE 4:1 v/v): $R_{\mathrm{f}}=0.34 ;{ }^{1} \mathrm{H}-\mathrm{NMR}\left(300 \mathrm{MHz}\right.$, DMSO- $\left.d_{6}\right)$ : $\delta 9.28(s, 1 \mathrm{H}), 7.12-7.06(m, 2 \mathrm{H}), 6.74-6.68(m, 2 \mathrm{H}), 4.56(s, 2 \mathrm{H}), 0.87(s, 9 \mathrm{H}), 0.04$ $(s, 6 \mathrm{H}) ;{ }^{13} \mathrm{C}-\mathrm{NMR}\left(75 \mathrm{MHz}\right.$, DMSO- $\left.d_{6}\right): \delta 139.2,131.6,127.5,114.6,64.0,25.6$,

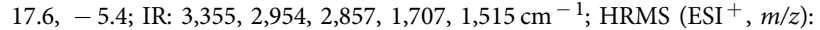
$[\mathrm{M}+\mathrm{Na}]^{+}$calcd. for $\mathrm{C}_{13} \mathrm{H}_{22} \mathrm{O}_{2} \mathrm{Si}, 261.1287$; found, 261.1285.

4-(((tert-Butyldimethylsilyl)oxy)methyl)phenyl-(4-nitrophenyl)-carbonate 12. Compound 11 (7.6 g; $32 \mathrm{mmol}$, 1.0 eq.) was dissolved in $100 \mathrm{ml} \mathrm{CH}_{2} \mathrm{Cl}_{2}$. 4-Nitrophenyl chloroformate ( $12.8 \mathrm{~g} ; 64 \mathrm{mmol}, 2.0 \mathrm{eq}$.) was added slowly to the reaction flask and the mixture was kept for $1 \mathrm{~h}$ at $\mathrm{rt}$. Then, for consumption of the excess of chloroformate and for facilitation of purification, $7.5 \mathrm{ml}$ tri(ethylene glycol) monomethyl ether $(7.9 \mathrm{~g}, 48 \mathrm{mmol}, 1.5$ eq.) was added. After $20 \mathrm{~min}$ the solution was diluted with $\mathrm{CH}_{2} \mathrm{Cl}_{2}$ and washed with $1 \mathrm{M} \mathrm{HCl}$. The organic phase was dried over $\mathrm{Na}_{2} \mathrm{SO}_{4}$, filtered and the solvent was removed by evaporation. Column chromatography (petroleum ether 50-70/ethyl acetate 6:1 v/v). Yield: $6.8 \mathrm{~g}$ $(17 \mathrm{mmol}, 53 \%)$ colourless solid. TLC (PE/EE 6:1 v/v): $R_{\mathrm{f}}=0.73 ;{ }^{1} \mathrm{H}-\mathrm{NMR}$ $\left(400 \mathrm{MHz}, \mathrm{DMSO}-d_{6}\right): \delta 8.38-8.33(m, 2 \mathrm{H}), 7.73-7.67(m, 2 \mathrm{H}), 7.43-7.36(m, 4 \mathrm{H})$ $4.73(s, 2 \mathrm{H}), 0.91(s, 9 \mathrm{H}), 0.09(s, 6 \mathrm{H}) ;{ }^{13} \mathrm{C}-\mathrm{NMR}\left(101 \mathrm{MHz}, \mathrm{DMSO}-d_{6}\right): \delta 155.2$, $150.7,149.3,145.4,139.6,127.2,125.4,122.7,120.9,63.6,25.8,18.0,-5.3$; IR: 2,954, 2,929, 2,857, 1,768,1,265 $\mathrm{cm}^{-1}$; HRMS (ESI $\left.{ }^{+}, m / z\right):[\mathrm{M}+\mathrm{Na}]^{+}$calcd. for $\mathrm{C}_{20} \mathrm{H}_{25} \mathrm{NO}_{6} \mathrm{Si}$, 426.1349; found, 426.1340 .

tert-Butylmethyl(2-(methylamino)ethyl)-carbamate 13. A flask containing $4.6 \mathrm{ml} \mathrm{N,N}$-dimethylethylendiamine ( $3.7 \mathrm{~g}, 42 \mathrm{mmol}, 3.8$ eq.) in $40 \mathrm{ml} \mathrm{CH}_{2} \mathrm{Cl}_{2}$ was cooled to $0{ }^{\circ} \mathrm{C}$. A solution of $2.4 \mathrm{~g}$ di-tert-butyl dicarbonate $(11 \mathrm{mmol}, 1.0 \mathrm{eq}$.) in $20 \mathrm{ml} \mathrm{CH}_{2} \mathrm{Cl}_{2}$ was added dropwise and, following the reaction mixture, was allowed to warm to rt. After $16 \mathrm{~h}$, the solvent was removed in vacuum. The product was extracted with ethyl acetate/water $(2: 1 \mathrm{v} / \mathrm{v})$ and washed with saturated aqueous $\mathrm{NaHCO}_{3}$. The organic phase was dried over $\mathrm{Na}_{2} \mathrm{SO}_{4}$, filtered and the solvent was removed by evaporation. Yield: $1.6 \mathrm{~g}(8.6 \mathrm{mmol}, 78 \%)$ yellowish oil. ${ }^{1} \mathrm{H}-\mathrm{NMR}$ $\left(600 \mathrm{MHz}, \mathrm{CDCl}_{3}\right): \delta 3.35-3.25(\mathrm{~m}, 2 \mathrm{H}$, rotamers), $2.85(\mathrm{~s}, 3 \mathrm{H}), 2.70(\mathrm{t}, J=6.7 \mathrm{~Hz}$, $2 \mathrm{H}), 2.42(\mathrm{~s}, 3 \mathrm{H}), 1.43(\mathrm{~s}, 9 \mathrm{H}) ;{ }^{13} \mathrm{C}-\mathrm{NMR}\left(151 \mathrm{MHz}, \mathrm{CDCl}_{3}\right): \delta$ 156.1, 79.5, 49.8, $48.8+48.3$ (rotamers), 36.4, 34.9+34.8 (rotamers), 28.6; IR: 2,974, 2,931, 1,687, $1,154 \mathrm{~cm}^{-1}$; HRMS $\left(\mathrm{ESI}^{+}, \mathrm{m} / z\right)$ : $[\mathrm{M}+\mathrm{Na}]^{+}$calcd. for $\mathrm{C}_{9} \mathrm{H}_{20} \mathrm{~N}_{2} \mathrm{O}_{2}, 211.1417$; found, 211.1411

\section{4-(Hydroxymethyl)phenyl-methyl(2-(methylamino)ethyl)-carbamate 14. At} $0^{\circ} \mathrm{C}$ to a stirred solution of $1.6 \mathrm{~g}$ compound $13(8.6 \mathrm{mmol}, 1.2 \mathrm{eq}),. 1.9 \mathrm{ml}$ diisopropylethylamine (1.4 g, $11 \mathrm{mmol}, 1.6 \mathrm{eq}$.) and catalytic amounts of 4-dimethylaminophenol in $30 \mathrm{ml}$ toluene $2.8 \mathrm{~g}$ activated carbonate $12(7.0 \mathrm{mmol}, 1.0 \mathrm{eq}$.) was added. The reaction mixture was allowed to warm to rt and stirred for $16 \mathrm{~h}$. The solution was diluted with ethyl acetate and washed with $1 \mathrm{M} \mathrm{HCl}$, followed by saturated aqueous $\mathrm{NaHCO}_{3}$. The organic phase was dried over $\mathrm{Na}_{2} \mathrm{SO}_{4}$, filtered and the solvent was removed by evaporation. For deprotection the residue was redissolved in a mixture of $\mathrm{CH}_{2} \mathrm{Cl}_{2}$ /trifluoroacetic acid $(1: 1 \mathrm{v} / \mathrm{v})$. After $1 \mathrm{~h}$ the volatile components were removed by evaporation and the residue was co-evaporated twice with toluene. The crude material was purified by automatic RP-18 chromatography (water/acetontrile gradient). Yield: $1.6 \mathrm{~g}(6.9 \mathrm{mmol}, 98 \%)$ yellowish oil. TLC $\left(\mathrm{CH}_{2} \mathrm{Cl}_{2} / \mathrm{MeOH} 4: 1 \mathrm{v} / \mathrm{v}\right): R_{\mathrm{f}}=0.67 ;{ }^{1} \mathrm{H}-\mathrm{NMR}\left(400 \mathrm{MHz}\right.$, DMSO- $\left.d_{6}\right): \delta 8.72,8.62$ (br.s, $2 \mathrm{H}$, rotamers), 7.34-7.28 (m, $2 \mathrm{H}), 7.14-7.07(m, 2 \mathrm{H}), 4.48(s, 2 \mathrm{H}), 3.69,3.57$ $(t, J=6.0 \mathrm{~Hz}, 2 \mathrm{H}$, rotamers), 3.24-3.10 ( $m, 2 \mathrm{H}$, rotamers), 3.05, $2.93(s, 3 \mathrm{H}$, rotamers), $2.68-2.57$ ( $m, 3 \mathrm{H}$, rotamers); ${ }^{13} \mathrm{C}-\mathrm{NMR}$ (101 MHz, DMSO- $\left.d_{6}\right)$ : $\delta 154.7+153.8$ (rotamers), $149.9,139.7,127.2,121.7+121.4$ (rotamers), 62.4 , 
$46.3+46.0$ (rotamers), $45.2,34.6+34.4$ (rotamers), $32.9+32.8$ (rotamers); IR $3,401,2,975,2,871,1,671,1,172 \mathrm{~cm}^{-1}$; $\mathrm{HRMS}\left(\mathrm{ESI}^{+}, \mathrm{m} / \mathrm{z}\right):[\mathrm{M}+\mathrm{Na}]^{+} \mathrm{calcd}$ for $\mathrm{C}_{12} \mathrm{H}_{18} \mathrm{~N}_{2} \mathrm{O}_{3}, 239.1390$; found, 239.1391.

General procedure B: preparation of bis-methylcarbamates 15. 4-(Hydroxymethyl)phenylcarbamate $\mathbf{1 4}$ (1.0 eq.) was dissolved in THF and cooled down to $0{ }^{\circ} \mathrm{C}$. After addition of imidazole (1.3 eq.) and TMSCl (1.2 eq.) the mixture was stirred for $2 \mathrm{~h}$. Triethylamine ( $3.1 \mathrm{eq}$.) and the corresponding alkyl chloroformate ( 3.0 eq.) were added. The reaction was kept for $1.5 \mathrm{~h}$ at $\mathrm{rt}$ and then diluted with $30 \mathrm{ml}$ of $1 \mathrm{vol} \%$ concentrated $(12 \mathrm{M}) \mathrm{HCl}$ in $\mathrm{EtOH}$ for desilylation. The solution was stirred for $1 \mathrm{~h}$ and the solvent evaported in vacuum. The residue was dissolved in $\mathrm{CH}_{2} \mathrm{Cl}_{2}$ and washed with saturated aqueous $\mathrm{NaHCO}_{3}$. The organic phase was dried over $\mathrm{Na}_{2} \mathrm{SO}_{4}$, filtered and the solvent was removed in vacuum. The crude material was purified using column chromatography.

n-Butyl-(4-(hydroxymethyl)phenyl)ethane-1,2-diylbis(methylcarbamate) 150. General procedure B with $2.1 \mathrm{~g} 14(8.8 \mathrm{mmol}, 1.0 \mathrm{eq}$ ), $0.78 \mathrm{~g}$ imidazole $(11 \mathrm{mmol}$, 1.3 eq.), $1.3 \mathrm{ml}$ TMSCl ( $1.1 \mathrm{~g}, 11 \mathrm{mmol}, 1.2 \mathrm{eq}.), 3.8 \mathrm{ml}$ triethylamine $(2.8 \mathrm{~g}$ $27 \mathrm{mmol}, 3.1 \mathrm{eq}$.), $3.4 \mathrm{ml}$ butyl chloroformate ( $3.6 \mathrm{~g}, 26 \mathrm{mmol}, 3.0$ eq.) dissolved in $15 \mathrm{ml}$ THF. Column chromatography (petroleum ether 50-70/ethyl acetate $1: 1 \mathrm{v} / \mathrm{v}$ ). Yield: $1.8 \mathrm{~g}(19 \mathrm{mmol}, 59 \%)$ colourless oil. TLC $\left(\mathrm{CH}_{2} \mathrm{Cl}_{2} / \mathrm{MeOH} 9: 1 \mathrm{v} / \mathrm{v}\right): R_{\mathrm{f}}=0.56$; ${ }^{1} \mathrm{H}-\mathrm{NMR}\left(400 \mathrm{MHz}, \mathrm{DMSO}-d_{6}\right): \delta 7.34-7.27(m, 2 \mathrm{H}), 7.04-6.97(m, 2 \mathrm{H}), 5.17$ $(t, J=5.6 \mathrm{~Hz}, 1 \mathrm{H}), 4.48(d, J=4.3 \mathrm{~Hz}, 2 \mathrm{H}), 4.02-3.91(m, 2 \mathrm{H}), 3.57-3.40$ ( $m, 4 \mathrm{H}$, rotamers), $3.02,2.90$ ( $s, 3 \mathrm{H}$, rotamers), $2.90-2.82(m, 3 \mathrm{H}$, rotamers), $1.60-1.44(m, 2 \mathrm{H}$, rotamers), $1.39-1.22(m, 2 \mathrm{H}$, rotamers), $0.87,0.80(t, J=7.3 \mathrm{~Hz}$, $3 \mathrm{H}$, rotamers); ${ }^{13} \mathrm{C}-\mathrm{NMR}\left(101 \mathrm{MHz}, \mathrm{DMSO}-d_{6}\right): \delta 155.8,153.9,150.0,139.3,127.2$, $121.4+121.3$ (rotamers), $64.5+64.4$ (rotamers), $62.4,46.5+46.2$ (rotamers), $46.0+45.6$ (rotamers), $35.2+35.0$ (rotamers), $34.7+34.5$ (rotamers), $30.6+30.6$ (rotamers), 18.6, 13.6; IR: 3,445, 2,958, 2,933, 1,694, 1,202 $\mathrm{cm}^{-1}$; $\mathrm{HRMS}_{(\mathrm{ESI}}{ }^{+}$, $m / z):[\mathrm{M}+\mathrm{H}]^{+}$calcd. for $\mathrm{C}_{17} \mathrm{H}_{26} \mathrm{~N}_{2} \mathrm{O}_{5}, 339.1914$; found, 339.1918.

n-Octyl-(4-(hydroxymethyl)phenyl)ethane-1,2-diylbis(methylcarbamate) 15p. General procedure B with $0.86 \mathrm{~g} 14$ (3.6 mmol, $1.0 \mathrm{eq}$.), $0.32 \mathrm{~g}$ imidazole $(4.7 \mathrm{mmol}$, 1.3 eq.), $0.55 \mathrm{ml}$ TMSCl $(0.47 \mathrm{~g}, 4.3 \mathrm{mmol}, 1.2 \mathrm{eq}),. 1.6 \mathrm{ml}$ triethylamine $(1.1 \mathrm{~g}$, $11 \mathrm{mmol}, 3.1 \mathrm{eq}.), 2.1 \mathrm{ml}$ octyl chloroformate $(2.1 \mathrm{~g}, 11 \mathrm{mmol}, 3.0$ eq.) dissolved in $5 \mathrm{ml}$ THF. Column chromatography (petroleum ether 50-70/ethyl acetate $1: 1 \mathrm{v} / \mathrm{v}$ ). Yield: $0.72 \mathrm{~g}(1.8 \mathrm{mmol}, 51 \%)$ colourless oil. TLC $\left(\mathrm{CH}_{2} \mathrm{Cl}_{2} / \mathrm{MeOH} 9: 1 \mathrm{v} / \mathrm{v}\right)$ : $R_{\mathrm{f}}=0.60 ;{ }^{1} \mathrm{H}-\mathrm{NMR}\left(400 \mathrm{MHz}, \mathrm{DMSO}-d_{6}\right): \delta 7.34-7.27(m, 2 \mathrm{H}), 7.02-6.98(m, 2 \mathrm{H})$, $5.17(t, J=5.7 \mathrm{~Hz}, 1 \mathrm{H}), 4.47(d, J=5.6 \mathrm{~Hz}, 2 \mathrm{H}), 4.01-3.90(m, 2 \mathrm{H}), 3.57-3.39$ ( $m, 4 \mathrm{H}$, rotamers), $3.02,2.90$ ( $s, 3 \mathrm{H}$, rotamers), $2.90-2.81$ ( $m, 3 \mathrm{H}$, rotamers), $1.62-1.44$ ( $m, 2 \mathrm{H}$, rotamers), $1.36-1.12(m, 10 \mathrm{H}), 0.89-0.80$ ( $m, 3 \mathrm{H}$, rotamers); ${ }^{13} \mathrm{C}-\mathrm{NMR}\left(101 \mathrm{MHz}, \mathrm{DMSO}-d_{6}\right): \delta 155.7,154.0,150.0,139.2,127.2,121.4+121.3$ (rotamers), $64.8+64.7$ (rotamers), 62.4, 46.5 + 46.2 (rotamers), $45.9+45.5$ (rotamers), $34.6+34.5$ (rotamers), 31.2, 28.7, 28.6+28.6 (rotamers), 25.4, 22.0, 13.9; IR: 3,447, 2,926, 2,856, 1,698, 1,203 $\mathrm{cm}^{-1}$; $\left.\mathrm{HRMS}_{(\mathrm{ESI}}{ }^{+}, \mathrm{m} / z\right):[\mathrm{M}+\mathrm{H}]^{+}$ calcd. for $\mathrm{C}_{21} \mathrm{H}_{34} \mathrm{~N}_{2} \mathrm{O}_{5}, 395.2540$; found, 395.2540.

n-Dodecyl-(4-(hydroxymethyl)phenyl)ethane-1,2-diylbis(methylcarbamate) 15q. General procedure B with $0.95 \mathrm{~g} 14$ ( $4.0 \mathrm{mmol}, 1.0 \mathrm{eq}$ ), $0.35 \mathrm{~g}$ imidazole $(5.2 \mathrm{mmol}$, 1.3 eq.), $0.61 \mathrm{ml} \mathrm{TMSCl}(0.52 \mathrm{~g}, 4.8 \mathrm{mmol}, 1.2 \mathrm{eq}),. 1.7 \mathrm{ml}$ triethylamin ( $1.3 \mathrm{~g}$, $12 \mathrm{mmol}, 3.1 \mathrm{eq}.), 3.2 \mathrm{ml}$ dodecyl chloroformate $(3.0 \mathrm{~g}, 12 \mathrm{mmol}, 3.0 \mathrm{eq}$.) dissolved in $15 \mathrm{ml} \mathrm{THF}$. Column chromatography (petroleum ether 50-70/ethyl acetate 1:1 v/ v). Yield: $0.75 \mathrm{~g}(1.7 \mathrm{mmol}, 42 \%)$ colourless oil. TLC $\left(\mathrm{CH}_{2} \mathrm{Cl}_{2} / \mathrm{MeOH} 9: 1 \mathrm{v} / \mathrm{v}\right)$ : $R_{\mathrm{f}}=0.65 ;{ }^{1} \mathrm{H}-\mathrm{NMR}\left(400 \mathrm{MHz}, \mathrm{CDCl}_{3}\right): \delta$ (p.p.m. $)=7.36-7.31(m, 2 \mathrm{H}), 7.10-7.05$ $(m, 2 \mathrm{H}), 4.64(\mathrm{~s}, 2 \mathrm{H}), 4.12-4.02(m, 2 \mathrm{H}), 3.63-3.44$ ( $m, 4 \mathrm{H}$, rotamers), 3.15-2.89 (s, $6 \mathrm{H}$, rotamers), $1.68-1.54(m, 2 \mathrm{H}$, rotamers $), 1.43-1.13(m, 10 \mathrm{H}), 0.88(t, J=6.8 \mathrm{~Hz}$, $3 \mathrm{H}) ;{ }^{13} \mathrm{C}-\mathrm{NMR}\left(101 \mathrm{MHz}, \mathrm{CDCl}_{3}\right): \delta 157.1,154.9,151.0,138.3,128.0$, $121.9+121.3$ (rotamers), $65.9+65.8$ (rotamers), 64.9, 47.4 + 47.3 (rotamers), $47.1+46.4$ (rotamers), $35.4+35.3$ (rotamers), 32.1, 29.8, 29.7, 29.7, $29.5+29.5$ (rotamers), 29.4, 29.2, 29.2, 26.1, 22.8, 14.2; IR: 3,459, 2,923, 1,699, 1,203 $\mathrm{cm}^{-1}$; HRMS $\left(\mathrm{ESI}^{+}, m / z\right):[\mathrm{M}+\mathrm{H}]^{+}$calcd. for $\mathrm{C}_{25} \mathrm{H}_{42} \mathrm{~N}_{2} \mathrm{O}_{5}, 451.3172$; found, 451.3167 .

\section{General procedure C: preparation of bis-(4-acyloxybenzyl)- $\mathbf{N}, \mathbf{N}$-diisopropyl-} phosphoramidites 5. Dichloro- $N, N$-diisopropylphosphoramidite (1.0 eq.) was dissolved in THF and cooled to $0^{\circ} \mathrm{C}$. Triethylamine (2.3 eq.) and the corresponding 4-acyloxybenzylalcohol 9 (2.1-2.2 eq.) in THF were added dropwise. The reaction mixture was kept at $0{ }^{\circ} \mathrm{C}$ for $18-24 \mathrm{~h}$. After filtration, the solvent was removed by evaporation. The crude products were purified either using column chromatography or using preparative TLC (chromatotron).

The syntheses and characterization of Bis-(4-acyloxybenzyl)-N,N-diisopropylphosphoramidite $\mathbf{5 a - k}$ were described previously ${ }^{33}$.

\section{Bis-(4-methyloxycarbonyloxybenzyl)-N,N-diisopropylaminophosphoramidite $\mathbf{5 I}$.} General procedure $\mathrm{C}$ with $0.74 \mathrm{~g}$ dichloro- $\mathrm{N}, \mathrm{N}$-diisopropylphosphoramidite ( $3.7 \mathrm{mmol}, 1.0 \mathrm{eq}$.) dissolved in $15 \mathrm{ml}$ THF, $1.2 \mathrm{ml}$ triethylamine $(0.85 \mathrm{~g}, 8.4 \mathrm{mmol}$, 2.3 eq.) and $1.5 \mathrm{~g}$ 4-(hydroxymethyl)phenylmethylcarbonate $(8.2 \mathrm{mmol}, 2.2 \mathrm{eq}$.) in $15 \mathrm{ml}$ THF. The crude product was purified by preparative TLC (petroleum ether 50-70/ethyl acetate $\left.4: 1 \mathrm{v} / \mathrm{v}+5 \% \mathrm{Et}_{3} \mathrm{~N}\right)$. Yield: $1.5 \mathrm{~g}(3.0 \mathrm{mmol}, 82 \%)$ colourless oil. TLC $\left(\mathrm{PE} / \mathrm{EE} 1: 1 \mathrm{v} / \mathrm{v}+5 \% \mathrm{Et}_{3} \mathrm{~N}\right): R_{\mathrm{f}}=0.77 ;{ }^{1} \mathrm{H}-\mathrm{NMR}\left(300 \mathrm{MHz}, \mathrm{DMSO}-d_{6}\right): \delta$ 7.42-7.34 ( $m, 4 \mathrm{H}), 7.18-7.07(m, 4 \mathrm{H}), 4.78-4.61(m, 4 \mathrm{H}), 3.82(s, 6 \mathrm{H}), 3.72-3.57$ $(m, 2 \mathrm{H}), 1.16(d, J=6.8 \mathrm{~Hz}, 12 \mathrm{H}) ;{ }^{13} \mathrm{C}-\mathrm{NMR}\left(75 \mathrm{MHz}, \mathrm{DMSO}-d_{6}\right): \delta 153.7,149.9$, $137.2(d, J=7.4 \mathrm{~Hz}), 128.0,121.1,64.1(d, J=18.1 \mathrm{~Hz}), 55.4,42.6(d, J=12.5 \mathrm{~Hz})$, $24.4(d, J=6.7 \mathrm{~Hz}) ;{ }^{31} \mathrm{P}-\mathrm{NMR}\left(202 \mathrm{MHz}, \mathrm{DMSO}-d_{6}\right): \delta 147.5$; IR: $2,965,2,916$, $1,760,1,200,1,126 \mathrm{~cm}^{-1}$; HRMS $\left(\mathrm{ESI}^{+}, \mathrm{m} / z\right):[\mathrm{M}+\mathrm{H}]^{+}$calcd. for $\mathrm{C}_{24} \mathrm{H}_{32} \mathrm{NO}_{8} \mathrm{P}$, 494.1938; found, 494.2276

Bis-(4-octyloxycarbonyloxybenzyl)-N,N-diisopropylaminophosphoramidite $\mathbf{5 m}$. General procedure $\mathrm{C}$ with $0.76 \mathrm{~g}$ dichloro- $\mathrm{N}, \mathrm{N}$-diisopropylphosphoramidite ( $3.8 \mathrm{mmol}, 1.0$ eq.) dissolved in $15 \mathrm{ml}$ THF, $1.3 \mathrm{ml}$ triethylamine $(0.88 \mathrm{~g}, 8.7 \mathrm{mmol}$, $2.3 \mathrm{eq}$.) and $2.3 \mathrm{~g}$ 4-(hydroxymethyl)phenyloctylcarbonate $(8.3 \mathrm{mmol}, 2.2 \mathrm{eq}$.) in $15 \mathrm{ml}$ THF. The crude product was purified by preparative TLC (petroleum ether 50-70/ethyl acetate $\left.6: 1 \mathrm{v} / \mathrm{v}+5 \% \mathrm{Et}_{3} \mathrm{~N}\right)$. Yield: $2.2 \mathrm{~g}(3.2 \mathrm{mmol}, 83 \%)$ colourless oil. TLC (PE/EE 6:1 v/v $\left.+5 \% \mathrm{Et}_{3} \mathrm{~N}\right): R_{\mathrm{f}}=0.43 ;{ }^{1} \mathrm{H}-\mathrm{NMR}\left(300 \mathrm{MHz}, \mathrm{CDCl}_{3}\right)$ : $\delta$ 7.39-7.31 $(m, 4 \mathrm{H}), 7.20-7.13(m, 4 \mathrm{H}), 4.80-4.62(m, 4 \mathrm{H}), 4.24(t, J=6.7 \mathrm{~Hz}, 4 \mathrm{H})$, 3.69 (dquint, $J=10.0 \mathrm{~Hz}, J=6.8 \mathrm{~Hz}, 2 \mathrm{H}), 1.82-1.66(m, 4 \mathrm{H}), 1.48-1.23(\mathrm{~m}, 16 \mathrm{H})$, $1.20(d, J=6.8 \mathrm{~Hz}, 12 \mathrm{H}), 0.89(t, J=6.7 \mathrm{~Hz}, 6 \mathrm{H}) ;{ }^{13} \mathrm{C}-\mathrm{NMR}\left(75 \mathrm{MHz}, \mathrm{CDCl}_{3}\right)$ : $\delta 153.9,150.4,137.4(d, J=7.5 \mathrm{~Hz}), 128.2,121.0,69.1,64.9(d, J=18.7 \mathrm{~Hz}), 42.2$ $(d, J=12.6 \mathrm{~Hz}), 31.9,29.3,29.3,25.8,22.8,28.7,24.8(d, J=7.6 \mathrm{~Hz}), 14.2 ;{ }^{31} \mathrm{P}-\mathrm{NMR}$ $\left(202 \mathrm{MHz}, \mathrm{CDCl}_{3}\right): \delta 148.0$; IR: 2,961, 2,926, 1,759, $1,215 \mathrm{~cm}^{-1}$; HRMS $\left(\mathrm{ESI}^{+}\right.$, $m / z):[\mathrm{M}+\mathrm{H}]^{+}$calcd. for $\mathrm{C}_{38} \mathrm{H}_{60} \mathrm{NO}_{8} \mathrm{P}, 690.4129$; found, 690.4086 .

Bis-(4-dodecyloxycarbonyloxybenzyl)- $\mathbf{N}, \mathbf{N}$-diisopropylaminophosphoramidite $\mathbf{5 n}$ General procedure $\mathrm{C}$ with $0.50 \mathrm{~g}$ dichloro- $N, N$-diisopropylphosphoramidite ( $2.5 \mathrm{mmol}, 1.0$ eq. $)$ dissolved in $14 \mathrm{ml} \mathrm{THF}, 0.80 \mathrm{ml}$ triethylamine $(0.58 \mathrm{~g}, 5.8 \mathrm{mmol}$, 2.3 eq.) and $1.8 \mathrm{~g}$ 4-(hydroxymethyl)phenyldodecylcarbonate $(5.2 \mathrm{mmol}, 2.1 \mathrm{eq}$.) in $10 \mathrm{ml}$ THF. The crude product was purified using preparative TLC (petroleum ether $50-70 /$ ethyl acetate $\left.10: 1 \mathrm{v} / \mathrm{v}+5 \% \mathrm{Et}_{3} \mathrm{~N}\right)$. Yield: $1.8 \mathrm{~g}(2.2 \mathrm{mmol}, 88 \%) \mathrm{col}$ ourless solid. TLC $\left(\mathrm{PE} / \mathrm{EE} 6: 1 \mathrm{v} / \mathrm{v}+5 \% \mathrm{Et}_{3} \mathrm{~N}\right): R_{\mathrm{f}}=0.53 ;{ }^{1} \mathrm{H}-\mathrm{NMR}(300 \mathrm{MHz}$, $\left.\mathrm{CDCl}_{3}\right): \delta 7.39-7.32(m, 4 \mathrm{H}), 7.17-7.09(m, 4 \mathrm{H}), 4.80-4.62(m, 4 \mathrm{H}), 4.24(t$, $J=6.7 \mathrm{~Hz}, 4 \mathrm{H}), 3.75-3.57(m, 2 \mathrm{H}), 1.80-1.67(m, 4 \mathrm{H}), 1.47-1.23(m, 36 \mathrm{H}), 1.20$ $(d, J=6.8 \mathrm{~Hz}, 12 \mathrm{H}), 0.88(t, J=6.7 \mathrm{~Hz}, 6 \mathrm{H}) ;{ }^{13} \mathrm{C}-\mathrm{NMR}\left(75 \mathrm{MHz}, \mathrm{CDCl}_{3}\right): \delta 153.9$, $150.4,137.4(d, J=7.8 \mathrm{~Hz}), 128.2,121.0,69.1,64.9(d, J=18.2 \mathrm{~Hz}), 43.2$ $(d, J=12.5 \mathrm{~Hz}), 32.1,29.8,29.7,29.6,29.5,29.4,25.8,22.8,28.6,24.8(d, J=7.4 \mathrm{~Hz})$, $14.3 ;{ }^{31} \mathrm{P}-\mathrm{NMR}\left(162 \mathrm{MHz}, \mathrm{CDCl}_{3}\right): \delta$ 148.0; IR: 2,961, 2,923, 2,853, 1,760, $1,216 \mathrm{~cm}^{-1}$; HRMS $\left(\mathrm{ESI}^{+}, \mathrm{m} / \mathrm{z}\right):[\mathrm{M}+\mathrm{H}]^{+}$calcd. for $\mathrm{C}_{46} \mathrm{H}_{76} \mathrm{NO}_{8} \mathrm{P}, 802.5381$; found, 802.5352 .

Bis-(4-(butyl-ethan-1,2-diylbis(methylcarbamate))-oxybenzyl)- $\mathbf{N}, \mathbf{N}$-diisopropylaminophosphoramidite 5o. General procedure C with $0.20 \mathrm{~g}$ dichloro- $N, N$ diisopropylphosphoramidite ( $0.99 \mathrm{mmol}, 1.0$ eq.) dissolved in $4 \mathrm{ml} \mathrm{THF}, 0.32 \mathrm{ml}$ triethylamine $(0.23 \mathrm{~g}, 2.3 \mathrm{mmol}, 2.3 \mathrm{eq}$.) and $0.75 \mathrm{~g}$ compound $15 \mathrm{o}(2.2 \mathrm{mmol}$, 2.2 eq.) in $5 \mathrm{ml}$ THF. The crude product was purified using column chromatography (petroleum ether 50-70/ethyl acetate $1: 1 \mathrm{v} / \mathrm{v}+5 \% \mathrm{Et}_{3} \mathrm{~N}$ ). Yield: $0.49 \mathrm{~g}$ $(0.61 \mathrm{mmol}, 62 \%)$ colourless oil. TLC $\left(\mathrm{PE} / \mathrm{EE} 1: 1 \mathrm{v} / \mathrm{v}+5 \% \mathrm{Et}_{3} \mathrm{~N}\right): R_{\mathrm{f}}=0.30$; ${ }^{1} \mathrm{H}-\mathrm{NMR}\left(400 \mathrm{MHz}, \mathrm{CDCl}_{3}\right): \delta$ 7.39-7.30 $(m, 4 \mathrm{H}), 7.10-7.01(m, 4 \mathrm{H}), 4.78-4.60$ $(m, 4 \mathrm{H}), 4.14-4.02(m, 4 \mathrm{H}), 3.76-3.61(m, 2 \mathrm{H}), 3.62-3.42(m, 8 \mathrm{H}$, rotamers $)$, $3.15-2.89$ ( $m, 12 \mathrm{H}$, rotamers), 1.65-1.56 ( $m, 4 \mathrm{H}$, rotamers), $1.46-1.30(m, 4 \mathrm{H}$, rotamers), $1.19(d, J=6.9 \mathrm{~Hz}, 12 \mathrm{H}), 0.93,0.88(t, J=7.4 \mathrm{~Hz}, 6 \mathrm{H}$, rotamers); ${ }^{13} \mathrm{C}-\mathrm{NMR}\left(101 \mathrm{MHz}, \mathrm{CDCl}_{3}\right): \delta 156.9,154.8,150.5,136.5,128.0,121.6+121.6$ (rotamers), $65.7+65.6$ (rotamers), $65.0(d, J=18.1 \mathrm{~Hz}), 47.8+47.4$ (rotamers) $47.0+46.4$ (rotamers), $43.3(d, J=12.2 \mathrm{~Hz}), 35.4+35.3$ (rotamers), $35.2+34.8$ (rotamers), $31.3+31.3$ (rotamers), $24.8(d, J=7.5 \mathrm{~Hz}), 19.3,13.9 ;{ }^{31} \mathrm{P}-\mathrm{NMR}$ $\left(162 \mathrm{MHz}, \mathrm{CDCl}_{3}\right): \delta 147.4$; IR: 2,962, 2,932, 2,871, 1,719, 1,695, $1,199 \mathrm{~cm}^{-1}$; HRMS $\left(\mathrm{ESI}^{+}, m / z\right):[\mathrm{M}+\mathrm{H}]^{+}$calcd. for $\mathrm{C}_{40} \mathrm{H}_{64} \mathrm{~N}_{5} \mathrm{O}_{10} \mathrm{P}, 806.4464$; found, 806.4440 .

Bis-(4-(octyl-ethan-1,2-diylbis(methylcarbamate))-oxybenzyl)- $\mathbf{N}, \mathrm{N}$-diisopropylaminophosphoramidite 5p. General procedure $\mathrm{C}$ with $0.14 \mathrm{~g}$ dichloro- $N, N$ diisopropylphosphoramidite $(0.71 \mathrm{mmol}, 1.0$ eq.) dissolved in $10 \mathrm{ml} \mathrm{THF}, 0.23 \mathrm{ml}$ triethylamine $(0.17 \mathrm{~g}, 1.6 \mathrm{mmol}, 2.3 \mathrm{eq}$.$) and 0.59 \mathrm{~g}$ compound $15 \mathrm{p}(1.5 \mathrm{mmol}$, 2.1 eq.) in $5 \mathrm{ml}$ THF. The crude product was purified using column chromatography (petroleum ether 50-70/ethyl acetate $1: 1 \mathrm{v} / \mathrm{v}+5 \% \mathrm{Et}_{3} \mathrm{~N}$ ). Yield: $0.59 \mathrm{~g}$ $(0.64 \mathrm{mmol}, 90 \%)$ colourless oil. TLC $\left(\mathrm{PE} / \mathrm{EE} 1: 1 \mathrm{v} / \mathrm{v}+5 \% \mathrm{Et}_{3} \mathrm{~N}\right): R_{\mathrm{f}}=0.41$; ${ }^{1} \mathrm{H}-\mathrm{NMR}\left(400 \mathrm{MHz} \mathrm{CDCl}_{3}\right): \delta 7.37-7.29(m, 4 \mathrm{H}), 7.10-7.02(m, 4 \mathrm{H}), 4.78-4.61$ $(m, 4 \mathrm{H}), 4.12-4.02(m, 4 \mathrm{H}), 3.74-3.63(m, 2 \mathrm{H}), 3.62-3.43(m, 8 \mathrm{H}$, rotamers), $3.15-2.89(m, 12 \mathrm{H}$, rotamers), $1.69-1.55(m, 4 \mathrm{H}$, rotamers $), 1.40-1.19(m, 36 \mathrm{H}$, rotamers), $1.19(d, J=6.8 \mathrm{~Hz}, 12 \mathrm{H}), 0.87(t, J=6.8 \mathrm{~Hz}, 6 \mathrm{H}, \mathrm{H}-\mathrm{n}$, rotamers $)$; ${ }^{13} \mathrm{C}-\mathrm{NMR}\left(101 \mathrm{MHz}, \mathrm{CDCl}_{3}\right): \delta 156.6,154.8,150.7,136.6,128.0,121.6+121.5$ (rotamers), $65.9+65.8$ (rotamers), $65.0(d, J=18.0 \mathrm{~Hz}), 47.6+47.4$ (rotamers) $47.0+46.4$ (rotamers), $43.2(d, J=12.6 \mathrm{~Hz}), 35.4+35.3$ (rotamers), $35.1+34.8$ (rotamers), 31.9, 29.4, 29.3, 29.2 + 29.2 (rotamers), 26.1, $24.8(d, J=7.2 \mathrm{~Hz}), 22.8$, 14.2; ${ }^{31} \mathrm{P}-\mathrm{NMR}\left(162 \mathrm{MHz}, \mathrm{CDCl}_{3}\right.$ ): $\delta$ 147.7; IR: 2,958, 2,927, 2,856, 1,722, 1,699, $1,202 \mathrm{~cm}^{-1}$; HRMS $\left(\mathrm{ESI}^{+}, \mathrm{m} / z\right):[\mathrm{M}+\mathrm{H}]^{+}$calcd. for $\mathrm{C}_{48} \mathrm{H}_{80} \mathrm{~N}_{5} \mathrm{O}_{10} \mathrm{P}, 918.5716$; found, 918.6124 . 
Bis-(4-(dodecyl-ethan-1,2-diylbis(methylcarbamate))-oxybenzyl)- $\mathbf{N}, \mathbf{N}$-diisopropylaminophosphoramidite 5q. General procedure $\mathrm{C}$ with $0.15 \mathrm{~g}$ dichloro$N, N$-diisopropylphosphoramidite ( $0.75 \mathrm{mmol}, 1.0$ eq.) dissolved in $3 \mathrm{ml} \mathrm{THF}$, $0.24 \mathrm{ml}$ triethylamine $(0.17 \mathrm{~g}, 1.7 \mathrm{mmol}, 2.3$ eq. $)$ and $0.71 \mathrm{~g}$ compound $\mathbf{1 5 q}$ $(1.6 \mathrm{mmol}, 2.1 \mathrm{eq}$.) in $5 \mathrm{ml}$ THF. The crude product was purified using column chromatography (petroleum ether 50-70/ethyl acetate 1:1 v/v $+5 \% \mathrm{Et}_{3} \mathrm{~N}$ ). Yield: $0.37 \mathrm{~g}(0.36 \mathrm{mmol}, 48 \%)$ colourless oil. TLC (PE/EE $\left.1: 1 \mathrm{v} / \mathrm{v}+5 \% \mathrm{Et}_{3} \mathrm{~N}\right): R_{\mathrm{f}}=0.50$; ${ }^{1} \mathrm{H}-\mathrm{NMR}\left(600 \mathrm{MHz}, \mathrm{CDCl}_{3}\right): \delta 7.36-7.30(m, 4 \mathrm{H}), 7.08-7.03(m, 4 \mathrm{H}), 4.76-4.62$ $(m, 4 \mathrm{H}), 4.11-4.02(m, 4 \mathrm{H}), 3.73-3.62(m, 2 \mathrm{H}), 3.61-3.42(m, 8 \mathrm{H}$, rotamers), $3.14-2.90(m, 12 \mathrm{H}$, rotamers), 1.67-1.56 ( $m, 4 \mathrm{H}$, rotamers), $1.37-1.21(m, 36 \mathrm{H})$ $1.19(d, J=6.8 \mathrm{~Hz}, 12 \mathrm{H}), 0.87\left(t, J=6.9 \mathrm{~Hz}, 6 \mathrm{H}\right.$, rotamers); ${ }^{13} \mathrm{C}-\mathrm{NMR}(101 \mathrm{MHz}$, $\left.\mathrm{CDCl}_{3}\right): \delta 157.0,154.7,150.7+150.6$ (rotamers), $136.6,128.0+128.0(d, J=2.6$ $\mathrm{Hz}$ ), $121.6+121.5$ (rotamers), $65.9+65.8$ (rotamers), $65.0(d, J=18.3 \mathrm{~Hz})$, $47.4+47.3$ (rotamers), $46.9+46.4$ (rotamers), $43.2(d, J=12.3 \mathrm{~Hz}), 35.4,35.3$ (rotamers), $35.0+34.6$ (rotamers), 32.0, 29.8, 29.7, 29.7, 29.7, 29.5, 29.4, $29.2+29.2$ (rotamers), 26.1, $24.8(d, J=7.4 \mathrm{~Hz}), 22.8,14.2{ }^{31}$ P-NMR $(162 \mathrm{MHz}$,

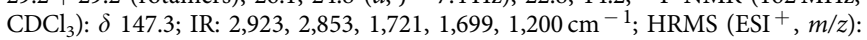
$[\mathrm{M}+\mathrm{H}]^{+}$calcd. for $\mathrm{C}_{48} \mathrm{H}_{80} \mathrm{~N}_{5} \mathrm{O}_{10} \mathrm{P}, 1030.6982$; found, 1030.6968 .

5-Chloro-cycloSal-3'-deoxy-2', $\mathbf{3}^{\prime}$-didehydrothymidine monophosphate 7. To a suspension of $0.50 \mathrm{~g} \mathrm{~d} 4 \mathrm{~T} \mathbf{1}(2.2 \mathrm{mmol}, 1.0 \mathrm{eq}$.$) in 8 \mathrm{ml}$, acetonitrile was added $0.53 \mathrm{ml}$ diisopropylethlyamine $(0.54 \mathrm{~g}, 3.1 \mathrm{mmol}, 1.4$ eq. $)$ followed by $0.60 \mathrm{~g}$ 5 -chlorosaligenylchlorophosphite $\mathbf{8}(2.7 \mathrm{mmol}, 1.2 \mathrm{eq}$.). The reaction mixture was stirred for $3 \mathrm{~h}$ and subsequently cooled to $0{ }^{\circ} \mathrm{C}$. By addition of a 5.5-M solution of $0.57 \mathrm{ml}$ tert-butylhydroperoxide in $n$-decane $(3.1 \mathrm{mmol}, 1.4 \mathrm{eq}$.) the phosphite was oxidized for $20 \mathrm{~min}$. The solvent was removed in vacuum. The residue was redissolved in $\mathrm{CH}_{2} \mathrm{Cl}_{2}$ and washed with $1 \mathrm{M}$ ammonium acetate solution. The organic phase was dried over $\mathrm{Na}_{2} \mathrm{SO}_{4}$, filtered and the solvent was removed by evaporation. The crude product was purified using column chromatography $\left(\mathrm{CH}_{2} \mathrm{Cl}_{2} / \mathrm{MeOH} 9: 1 \mathrm{v} / \mathrm{v}\right)$. Yield: $0.91 \mathrm{~g}(2.1 \mathrm{mmol}, 97 \%)$ colourless foam as a mixture of two diastereomers. TLC $\left(\mathrm{CH}_{2} \mathrm{Cl}_{2} / \mathrm{MeOH} 9: 1 \mathrm{v} / \mathrm{v}\right): R_{\mathrm{f}}=0.29 ;{ }^{1} \mathrm{H}-\mathrm{NMR}$ $\left(500 \mathrm{MHz}, \mathrm{CDCl}_{3}\right): \delta 8.92,8.92$ (br.s, $1 \mathrm{H}$, diasteromers), 7.33-7.26 $(\mathrm{m}, 1 \mathrm{H}, \mathrm{ds})$, 7.20, $7.18(s, 1 \mathrm{H}, \mathrm{ds}), 7.12-7.07(m, 1 \mathrm{H}, \mathrm{ds}), 7.04-6.95(m, 2 \mathrm{H}, \mathrm{ds}), 6.40-6.32$ $(m, 1 \mathrm{H}, \mathrm{ds}), 5.94,5.94(d, J=5.8 \mathrm{~Hz}, \mathrm{ds}), 5.43-5.18(m, 2 \mathrm{H}, \mathrm{ds}), 5.06-4.99$ $(m, 1 \mathrm{H}, \mathrm{ds}), 4.47-4.30(m, 2 \mathrm{H}, \mathrm{ds}), 1.82,1.73(s, 3 \mathrm{H}, \mathrm{ds}) ;{ }^{13} \mathrm{C}-\mathrm{NMR}(126 \mathrm{MHz}$, $\left.\mathrm{CDCl}_{3}\right): \delta 163.9+163.8$ (diastereomers), $150.9+150.8(\mathrm{ds}), 148.7+148.7(\mathrm{ds})$, $135.8+135.6(\mathrm{ds}), 132.8+132.7(\mathrm{ds}), 130.3+130.3(\mathrm{ds}), 130.1+130.1(\mathrm{ds})$, $128.1+128.0(\mathrm{ds}), 125.7+125.6(\mathrm{ds}), 122.3+122.3(\mathrm{ds}), 120.1+120.0(d$, $J=5.3 \mathrm{~Hz}, \mathrm{ds}), 111.5+111.4(\mathrm{ds}), 90.0+89.9(\mathrm{ds}), 84.6+84.5(\mathrm{ds}), 68.7+68.6$ (ds), $68.1+67.9(d, J=6.7 \mathrm{~Hz}, \mathrm{ds}), 12.4+12.3(\mathrm{ds}) ;{ }^{31} \mathrm{P}-\mathrm{NMR}\left(162 \mathrm{MHz}, \mathrm{CDCl}_{3}\right)$ $\delta-9.80,-9.87$ (s, diastereomers); IR: $3,168,3,050,2,886,1,684 \mathrm{~cm}^{-1}$; HRMS $\left(\mathrm{ESI}^{+}, m / z\right):[\mathrm{M}+\mathrm{H}]^{+}$calcd. for $\mathrm{C}_{17} \mathrm{H}_{16} \mathrm{ClN}_{2} \mathrm{O}_{7} \mathrm{P}, 449.0276$; found, 449.0287 .

\section{$3^{\prime}$-Deoxy-2', $\mathbf{3}^{\prime}$-didehydrothymidinediphosphate 6 (d4TDP, tetra-n-buty-} lammonium salt). cycloSal-triester 7 ( $1.1 \mathrm{~g} ; 2.5 \mathrm{mmol}, 1.0 \mathrm{eq}$.) was dissolved in $10 \mathrm{ml}$ DMF and added dropwise to a solution of $2.1 \mathrm{~g}$ mono-(tetra- $n$-butylammonium)-phosphate (6.2 mmol, 2.5 eq.) in $12 \mathrm{ml}$ DMF. After $16 \mathrm{~h}$, the solvent was removed in vacuum. The residue was extracted with ethyl acetate/water followed by freeze-drying of the aqueous phase. The crude product was purified using automatic RP-18 chromatography (water/acetonitrile gradient: 5-100\%, 0-90 $\mathrm{min}$, flow $1 \mathrm{ml} \mathrm{min}^{-1}$ ). The purification had to repeat for complete removement of the excess of the monophosphate salt. Yield: $0.78 \mathrm{~g}(0.90 \mathrm{mmol}$, $36 \%, 2 \times \mathrm{Bu}_{4} \mathrm{~N}^{+}$) colourless solid. TLC (isopropanol $/ \mathrm{NH}_{3} /$ water 4:1:2.5 v/v/v): $R_{\mathrm{f}}=0.16 ;{ }^{1} \mathrm{H}-\mathrm{NMR}\left(300 \mathrm{MHz}, \mathrm{D}_{2} \mathrm{O}\right): \delta 7.60(d, J=1.3 \mathrm{~Hz}, 1 \mathrm{H}), 6.93(\mathrm{dt}, J=3.3 \mathrm{~Hz}$, $J=1.7 \mathrm{~Hz}, 1 \mathrm{H}), 6.48(\mathrm{dt}, J=6.2 \mathrm{~Hz}, J=1.8 \mathrm{~Hz}, 1 \mathrm{H}), 5.91(\mathrm{ddd}, J=6.1 \mathrm{~Hz}, J=2.4$ $\mathrm{Hz}, J=1.4 \mathrm{~Hz}, 1 \mathrm{H}), 5.10-5.04(m, 1 \mathrm{H}), 4.11(\mathrm{dt}, J=6.2 \mathrm{~Hz}, J=3.3 \mathrm{~Hz}, 2 \mathrm{H})$, $3.25-3.05(m, 16 \mathrm{H}), 1.86(d, J=1.3 \mathrm{~Hz}, 3 \mathrm{H}), 1.73-1.49(m, 16 \mathrm{H}), 1.22$ (sext, $J=7.4 \mathrm{~Hz}, 16 \mathrm{H}), 0.91(t, J=7.3 \mathrm{~Hz}, 24 \mathrm{H}) ;{ }^{13} \mathrm{C}-\mathrm{NMR}\left(75 \mathrm{MHz}, \mathrm{D}_{2} \mathrm{O}\right): \delta 166.8$, $152.2,138.1,134.2,125.1,111.2,89.8,85.8(d, J=8.5 \mathrm{~Hz}), 66.2(d, J=5.6 \mathrm{~Hz}), 58.0$, $23.0,19.0,12.8,11.4 ;{ }^{31} \mathrm{P}-\mathrm{NMR}\left(162 \mathrm{MHz}, \mathrm{D}_{2} \mathrm{O}\right): \delta-8.32(d, J=21.7 \mathrm{~Hz}),-11.23$ $(d, J=21.7 \mathrm{~Hz}) ;$ IR: $3,220,1,645,1,486 \mathrm{~cm}^{-1}$; MALDI-MS $\left(\mathrm{ESI}^{+}, \mathrm{m} / z\right):[\mathrm{M}-\mathrm{H}]$ calcd. for $\mathrm{C}_{10} \mathrm{H}_{14} \mathrm{~N}_{2} \mathrm{O}_{10} \mathrm{P}_{2}$, 383.005; found, 382.928 .

General procedure D: preparation of $\gamma$-bis(4-alkanoyloxybenzyl)-d4TTPs 3. D4TDP 6 (1.0 eq.) were once co-evaporated with DMF and then dissolved in acetonitrile. Phosphoramidites 5 (1.7-2.0 eq.) were added and the solvent removed in vacuum quantitatively. The residue was redissolved in a minimum of acetonitrile or in a mixture of acetonitrile/THF (1:1), and the reaction was started by addition of a $0.25-\mathrm{M}$ solution of DCI in acetonitrile (1.2-1.4 eq.). After stirring for $1 \mathrm{~min}$ the reaction was cooled to $-10^{\circ} \mathrm{C}$, and a $5.5 \mathrm{M}$ solution of $t$ - $\mathrm{BuOOH}$ in $n$-decane (2.1-2.2 eq.) was added for oxidation. The mixture was stirred for $20 \mathrm{~min}$ and the volatile components were removed in vacuum. The reaction was monitored with HPLC. If the conversion of d4TDP was not complete, the procedure was repeated as described above. The crude products were purified by automatic RP-18 flash chromatography followed by an ion exchange to the ammonium form with Dowex 50WX8 cation exchange resin and a second RP-18 chromatography (3a-g, l-q). For elution water/acetonitrile $\left(5-100 \%, 0-40 \mathrm{~min}\right.$, flow $1 \mathrm{ml} \mathrm{min}^{-1}$ ) or water/THF gradients $\left(5-80 \%, 0-40 \mathrm{~min}\right.$, flow $1 \mathrm{ml} \mathrm{min}^{-1}$ were used. Product-containing fractions were pooled and the organic solvent evaporated. The remaining aqueous solutions were freeze-dried and the desired product obtained as colourless solids.

$\gamma$-Bis-(4-acetyloxybenzyl)-d4TTP 3a (ammonium salt). General procedure D with $86 \mathrm{mg}$ d4TDP 6 ( $99 \mu \mathrm{mol}, 1.0 \mathrm{eq}$.), $92 \mathrm{mg} 5 \mathbf{a}(0.20 \mathrm{mmol}, 2.0$ eq.), $0.55 \mathrm{ml}$ $0.25 \mathrm{M}$ solution of DCI in acetonitrile $(0.14 \mathrm{mmol}, 1.4 \mathrm{eq}),. 40 \mu \mathrm{l} 5.5 \mathrm{M}$ solution of $t$-BuOOH in $n$-decane $(0.22 \mathrm{mmol}, 2.2 \mathrm{eq}$.) in $0.7 \mathrm{ml}$ acetonitrile. The crude product was purified using automatic RP-18 chromatography (water/acetonitrile gradient). Yield: $46 \mathrm{mg}(58 \mu \mathrm{mol}, 59 \%)$ colourless solid. UV (HPLC): $\lambda_{\max }=265$ nm; HPLC: $t_{\mathrm{R}}=11.00 \min (\operatorname{method} \mathrm{A}) ; 8.75 \min (\operatorname{method~B}) ;{ }^{1} \mathrm{H}-\mathrm{NMR}(400 \mathrm{MHz}$, $\left.\mathrm{CD}_{3} \mathrm{OD}\right): \delta 7.67(d, J=1.3 \mathrm{~Hz}, 1 \mathrm{H}), 7.46-7.40(m, 4 \mathrm{H}), 7.13-7.06(m, 4 \mathrm{H}), 6.94$ $(\mathrm{dt}, J=3.4 \mathrm{~Hz}, J=1.8 \mathrm{~Hz}, 1 \mathrm{H}), 6.48(\mathrm{dt}, J=5.9 \mathrm{~Hz}, J=1.9 \mathrm{~Hz}, 1 \mathrm{H}), 5.82$ $(\mathrm{dt}, J=5.9 \mathrm{~Hz}, J=1.9 \mathrm{~Hz}, 1 \mathrm{H}), 5.18(d, J=8.1 \mathrm{~Hz}, 4 \mathrm{H}), 4.99-4.93(m, 1 \mathrm{H})$, $4.32-4.17(m, 2 \mathrm{H}), 2.30(s, 6 \mathrm{H}), 1.92(d, J=1.3 \mathrm{~Hz}, 3 \mathrm{H}) ;{ }^{13} \mathrm{C}-\mathrm{NMR}(101 \mathrm{MHz}$, $\left.\mathrm{CD}_{3} \mathrm{OD}\right): \delta 171.1,166.5,152.8,152.3,138.7,134.9,134.9$ (d, $\left.J=6.8 \mathrm{~Hz}\right), 130.4$ $(d, J=2.7 \mathrm{~Hz}), 127.3,122.9,112.0,90.8,87.1(d, J=8.8 \mathrm{~Hz}), 70.3(d, J=6.1 \mathrm{~Hz})$, 67.6, 20.9, 12.5; ${ }^{31}$ P-NMR (162 MHz, $\left.\mathrm{CD}_{3} \mathrm{OD}\right): \delta-11.69(d, J=19.4 \mathrm{~Hz}),-13.11$ $(d, J=17.1 \mathrm{~Hz}),-23.51(t, J=17.8 \mathrm{~Hz}) ; \mathrm{IR}: 3,191,2,988,1,756,1,687,1,193 \mathrm{~cm}^{-1}$ MALDI-MS $(m / z)$ : $[\mathrm{M}-\mathrm{H}]^{-}$calcd. for $\mathrm{C}_{28} \mathrm{H}_{31} \mathrm{~N}_{2} \mathrm{O}_{17} \mathrm{P}_{3}, 759.076$; found, 759.131 .

$\gamma$-Bis-(4-propanoyloxybenzyl)-d4TTP 3b (ammonium salt). General procedure D with $87 \mathrm{mg}$ d4TDP 6 ( $0.10 \mathrm{mmol}, 1.0$ eq. $), 93 \mathrm{mg} 5 \mathbf{b}(0.20 \mathrm{mmol}, 2.0$ eq. $), 0.48 \mathrm{ml}$ $0.25 \mathrm{M}$ solution of DCI in acetonitrile $(0.12 \mathrm{mmol}, 1.2 \mathrm{eq}$.), $38 \mu \mathrm{l} 5.5 \mathrm{M}$ solution of $t$-BuOOH in $n$-decane $(0.21 \mathrm{mmol}, 2.1$ eq.) in $0.5 \mathrm{ml}$ acetonitrile. The crude product was purified using automatic RP-18 chromatography (water/acetonitrile gradient). Yield: $35 \mathrm{mg}(43 \mu \mathrm{mol}, 43 \%)$ colourless solid. UV (HPLC): $\lambda_{\max }=265$ nm; HPLC: $t_{\mathrm{R}}=11.83 \mathrm{~min}(\operatorname{method} \mathrm{A}) ; 10.09 \mathrm{~min}(\operatorname{method} \mathrm{B}) ;{ }^{1} \mathrm{H}-\mathrm{NMR}$ $\left(200 \mathrm{MHz}, \mathrm{CD}_{3} \mathrm{OD}\right): \delta 7.63(d, J=1.3 \mathrm{~Hz}, 1 \mathrm{H}), 7.44-7.32(m, 4 \mathrm{H}), 7.09-6.99$ $(m, 4 \mathrm{H}), 6.90(\mathrm{dt}, J=3.4 \mathrm{~Hz}, J=1.6 \mathrm{~Hz}, 1 \mathrm{H}), 6.43(\mathrm{dt}, J=5.9 \mathrm{~Hz}, J=1.7 \mathrm{~Hz}, 1 \mathrm{H})$, 5.77 (ddd, $J=5.9 \mathrm{~Hz}, J=2.4 \mathrm{~Hz}, J=1.4 \mathrm{~Hz}, 1 \mathrm{H}), 5.12(d, J=8.0 \mathrm{~Hz}, 4 \mathrm{H}), 4.94-4.89$ $(m, 1 \mathrm{H}), 4.31-4.08(m, 2 \mathrm{H}), 2.58(q, J=7.5 \mathrm{~Hz}, 4 \mathrm{H}), 1.86(d, J=1.3 \mathrm{~Hz}, 3 \mathrm{H}), 1.20$ $(t, J=7.5 \mathrm{~Hz}, 6 \mathrm{H}) ;{ }^{13} \mathrm{C}-\mathrm{NMR}\left(75 \mathrm{MHz}, \mathrm{CD}_{3} \mathrm{OD}\right): \delta 174.5,166.5,152.8,152.4$ 138.7, 135.7, $134.9(d, J=7.6 \mathrm{~Hz}), 130.4(d, J=2.4 \mathrm{~Hz}), 127.2,122.9,112.0$, 90.8, 87.2 $(d, J=9.0 \mathrm{~Hz}), 70.3(d, J=5.6 \mathrm{~Hz}), 67.6(d, J=6.3 \mathrm{~Hz}), 28.3,12.5,9.3$; ${ }^{31} \mathrm{P}-\mathrm{NMR}\left(81 \mathrm{MHz}, \mathrm{CD}_{3} \mathrm{OD}\right): \delta-11.76(d, J=19.4 \mathrm{~Hz}),-13.19(d, J=17.1 \mathrm{~Hz})$, $-23.51(t, J=18.4 \mathrm{~Hz})$; IR: $3,195,2,987,1,758,1,691,1,254 \mathrm{~cm}^{-1}$; MALDI-MS (m/z): $[\mathrm{M}-\mathrm{H}]^{-}$calcd. for $\mathrm{C}_{30} \mathrm{H}_{35} \mathrm{~N}_{2} \mathrm{O}_{17} \mathrm{P}_{3}, 787.108$; found, 787.275.

$\gamma$-Bis-(4-pentanoyloxybenzyl)-d4TTP 3c (ammonium salt). General procedure D with $90 \mathrm{mg}$ d4TDP 6 ( $0.10 \mathrm{mmol}, 1.0$ eq. $), 0.11 \mathrm{~g} 5 \mathbf{c}(0.21 \mathrm{mmol}, 2.0$ eq.), $0.50 \mathrm{ml}$ $0.25 \mathrm{M}$ solution of DCI in acetonitrile $(0.13 \mathrm{mmol}, 1.2 \mathrm{eq}),. 40 \mu \mathrm{l} 5.5 \mathrm{M}$ solution of $t$ - $\mathrm{BuOOH}$ in $n$-decane $(0.21 \mathrm{mmol}, 2.1 \mathrm{eq}$.) in $0.5 \mathrm{ml}$ acetonitrile. The crude product was purified using automatic RP-18 chromatography (water/acetonitrile gradient). Yield: $43 \mathrm{mg}(49 \mu \mathrm{mol}, 47 \%)$ colourless solid. UV (HPLC): $\lambda_{\max }=265$ nm; HPLC: $t_{\mathrm{R}}=13.61 \mathrm{~min}(\operatorname{method} \mathrm{A}) ;{ }^{1} \mathrm{H}-\mathrm{NMR}\left(400 \mathrm{MHz}, \mathrm{CD}_{3} \mathrm{OD}\right): \delta 7.59$ $(d, J=1.5 \mathrm{~Hz}, 1 \mathrm{H}), 7.38-7.32(m, 4 \mathrm{H}), 7.04-6.97(m, 4 \mathrm{H}), 6.87(\mathrm{dt}, J=3.4 \mathrm{~Hz}$, $J=1.7 \mathrm{~Hz}, 1 \mathrm{H}), 6.39(\mathrm{dt}, J=5.9 \mathrm{~Hz}, J=1.8 \mathrm{~Hz}, 1 \mathrm{H}), 5.77(\mathrm{ddd}, J=5.9 \mathrm{~Hz}, J=2.4$ $\mathrm{Hz}, J=1.4 \mathrm{~Hz}, 1 \mathrm{H}), 5.12(d, J=8.1 \mathrm{~Hz}, 4 \mathrm{H}), 4.94-4.84(m, 1 \mathrm{H}), 4.26-4.08(m, 2 \mathrm{H})$, 2.57-2.50 $(m, 4 \mathrm{H}), 1.84(d, J=1.5 \mathrm{~Hz}, 3 \mathrm{H}), 1.71-1.61(m, 4 \mathrm{H}), 1.47-1.26(m, 4 \mathrm{H})$ $0.93(t, J=7.4 \mathrm{~Hz}, 6 \mathrm{H}) ;{ }^{13} \mathrm{C}-\mathrm{NMR}\left(101 \mathrm{MHz}, \mathrm{CD}_{3} \mathrm{OD}\right): \delta 173.8,166.5,152.7,152.3$ 138.6, 135.6, $134.8(d, J=7.3 \mathrm{~Hz}), 130.5(d, J=3.1 \mathrm{~Hz}), 127.2,122.9,112.0,90.8$, $87.1(d, J=8.8 \mathrm{~Hz}), 70.4(\mathrm{dd}, J=6.0 \mathrm{~Hz}, J=2.1 \mathrm{~Hz}), 67.9(d, J=5.4 \mathrm{~Hz}), 34.7,28.1$, 23.2, 14.1, 12.5; ${ }^{31} \mathrm{P}-\mathrm{NMR}\left(81 \mathrm{MHz}, \mathrm{CD}_{3} \mathrm{OD}\right): \delta-11.76(d, J=19.3 \mathrm{~Hz}),-13.19$ $(d, J=17.1 \mathrm{~Hz}),-23.51(t, J=18.2 \mathrm{~Hz}) ; \mathrm{IR}: 3,183,2,959,1,755,1,687,1,219 \mathrm{~cm}^{-1}$ MALDI-MS $(\mathrm{m} / z)$ : [M-H] ${ }^{-}$calcd. for $\mathrm{C}_{34} \mathrm{H}_{43} \mathrm{~N}_{2} \mathrm{O}_{17} \mathrm{P}_{3}, 843.170$; found, 843.267.

$\gamma$-Bis-(4-heptanoyloxybenzyl)-d4TTP 3d (ammonium salt). General procedure D with $99 \mathrm{mg}$ d4TDP 6 ( $0.11 \mathrm{mmol}, 1.0$ eq.), $0.14 \mathrm{~g} \mathbf{5 d}(0.23 \mathrm{mmol}, 2.0$ eq.), $0.55 \mathrm{ml}$ $0.25 \mathrm{M}$ solution of DCI in acetonitrile $(0.14 \mathrm{mmol}, 1.2 \mathrm{eq}),. 44 \mu \mathrm{l} 5.5 \mathrm{M}$ solution of $t$-BuOOH in $n$-decane $(0.24 \mathrm{mmol}, 2.1$ eq. $)$ in $0.5 \mathrm{ml}$ acetonitrile. The crude product was purified using automatic RP-18 chromatography (water/acetonitrile gradient). Yield: $41 \mathrm{mg}(44 \mu \mathrm{mol}, 40 \%)$ colourless solid. UV (HPLC): $\lambda_{\max }=265$ nm; HPLC: $t_{\mathrm{R}}=15.40 \mathrm{~min}(\operatorname{method} \mathrm{A}) ;{ }^{1} \mathrm{H}-\mathrm{NMR}\left(400 \mathrm{MHz}, \mathrm{CD}_{3} \mathrm{OD}\right): \delta 7.68$ $(d, J=1.2 \mathrm{~Hz}, 1 \mathrm{H}), 7.46-7.39(m, 4 \mathrm{H}), 7.11-7.05(m, 4 \mathrm{H}), 6.95(\mathrm{dt}, J=3.4 \mathrm{~Hz}$, $J=1.6 \mathrm{~Hz}, 1 \mathrm{H}), 6.48(\mathrm{dt}, J=6.1 \mathrm{~Hz}, J=1.7 \mathrm{~Hz}, 1 \mathrm{H}), 5.86-5.80(m, 1 \mathrm{H}), 5.18$ $(d, J=8.2 \mathrm{~Hz}, 4 \mathrm{H}), 5.01-4.94(m, 1 \mathrm{H}), 4.34-4.16(m, 2 \mathrm{H}), 2.60(t, J=7.4 \mathrm{~Hz}, 4 \mathrm{H})$, $1.92(d, J=1.2 \mathrm{~Hz}, 3 \mathrm{H}), 1.76$ (quint, $J=7.4 \mathrm{~Hz}, 4 \mathrm{H}), 1.51-1.34(m, 12 \mathrm{H}), 0.96$ $(t, J=6.8 \mathrm{~Hz}, 6 \mathrm{H}) ;{ }^{13} \mathrm{C}-\mathrm{NMR}\left(101 \mathrm{MHz}, \mathrm{CD}_{3} \mathrm{OD}\right): \delta 173.8,166.5,152.8,152.3$, $138.4,135.8,134.9(d, J=7.8 \mathrm{~Hz}), 130.5(d, J=2.9 \mathrm{~Hz}), 127.2,122.9,112.1,90.8$, $87.2(d, J=8.9 \mathrm{~Hz}), 70.4(d, J=6.8 \mathrm{~Hz}), 67.9(d, J=4.9 \mathrm{~Hz}), 35.0,32.7,29.9$, 23.6, 25.9, 14.4, 12.5; ${ }^{31}$ P-NMR (162 MHz, $\left.\mathrm{CD}_{3} \mathrm{OD}\right): \delta-11.64$ (br.s), -13.08 $(d, J=17.5 \mathrm{~Hz}),-23.47$ (br.s); IR: $3,190,2,928,1,756,1,689,1,250 \mathrm{~cm}^{-1}$; MALDI-MS $(\mathrm{m} / z)$ : $[\mathrm{M}-\mathrm{H}]^{-}$calcd. for $\mathrm{C}_{38} \mathrm{H}_{51} \mathrm{~N}_{2} \mathrm{O}_{17} \mathrm{P}_{3}, 899.233$; found, 899.229.

$\gamma$-Bis-(4-nonanoyloxybenzyl)-d4TTP 3e (ammonium salt). General procedure D with $0.15 \mathrm{~g}$ d4TDP 6 ( $0.17 \mathrm{mmol}, 1.0$ eq.), $0.22 \mathrm{~g} \mathbf{5 e}(0.34 \mathrm{mmol}, 2.0$ eq. $), 0.88 \mathrm{ml}$ $0.25 \mathrm{M}$ solution of DCI in acetonitrile $(0.22 \mathrm{mmol}, 1.3 \mathrm{eq}),. 68 \mu \mathrm{l} 5.5 \mathrm{M}$ solution of $t$ - $\mathrm{BuOOH}$ in $n$-decane $(0.37 \mathrm{mmol}, 2.2$ eq. $)$ in $3 \mathrm{ml}$ acetonitrile. The crude product 
was purified using automatic RP-18 chromatography (water/acetonitrile gradient). Yield: $70 \mathrm{mg}(71 \mu \mathrm{mol}, 42 \%)$ beige solid. UV (HPLC): $\lambda_{\max }=265 \mathrm{~nm}$; HPLC: $t_{\mathrm{R}}=17.31 \mathrm{~min}(\operatorname{method} \mathrm{A}) ;{ }^{1} \mathrm{H}-\mathrm{NMR}\left(300 \mathrm{MHz}, \mathrm{CD}_{3} \mathrm{OD}\right): \delta 7.65(d, J=1.3 \mathrm{~Hz}$, $1 \mathrm{H}), 7.42-7.35(m, 4 \mathrm{H}), 7.07-7.00(m, 4 \mathrm{H}), 6.92(\mathrm{dt}, J=3.5 \mathrm{~Hz}, J=1.6 \mathrm{~Hz}, 1 \mathrm{H})$, $6.45(\mathrm{dt}, J=6.1 \mathrm{~Hz}, J=1.7 \mathrm{~Hz}, 1 \mathrm{H}), 5.79(\mathrm{ddd}, J=6.0 \mathrm{~Hz}, J=2.4 \mathrm{~Hz}, J=1.7 \mathrm{~Hz}$, $1 \mathrm{H}), 5.14(d, J=8.1 \mathrm{~Hz}, 4 \mathrm{H}), 4.96-4.90(m, 1 \mathrm{H}), 4.31-4.13(m, 2 \mathrm{H}), 2.57$ $(t, J=7.4 \mathrm{~Hz}, 4 \mathrm{H}), 1.88(d, J=1.3 \mathrm{~Hz}, 3 \mathrm{H}), 1.72$ (quint, $J=7.3 \mathrm{~Hz}, 4 \mathrm{H}), 1.49-1.24$ $(m, 20 \mathrm{H}), 0.96-0.85(m, 6 \mathrm{H}) ;{ }^{13} \mathrm{C}-\mathrm{NMR}\left(75 \mathrm{MHz}, \mathrm{CD}_{3} \mathrm{OD}\right): \delta 173.4,166.5,152.9$, $152.3,138.4,135.8,134.5,130.2(d, J=2.4 \mathrm{~Hz}), 126.9,122.6,111.9,90.5,86.8$ $(d, J=9.5 \mathrm{~Hz}), 70.1(d, J=5.2 \mathrm{~Hz}), 67.6(d, J=5.6 \mathrm{~Hz}), 34.7,32.7,30.1,30.1,29.9$, 25.7, 23.5, 14.2, 12.2; ${ }^{31} \mathrm{P}-\mathrm{NMR}\left(162 \mathrm{MHz}, \mathrm{CD}_{3} \mathrm{OD}\right): \delta-11.83(d, J=20.1 \mathrm{~Hz})$, $-3.28(d, J=17.5 \mathrm{~Hz}),-23.82(t, J=18.8 \mathrm{~Hz})$; IR: $3,192,3,062,2,926,1,757$, $1,694,1,250 \mathrm{~cm}^{-1}$; MALDI-MS $(\mathrm{m} / z):[\mathrm{M}-\mathrm{H}]^{-}$calcd. for $\mathrm{C}_{42} \mathrm{H}_{59} \mathrm{~N}_{2} \mathrm{O}_{17} \mathrm{P}_{3}$, 955.295; found, 955.296

$\boldsymbol{\gamma}$-Bis-(4-decanoyloxybenzyl)-d4TTP 3f. General procedure D with $71 \mathrm{mg}$ d4TDP 6 ( $82 \mu \mathrm{mol}, 1.0$ eq.), 0.11 g 5 f $(0.16 \mathrm{mmol}, 2.0$ eq. $), 0.40 \mathrm{ml} 0.25 \mathrm{M}$ solution of DCI in acetonitrile $(0.10 \mathrm{mmol}, 1.2 \mathrm{eq}$. $), 32 \mu \mathrm{l} 5.5 \mathrm{M}$ solution of $t-\mathrm{BuOOH}$ in $n$-decane $(0.18 \mathrm{mmol}, 2.2 \mathrm{eq}$.) in $1.2 \mathrm{ml}$ acetonitrile. The crude product was purified using automatic RP-18 chromatography (water/acetonitrile gradient). Yield: $23 \mathrm{mg}$ $(21 \mu \mathrm{mol}, 26 \%)$ colourless solid (counterions: $\left.0.2 \times \mathrm{Bu}_{4} \mathrm{~N}^{+}, 1.8 \times \mathrm{NH}_{4}^{+}\right)$. UV (HPLC): $\lambda_{\max }=265 \mathrm{~nm}$; HPLC: $t_{\mathrm{R}}=18.06 \mathrm{~min}\left(\operatorname{method~A);~}{ }^{1} \mathrm{H}-\mathrm{NMR}(400 \mathrm{MHz}\right.$, $\left.\mathrm{CD}_{3} \mathrm{OD}\right): \delta 7.69(d, J=1.4 \mathrm{~Hz}, 1 \mathrm{H}), 7.46-7.39(m, 4 \mathrm{H}), 7.12-7.05(m, 4 \mathrm{H}), 6.96$ $(\mathrm{dt}, J=3.4 \mathrm{~Hz}, J=1.6 \mathrm{~Hz}, 1 \mathrm{H}), 6.50(\mathrm{dt}, J=6.0 \mathrm{~Hz}, J=1.7 \mathrm{~Hz}, 1 \mathrm{H}), 5.86-5.81$ $(m, 1 \mathrm{H}), 5.19(d, J=8.1 \mathrm{~Hz}, 4 \mathrm{H}), 5.00-4.95(m, 1 \mathrm{H}), 4.35-4.17(m, 2 \mathrm{H}), 3.30-3.23$ $(m, 1.5 \mathrm{H}), 2.61(t, J=7.4 \mathrm{~Hz}, 4 \mathrm{H}), 1.93(d, J=1.4 \mathrm{~Hz}, 3 \mathrm{H}), 1.76$ (quint, $J=7.3 \mathrm{~Hz}$, $4 \mathrm{H}), 1.73-1.64(m, 1.5 \mathrm{H}), 1.52-1.28(m, 25.5 \mathrm{H}), 1.06(t, J=7.4 \mathrm{~Hz}, 2.3 \mathrm{H})$, $0.97-0.90(m, 6 \mathrm{H}) ;{ }^{13} \mathrm{C}$-NMR $\left(101 \mathrm{MHz}, \mathrm{CD}_{3} \mathrm{OD}\right): \delta 173.7,166.7,152.6,152.6$, $138.7,135.8,135.0(d, J=7.8 \mathrm{~Hz}), 130.5(d, J=2.9 \mathrm{~Hz}), 127.1,122.9,112.1,90.9$, $87.2(d, J=9.7 \mathrm{~Hz}), 70.4(\mathrm{dd}, J=5.6 \mathrm{~Hz}, J=1.7 \mathrm{~Hz}), 67.9(d, J=4.8 \mathrm{~Hz}), 59.5,35.0$, $33.0,30.6,30.4,30.4,30.2,26.0,23.7,24.8,19.4,14.4,13.9,12.5 ;{ }^{31} \mathrm{P}-\mathrm{NMR}$ $\left(162 \mathrm{MHz}, \mathrm{CD}_{3} \mathrm{OD}\right): \delta-11.80(d, J=19.9 \mathrm{~Hz}),-13.07(d, J=17.5 \mathrm{~Hz}),-23.82$ (br.s); IR: $3,174,2,925,1,758,1,690,1,249 \mathrm{~cm}^{-1}$; MALDI-MS $(\mathrm{m} / \mathrm{z})$ : $[\mathrm{M}-\mathrm{H}]^{-}$ calcd. for $\mathrm{C}_{44} \mathrm{H}_{63} \mathrm{~N}_{2} \mathrm{O}_{17} \mathrm{P}_{3}$, 983.327; found, 983.512 .

$\boldsymbol{\gamma}$-Bis-(4-dodecanoyloxybenzyl)-d4TTP 3g. General procedure D with $74 \mathrm{mg}$ d4TDP 6 ( $85 \mu \mathrm{mol}, 1.0$ eq.), $0.13 \mathrm{~g} 5 \mathbf{g}(0.17 \mathrm{mmol}, 2.0$ eq.), $0.41 \mathrm{ml} 0.25 \mathrm{M}$ solution of DCI in acetonitrile $(0.11 \mathrm{mmol}, 1.2 \mathrm{eq}$.), $33 \mu \mathrm{l} 5.5 \mathrm{M}$ solution of $t-\mathrm{BuOOH}$ in $n$-decane $(0.18 \mathrm{mmol}, 2.1 \mathrm{eq}$.) in $1.2 \mathrm{ml}$ acetonitrile and $1.0 \mathrm{ml}$ THF. The crude product was purified by automatic RP-18 chromatography (water/acetonitrile gradient). Yield: $44 \mathrm{mg}(37 \mu \mathrm{mol}, 44 \%)$ colourless solid (counterions: $1.6 \times$ $\mathrm{Bu}_{4} \mathrm{~N}^{+}, 0.4 \times \mathrm{NH}_{4}^{+}$). UV (HPLC): $\lambda_{\max }=265 \mathrm{~nm}$; HPLC: $t_{\mathrm{R}}=20.15 \mathrm{~min}$ (method A); ${ }^{1} \mathrm{H}-\mathrm{NMR}\left(400 \mathrm{MHz}, \mathrm{CD}_{3} \mathrm{OD}\right): \delta \quad 7.74(d, J=1.5 \mathrm{~Hz}, 1 \mathrm{H}), 7.47-7.39$ $(m, 4 \mathrm{H}), 7.10-7.03(m, 4 \mathrm{H}), 6.96(\mathrm{dt}, J=3.4 \mathrm{~Hz}, J=1.6 \mathrm{~Hz}, 1 \mathrm{H}), 6.56(\mathrm{dt}, J=6.0$ $\mathrm{Hz}, J=1.8 \mathrm{~Hz}, 1 \mathrm{H}), 5.83-5.78(m, 1 \mathrm{H}), 5.22(\mathrm{dd}, J=8.0 \mathrm{~Hz}, J=2.0 \mathrm{~Hz}, 4 \mathrm{H})$, 5.01-4.95 $(m, 1 \mathrm{H}), 4.43-4.19(m, 2 \mathrm{H}), 3.31-3.19(m, 12.8 \mathrm{H}), 2.61(t, J=7.4 \mathrm{~Hz}$, $4 \mathrm{H}), 1.93(d, J=1.5 \mathrm{~Hz}, 3 \mathrm{H}), 1.76$ (quint, $J=6.7 \mathrm{~Hz}, 4 \mathrm{H}), 1.73-1.63(m, 12.8 \mathrm{H})$, $1.44($ sext, $J=7.4 \mathrm{~Hz}, 12.8 \mathrm{H}), 1.51-1.28(m, 32 \mathrm{H}), 1.05(t, J=7.4 \mathrm{~Hz}, 19.2 \mathrm{H})$, $0.98-0.89(m, 6 \mathrm{H}) ;{ }^{13} \mathrm{C}-\mathrm{NMR}\left(101 \mathrm{MHz}, \mathrm{CD}_{3} \mathrm{OD}\right): \delta 173.7,166.5,152.8,152.2$, $138.8,136.2,135.2(d, J=7.8 \mathrm{~Hz}), 130.5(d, J=2.8 \mathrm{~Hz}), 126.9,122.8,112.1,90.8$, $87.4(d, J=6.3 \mathrm{~Hz}), 70.4(d, J=5.7 \mathrm{~Hz}), 67.8,59.4,35.0,33.1,30.7,30.7,30.6,30.4$ $30.4,30.2,26.0,23.7,24.8,20.7,14.5,14.0,12.5$; ${ }^{31}$ P-NMR $\left(162 \mathrm{MHz}, \mathrm{CD}_{3} \mathrm{OD}\right)$ : $\delta-11.91$ (br.s), $-13.28(d, J=17.6 \mathrm{~Hz}),-3.99$ (br.s); IR: 3,203, 2,925, 1,757, $1,690,1,262 \mathrm{~cm}^{-1}$; MALDI-MS (m/z): [M-H] ${ }^{-}$calcd. for $\mathrm{C}_{48} \mathrm{H}_{69} \mathrm{~N}_{2} \mathrm{O}_{17} \mathrm{P}_{3}$, 1039.389; found, 1039.561

$\boldsymbol{\gamma}$-Bis-(4-tetradecanoyloxybenzyl)-d4TTP 3 h. General procedure D with $48 \mathrm{mg}$ d4TDP 6 ( $53 \mu \mathrm{mol}, 1.0$ eq.), $85 \mathrm{mg} 5 \mathbf{h}(0.11 \mathrm{mmol}, 2.0$ eq.), $0.28 \mathrm{ml} 0.25 \mathrm{M}$ solution of DCI in acetonitrile $(69 \mu \mathrm{mol}, 1.3 \mathrm{eq}),. 21 \mu \mathrm{l} 5.5 \mathrm{M}$ solution of $t$-BuOOH in $n$-decane $(0.12 \mathrm{mmol}, 2.2 \mathrm{eq}$. $)$ in $0.5 \mathrm{ml}$ acetonitrile and $0.7 \mathrm{ml}$ THF. The reaction was restarted once. The crude product was purified using automatic RP-18 chromatography (water/THF gradient). Yield: $72 \mathrm{mg}(37 \mu \mathrm{mol}, 70 \%$ (exclusive contamination)) colourless solid (counterions: $\left.1.0 \times \mathrm{Bu}_{4} \mathrm{~N}^{+}, 1.0 \times \mathrm{DIPAH}^{+}\right)$, contaminated with $\mathrm{Bu}_{4} \mathrm{~N}^{+}$and diisopropylammonium salts. UV (HPLC): $\lambda_{\max }=265 \mathrm{~nm}$; HPLC: $t_{\mathrm{R}}=22.22 \mathrm{~min}(\operatorname{method~A}) ;{ }^{1} \mathrm{H}-\mathrm{NMR}\left(300 \mathrm{MHz}, \mathrm{THF}-d_{8}\right):$ $\delta 10.10(s, 1 \mathrm{H}), 7.88(d, J=1.2 \mathrm{~Hz}, 1 \mathrm{H}), 7.53-7.44(m, 4 \mathrm{H}), 7.04-6.96(m, 4 \mathrm{H}), 6.91$ $(\mathrm{dt}, J=3.3 \mathrm{~Hz}, J=1.6 \mathrm{~Hz}, 1 \mathrm{H}), 6.62(\mathrm{dt}, J=5.9 \mathrm{~Hz}, J=1.7 \mathrm{~Hz}, 1 \mathrm{H}), 5.61-5.56(m$, $1 \mathrm{H}), 5.26-5.17(m, 4 \mathrm{H}), 4.85-4.78(m, 1 \mathrm{H}), 4.44-4.31(m, 1 \mathrm{H}), 4.14-4.01(m, 1 \mathrm{H})$, $3.50-3.39(m, 8 \mathrm{H}), 3.33-2.85(m, 2 \mathrm{H}), 2.52(t, J=7.5 \mathrm{~Hz}, 4 \mathrm{H}), 1.91(d, J=1.2 \mathrm{~Hz}$, $3 \mathrm{H}), 1.77-1.59(m, 12 \mathrm{H}), 1.50-1.23(m, 60 \mathrm{H}), 0.94(t, J=7.4 \mathrm{~Hz}, 12 \mathrm{H}), 0.89$ $(t, J=6.8 \mathrm{~Hz}, 6 \mathrm{H}) ;{ }^{13} \mathrm{C}-\mathrm{NMR}\left(75 \mathrm{MHz}\right.$, THF- $\left.d_{8}\right): \delta 172.2,164.9,152.1,151.8,138.2$, $136.9,136.1(d, J=8.5 \mathrm{~Hz}), 130.1(d, J=1.6 \mathrm{~Hz}), 126.2,122.3,111.3,90.1,87.8$ $(d, J=8.5 \mathrm{~Hz}), 69.2(d, J=5.4 \mathrm{~Hz}), 67.2,59.3,47.2,34.9,33.1,30.8,30.8,30.8,30.8$, $30.7,30.5,30.5,30.2,26.0,25.0,23.8,20.7,19.9,14.6,14.4,12.8 ;{ }^{31} \mathrm{P}-\mathrm{NMR}$ $\left(162 \mathrm{MHz}, \mathrm{THF}-d_{8}\right): \delta-14.16(d, J=20.8 \mathrm{~Hz}),-14.65(d, J=17.8 \mathrm{~Hz}),-23.82$ $(t, J=19.1 \mathrm{~Hz})$; IR: $3,400,2,924,1,757,1,689,1,263 \mathrm{~cm}^{-1}$; MALDI-MS $(\mathrm{m} / z)$ : $[\mathrm{M}-\mathrm{H}]^{-}$calcd. for $\mathrm{C}_{52} \mathrm{H}_{79} \mathrm{~N}_{2} \mathrm{O}_{17} \mathrm{P}_{3}, 1095.452$; found, 1095.503 .
$\gamma$-Bis-(4-hexadecanoyloxybenzyl)-d4TTP 3i. General procedure D with $90 \mathrm{mg}$ d4TDP 6 ( $0.10 \mathrm{mmol}, 1.0$ eq. $), 0.18 \mathrm{~g} 5 \mathbf{i}(0.21 \mathrm{mmol}, 2.0$ eq. $), 0.50 \mathrm{ml} 0.25 \mathrm{M}$ solution of DCI in acetonitrile ( $0.13 \mathrm{mmol}, 1.3 \mathrm{eq}$.), $42 \mu \mathrm{l} 5.5 \mathrm{M}$ solution of $t$ - $\mathrm{BuOOH}$ in $n$-decane $(0.23 \mathrm{mmol}, 2.2 \mathrm{eq}$. $)$ in $0.3 \mathrm{ml}$ acetonitrile and $0.9 \mathrm{ml}$ THF. The reaction was restarted once. The crude product was purified using automatic RP-18 chromatography (water/THF gradient). Yield: $96 \mathrm{mg}(64 \mu \mathrm{mol}, 62 \%)$ colourless solid (counterions: $1.0 \times \mathrm{Bu}_{4} \mathrm{~N}^{+}, 1.0 \times \mathrm{DIPAH}^{+}$). UV (HPLC): $\lambda_{\max }=265 \mathrm{~nm}$; HPLC: $t_{\mathrm{R}}=23.28 \mathrm{~min}(\operatorname{method} \mathrm{A}) ;{ }^{1} \mathrm{H}-\mathrm{NMR}\left(500 \mathrm{MHz}\right.$, THF- $\left.d_{8}\right): \delta 10.22(s, 1 \mathrm{H})$, $7.88(d, J=1.3 \mathrm{~Hz}, 1 \mathrm{H}), 7.48-7.42(m, 4 \mathrm{H}), 7.05-6.99(m, 4 \mathrm{H}), 6.92(\mathrm{dt}, J=3.4 \mathrm{~Hz}$, $J=1.6 \mathrm{~Hz}, 1 \mathrm{H}), 6.55(\mathrm{dt}, J=5.8 \mathrm{~Hz}, J=1.6 \mathrm{~Hz}, 1 \mathrm{H}), 5.67-5.61(m, 1 \mathrm{H}), 5.22-5.13$ ( $m, 4 \mathrm{H}), 4.87-4.82(m, 1 \mathrm{H}), 4.38-4.29(m, 1 \mathrm{H}), 4.15-4.07(m, 1 \mathrm{H}), 3.43-3.27$ $(m, 8 \mathrm{H}), 3.31-3.15(m, 2 \mathrm{H}), 2.53(t, J=7.5 \mathrm{~Hz}, 4 \mathrm{H}), 1.90(d, J=1.0 \mathrm{~Hz}, 3 \mathrm{H})$, $1.74-1.62(m, 12 \mathrm{H}), 1.48-1.20(m, 68 \mathrm{H}), 0.95(t, J=7.2 \mathrm{~Hz}, 12 \mathrm{H}), 0.89(t, J=6.8$ Hzm, 6H); ${ }^{13} \mathrm{C}-\mathrm{NMR}\left(75 \mathrm{MHz}\right.$, THF- $\left.d_{8}\right): \delta 172.1,164.9,152.1,152.0,137.8,136.3$, $135.5(d, J=8.6 \mathrm{~Hz}), 130.1,126.6,122.5,111.3,90.2,87.3(d, J=7.7 \mathrm{~Hz}), 69.4$ $(d, J=7.2 \mathrm{~Hz}), 67.0,59.3,47.4,34.9,33.0,30.8,30.8,30.8,30.8,30.7,30.5,30.5$, $30.2,26.1,24.8,23.6,20.7,19.8,14.6,14.4,12.8 ;{ }^{31} \mathrm{P}-\mathrm{NMR}\left(202 \mathrm{MHz}, \mathrm{THF}-d_{8}\right)$ : $\delta-12.56(d, J=19.6 \mathrm{~Hz}),-13.38(d, J=17.5 \mathrm{~Hz}),-24.17(t, J=18.5 \mathrm{~Hz}) ;$ IR: $2,987,2,916,1,756,1,691,1,251 \mathrm{~cm}^{-1}$; MALDI-MS $(\mathrm{m} / \mathrm{z}):[\mathrm{M}-\mathrm{H}]^{-}$calcd. for $\mathrm{C}_{56} \mathrm{H}_{85} \mathrm{~N}_{2} \mathrm{O}_{17} \mathrm{P}_{3}, 1151.515$; found, 1151.663 .

$\gamma$-Bis-(4-octadecanoyloxybenzyl)-d4TTP 3j. General procedure D with $87 \mathrm{mg}$ d4TDP 6 ( $0.10 \mathrm{mmol}, 1.0$ eq.), $0.19 \mathrm{~g} 5 \mathbf{5 j}(0.20 \mathrm{mmol}, 2.0$ eq.), $0.52 \mathrm{ml} 0.25 \mathrm{M}$ solution of DCI in acetonitrile $(0.13 \mathrm{mmol}, 1.3 \mathrm{eq}),. 38 \mu \mathrm{l} 5.5 \mathrm{M}$ solution of $t$ $\mathrm{BuOOH}$ in $n$-decane $(0.21 \mathrm{mmol}, 2.1 \mathrm{eq}$.) in $0.3 \mathrm{ml}$ acetonitrile and $0.9 \mathrm{ml}$ THF. The reaction was restarted once. The crude product was purified using automatic RP-18 chromatography (water/THF gradient). Yield: $69 \mathrm{mg}(44 \mu \mathrm{mol}, 44 \%)$ colourless solid (counterions: $1.0 \times \mathrm{Bu}_{4} \mathrm{~N}^{+}, 1.0 \times \mathrm{DIPAH}^{+}$).

UV (HPLC): $\lambda_{\max }=265 \mathrm{~nm}$; HPLC: $t_{\mathrm{R}}=19.45 \mathrm{~min}(\operatorname{method} \mathrm{C}) ;{ }^{1} \mathrm{H}-\mathrm{NMR}$ $\left(300 \mathrm{MHz}, \mathrm{THF}-d_{8}\right): \delta 10.16(s, 1 \mathrm{H}), 7.84(d, J=1.4 \mathrm{~Hz}, 1 \mathrm{H}), 7.50-7.41(m, 4 \mathrm{H})$, 7.05-6.96 $(m, 4 \mathrm{H}), 6.91(\mathrm{dt}, J=3.3 \mathrm{~Hz}, J=1.5 \mathrm{~Hz}, 1 \mathrm{H}), 6.62-6.53(m, 1 \mathrm{H})$, 5.65-5.57 $(m, 1 \mathrm{H}), 5.24-5.13(m, 4 \mathrm{H}), 4.89-4.79(m, 1 \mathrm{H}), 4.43-4.30(m, 1 \mathrm{H})$, 4.17-4.04 (m, 1H), 3.51-3.28 (m, 8H), 3.30-3.09 ( $m, 2 \mathrm{H}), 2.51(t, J=7.4 \mathrm{~Hz}, 4 \mathrm{H})$, $1.91(d, J=0.7 \mathrm{~Hz}, 3 \mathrm{H}), 1.77-1.60(m, 13 \mathrm{H}), 1.49-1.19(m, 76 \mathrm{H}), 1.00-0.82$ $(m, 18 \mathrm{H}) ;{ }^{13} \mathrm{C}-\mathrm{NMR}\left(75 \mathrm{MHz}\right.$, THF- $\left.d_{8}\right): \delta 172.1,164.8,152.1,151.9,138.0,136.6$, $135.8(d, J=7.8 \mathrm{~Hz}), 130.1,126.5,122.4,111.3,90.2,87.5(d, J=8.4 \mathrm{~Hz}), 69.2$ $(d, J=5.3 \mathrm{~Hz}), 67.1,59.3,47.2,34.9,33.1,30.8,30.8,30.7,30.5,30.5,30.3,26.0$, $24.9,23.8,20.8,19.8,14.6,14.4,12.8 ;{ }^{31} \mathrm{P}-\mathrm{NMR}\left(162 \mathrm{MHz}\right.$, THF- $\left.d_{8}\right): \delta-12.74$ $(d, J=19.2 \mathrm{~Hz}),-12.83(d, J=18.3 \mathrm{~Hz}),-23.46(t, J=18.7 \mathrm{~Hz}) ; \mathrm{IR:}: 2,959,2,916$, $1,756,1,688,1,252 \mathrm{~cm}^{-1}$; MALDI-MS $(\mathrm{m} / z)$ : $[\mathrm{M}-\mathrm{H}]^{-}$calcd. for $\mathrm{C}_{60} \mathrm{H}_{95} \mathrm{~N}_{2} \mathrm{O}_{17} \mathrm{P}_{3}$, 1207.577; found, 1207.670 .

$\gamma$-Bis(4-(Z)-octadec-9-enoyloxybenzyl)-d4TTP 3k. General procedure D with $96 \mathrm{mg}$ d4TDP 6 ( $0.11 \mathrm{mmol}, 1.0$ eq.), $0.20 \mathrm{~g} 5 \mathbf{k}(0.22 \mathrm{mmol}, 2.0$ eq. $), 0.53 \mathrm{ml} 0.25 \mathrm{M}$ solution of DCI in acetonitrile $(0.13 \mathrm{mmol}, 1.2 \mathrm{eq}),. 42 \mu \mathrm{l} 5.5 \mathrm{M}$ solution of $t$ - $\mathrm{BuOOH}$ in $n$-decane $(0.23 \mathrm{mmol}, 2.1 \mathrm{eq}$.) in $0.3 \mathrm{ml}$ acetonitrile and $0.9 \mathrm{ml} \mathrm{THF}$. The reaction was restarted once. The crude product was purified using automatic RP-18 chromatography (water/THF gradient). Yield: $99 \mathrm{mg}(64 \mu \mathrm{mol}, 58 \%)$ colourless solid (counterions: $1.0 \times \mathrm{Bu}_{4} \mathrm{~N}^{+}, 1.0 \times \mathrm{DIPAH}^{+}$). UV (HPLC): $\lambda_{\max }=265 \mathrm{~nm}$; HPLC: $t_{\mathrm{R}}=22.92 \mathrm{~min}(\operatorname{method} \mathrm{A}) ;{ }^{1} \mathrm{H}-\mathrm{NMR}\left(300 \mathrm{MHz}\right.$, THF- $\left.d_{8}\right):$ $\delta 10.20(s, 1 \mathrm{H}), 7.86(s, 1 \mathrm{H}), 7.52-7.42(m, 4 \mathrm{H}), 7.07-6.96(m, 4 \mathrm{H}), 6.94-6.88(m$, $1 \mathrm{H}), 6.67-6.53(m, 1 \mathrm{H}), 5.68-5.54(m, 1 \mathrm{H}), 5.44-5.27(m, 4 \mathrm{H}), 5.24-5.14(m, 4 \mathrm{H})$, $4.90-4.79(m, 1 \mathrm{H}), 4.43-4.31(m, 1 \mathrm{H}), 4.18-4.03(m, 1 \mathrm{H}), 3.57-3.25(m, 8 \mathrm{H})$, $3.32-3.02(m, 2 \mathrm{H}), 2.52(t, J=7.5 \mathrm{~Hz}, 4 \mathrm{H}), 2.14-1.95(m, 8 \mathrm{H}), 1.91(s, 3 \mathrm{H})$, $1.80-1.58(m, 12 \mathrm{H}), 1.54-1.16(\mathrm{~m}, 60 \mathrm{H}), 1.05-0.75(\mathrm{~m}, 18 \mathrm{H}) ;{ }^{13} \mathrm{C}-\mathrm{NMR}(75 \mathrm{MHz}$, THF- $\left.d_{8}\right): \delta 172.1,164.8,152.1,151.9,138.0,137.3,135.9(d, J=7.9 \mathrm{~Hz}), 130.7$, 130.7, $130.1(d, J=1.5 \mathrm{~Hz}), 126.3,122.4,111.2,90.2,87.6(d, J=8.8 \mathrm{~Hz}), 69.1,67.1$ $59.3,47.2,34.9,33.0,30.9,30.7,30.5,30.4,30.3,30.2,28.2,28.2,25.9,25.0,23.7$, $20.8,19.8,14.7,14.4,12.8 ;{ }^{31}$ P-NMR $\left(162 \mathrm{MHz}\right.$, THF- $\left.d_{8}\right): \delta-14.44(d, J=19.0$ $\mathrm{Hz}),-14.94(d, J=18.0 \mathrm{~Hz}),-25.55(t, J=18.5 \mathrm{~Hz})$; IR: $3,358,2,965,2,924$, $1,757,1,689,1,262 \mathrm{~cm}^{-1}$; MALDI-MS $(\mathrm{m} / z)$ : $[\mathrm{M}-\mathrm{H}]^{-}$calcd. for $\mathrm{C}_{60} \mathrm{H}_{91} \mathrm{~N}_{2} \mathrm{O}_{17} \mathrm{P}_{3}$, 1203.557; found, 1203.546 .

$\gamma$-Bis-(4-methyloxycarbonyloxybenzyl)-d4TTP 3I (ammonium salt). General procedure D with $99 \mathrm{mg}$ d4TDP $6(0.11 \mathrm{mmol}, 1.0$ eq.), $0.11 \mathrm{~g} 51$ ( $0.23 \mathrm{mmol}$, 2.0 eq.), $0.59 \mathrm{ml} 0.25 \mathrm{M}$ solution of DCI in acetonitrile $(0.15 \mathrm{mmol}, 1.3 \mathrm{eq}$.), $46 \mu \mathrm{l}$ $5.5 \mathrm{M}$ solution of $t-\mathrm{BuOOH}$ in $n$-decane $(0.25 \mathrm{mmol}, 2.2 \mathrm{eq}$. $)$ in $0.7 \mathrm{ml}$ acetonitrile. The crude product was purified using automatic RP-18 chromatography (water/acetonitrile gradient). Yield: $49 \mathrm{mg}(59 \mu \mathrm{mol}, 52 \%)$ colourless solid. UV (HPLC): $\lambda_{\max }=265 \mathrm{~nm}$; HPLC: $t_{\mathrm{R}}=11.28 \mathrm{~min}(\operatorname{method~A}) ; 9.17 \mathrm{~min}($ method B); ${ }^{1} \mathrm{H}-\mathrm{NMR}\left(400 \mathrm{MHz}, \mathrm{CD}_{3} \mathrm{OD}\right): \delta 7.68(d, J=1.2 \mathrm{~Hz}, 1 \mathrm{H}), 7.43-7.38(m, 4 \mathrm{H})$, 7.16-7.11 $(m, 4 \mathrm{H}), 6.92(\mathrm{dt}, J=3.4 \mathrm{~Hz}, J=1.8 \mathrm{~Hz}, 1 \mathrm{H}), 6.47(\mathrm{dt}, J=6.0 \mathrm{~Hz}$, $J=1.7 \mathrm{~Hz}, 1 \mathrm{H}), 5.82(\mathrm{ddd}, J=6.1 \mathrm{~Hz}, J=2.5 \mathrm{~Hz}, J=1.4 \mathrm{~Hz}, 1 \mathrm{H}), 5.18(d, J=8.0$ $\mathrm{Hz}, 4 \mathrm{H}), 4.96-4.90(m, 1 \mathrm{H}), 4.31-4.15(m, 2 \mathrm{H}), 3.86(s, 6 \mathrm{H}), 1.88(d, J=1.2 \mathrm{~Hz}$, $3 \mathrm{H}) ;{ }^{13} \mathrm{C}-\mathrm{NMR}\left(101 \mathrm{MHz}, \mathrm{CD}_{3} \mathrm{OD}\right): \delta 166.7,155.7,152.8,152.7,138.7,135.8,135.4$ $(d, J=7.6 \mathrm{~Hz}), 130.5(d, J=3.5 \mathrm{~Hz}), 127.1,122.3,112.1,90.8,87.3(d, J=9.5 \mathrm{~Hz})$, $70.3(\mathrm{dd}, J=5.8 \mathrm{~Hz}, J=2.1 \mathrm{~Hz}), 67.6(d, J=5.9 \mathrm{~Hz}), 56.0,12.5 ;{ }^{31} \mathrm{P}-\mathrm{NMR}$ $\left(162 \mathrm{MHz}, \mathrm{CD}_{3} \mathrm{OD}\right): \delta-11.79(d, J=19.8 \mathrm{~Hz}),-13.23(d, J=17.6 \mathrm{~Hz}),-23.71$ 
$(t, J=18.5 \mathrm{~Hz})$; IR: $3,191,3,050,1,764,1,692,1,263 \mathrm{~cm}^{-1}$; MALDI-MS $(\mathrm{m} / \mathrm{z})$ : $[\mathrm{M}-\mathrm{H}]^{-}$calcd. for $\mathrm{C}_{28} \mathrm{H}_{31} \mathrm{~N}_{2} \mathrm{O}_{19} \mathrm{P}_{3}, 791.066$; found, 791.003.

$\boldsymbol{\gamma}$-Bis-(4-octyloxycarbonyloxybenzyl)-d4TTP 3m. General procedure D with $0.11 \mathrm{~g}$ d4TDP 6 ( $0.13 \mathrm{mmol}, 1.0$ eq.), $0.18 \mathrm{~g} 5 \mathrm{~m}(0.26 \mathrm{mmol}, 2.0$ eq.), $0.68 \mathrm{ml} 0.25 \mathrm{M}$ solution of DCI in acetonitrile $(0.17 \mathrm{mmol}, 1.3 \mathrm{eq}$.), $53 \mu \mathrm{l} 5.5 \mathrm{M}$ solution of $t$ - $\mathrm{BuOOH}$ in $n$-decane $(0.29 \mathrm{mmol}, 2.2 \mathrm{eq}$. $)$ in $0.7 \mathrm{ml}$ acetonitrile. The crude product was purified using automatic RP-18 chromatography (water/acetonitrile gradient). Yield: $75 \mathrm{mg}(69 \mu \mathrm{mol}, 52 \%)$ colourless solid (counterions: $0.3 \times \mathrm{Bu}_{4} \mathrm{~N}^{+}$ $\left.1.7 \times \mathrm{NH}_{4}^{+}\right)$. UV (HPLC): $\lambda_{\max }=265 \mathrm{~nm}$; HPLC: $t_{\mathrm{R}}=16.72 \mathrm{~min}(\operatorname{method~A)}$; ${ }^{1} \mathrm{H}-\mathrm{NMR}\left(400 \mathrm{MHz}, \mathrm{CD}_{3} \mathrm{OD}\right): \delta 7.65(\mathrm{~d}, J=1.1 \mathrm{~Hz}, 1 \mathrm{H}), 7.43$ MALDI-MS $(\mathrm{m} / \mathrm{z})$ : $[\mathrm{M}-\mathrm{H}]^{-}$calcd7.36 $(m, 4 \mathrm{H}), 7.17 \mathrm{MALDI}-\mathrm{MS}(\mathrm{m} / \mathrm{z}):[\mathrm{M}-\mathrm{H}]^{-}$calcd7.09 $(m, 4 \mathrm{H})$, $6.91(\mathrm{dt}, J=3.5 \mathrm{~Hz}, J=1.9 \mathrm{~Hz}, 1 \mathrm{H}), 6.44(\mathrm{dt}, J=6.0 \mathrm{~Hz}, J=1.8 \mathrm{~Hz}, 1 \mathrm{H}), 5.82(\mathrm{ddd}$, $J=6.0 \mathrm{~Hz}, J=2.4 \mathrm{~Hz}, J=1.3 \mathrm{~Hz}, 1 \mathrm{H}), 5.14(\mathrm{~d}, J=8.2 \mathrm{~Hz}, 4 \mathrm{H}), 4.96-4.90(m, 1 \mathrm{H})$, 4.29-4.13 $(m, 2 \mathrm{H}), 4.22(t, J=6.6 \mathrm{~Hz}, 4 \mathrm{H}), 3.25-3.15(m, 2.5 \mathrm{H}), 1.88(\mathrm{~d}, J=1.1 \mathrm{~Hz}$, $3 \mathrm{H}), 1.77-1.64(m, 4 \mathrm{H}), 1.67-1.57(m, 2.5 \mathrm{H}), 1.47-1.22(m, 22.5 \mathrm{H}), 1.00(t, J=7.3$ $\mathrm{Hz}, 3.8 \mathrm{H}), 0.90(t, J=6.7 \mathrm{~Hz}, 6 \mathrm{H}) ;{ }^{13} \mathrm{C}-\mathrm{NMR}\left(101 \mathrm{MHz}, \mathrm{CD}_{3} \mathrm{OD}\right): \delta 166.5,155.1$, $152.7,152.7,138.6,135.7,135.2(\mathrm{~d}, J=7.6 \mathrm{~Hz}), 130.5(\mathrm{~d}, J=2.3 \mathrm{~Hz}), 127.2,122.3$, $112.0,90.8,87.3(\mathrm{~d}, J=9.5 \mathrm{~Hz}), 70.3(\mathrm{dd}, J=5.4 \mathrm{~Hz}, J=1.4 \mathrm{~Hz}), 70.0,67.8$ $(\mathrm{d}, J=5.6 \mathrm{~Hz}), 59.4,32.9,30.3,30.3,29.7,26.8,24.7,23.7,20.7,14.5,14.0,12.5$; ${ }^{31}$ P-NMR (162 MHz, CD 30 OD): $\delta-11.68(\mathrm{~d}, J=19.3 \mathrm{~Hz}),-13.15(\mathrm{~d}, J=16.1 \mathrm{~Hz})$, $-23.53(t, J=18.0 \mathrm{~Hz})$; IR: 3,198, 2,926, 1,760, 1,690, 1,250 $\mathrm{cm}^{-1}$; MALDI-MS (m/z): $[\mathrm{M}-\mathrm{H}]^{-}$calcd. for $\mathrm{C}_{42} \mathrm{H}_{59} \mathrm{~N}_{2} \mathrm{O}_{19} \mathrm{P}_{3}, 987.285$; found, 987.396.

$\gamma$-Bis-(4-dodecyloxycarbonyloxybenzyl)-d4TTP $3 n$. General procedure D with $80 \mathrm{mg}$ d4TDP 6 ( $92 \mu \mathrm{mol}, 1.0$ eq.), $0.15 \mathrm{~g}$ 5n $(0.19 \mathrm{mmol}, 2.0$ eq.), $0.48 \mathrm{ml} 0.25 \mathrm{M}$ solution of DCI in acetonitrile $(0.12 \mathrm{mmol}, 1.3 \mathrm{eq}),. 37 \mu \mathrm{l} 5.5 \mathrm{M}$ solution of $\mathrm{t}$-BuOOH in $n$-decane $(0.20 \mathrm{mmol}, 2.1$ eq.) in $0.5 \mathrm{ml}$ acetonitrile and $0.5 \mathrm{ml} \mathrm{THF}$. The crude product was purified using automatic RP-18 chromatography (water/acetonitrile gradient). Yield: $52 \mathrm{mg}(38 \mu \mathrm{mol}, 41 \%)$ colourless solid (counterions: $\left.1.1 \times \mathrm{Bu}_{4} \mathrm{~N}^{+}, 0.9 \times \mathrm{NH}_{4}^{+}\right)$. UV (HPLC): $\lambda_{\max }=265 \mathrm{~nm}$; HPLC: $t_{\mathrm{R}}=20.53 \mathrm{~min}(\operatorname{method} \mathrm{A}) ;{ }^{1} \mathrm{H}-\mathrm{NMR}\left(300 \mathrm{MHz}, \mathrm{CD}_{3} \mathrm{OD}\right): \delta 7.70(d, J=1.3 \mathrm{~Hz}$ $1 \mathrm{H}), 7.43-7.36(m, 4 \mathrm{H}), 7.19-7.11(m, 4 \mathrm{H}), 6.94(\mathrm{dt}, J=3.4 \mathrm{~Hz}, J=1.7 \mathrm{~Hz}, 1 \mathrm{H})$, $6.52(\mathrm{dt}, J=6.0 \mathrm{~Hz}, J=1.8 \mathrm{~Hz}, 1 \mathrm{H}), 5.80(\mathrm{ddd}, J=6.0 \mathrm{~Hz}, J=2.4 \mathrm{~Hz}, J=1.4 \mathrm{~Hz}$, $1 \mathrm{H}), 5.19(d, J=8.0 \mathrm{~Hz}, 4 \mathrm{H}), 5.00-4.93(m, 1 \mathrm{H}), 4.37-4.15(m, 2 \mathrm{H}), 4.25$ $(t, J=6.6 \mathrm{~Hz}, 4 \mathrm{H}), 3.29-3.14(m, 9 \mathrm{H}), 1.92(d, J=1.3 \mathrm{~Hz}, 3 \mathrm{H}), 1.80-1.66$ $(m, 4 \mathrm{H}), 1.71-1.58(m, 9 \mathrm{H}), 1.50-1.25(m, 45 \mathrm{H}), 1.03(t, J=7.4 \mathrm{~Hz}, 13.5 \mathrm{H}), 0.92$ $(t, J=6.6 \mathrm{~Hz}, 6 \mathrm{H}) ;{ }^{13} \mathrm{C}-\mathrm{NMR}\left(75 \mathrm{MHz}, \mathrm{CD}_{3} \mathrm{OD}\right): \delta 166.5,155.1,152.7,152.6$, $138.7,136.0,135.4(d, J=7.8 \mathrm{~Hz}), 130.5(d, J=2.4 \mathrm{~Hz}), 127.0,122.3,112.1,90.8$ $87.3(d, J=9.2 \mathrm{~Hz}), 70.2(d, J=5.6 \mathrm{~Hz}), 70.0,67.8(d, J=6.0 \mathrm{~Hz}), 59.5,33.1,30.8$, $30.7,30.6,30.5,30.3,29.7,26.8,24.8,23.7,20.7,19.4,14.5,13.9,12.5 ;{ }^{31}$ P-NMR $\left(162 \mathrm{MHz}, \mathrm{CD}_{3} \mathrm{OD}\right): \delta-12.07(d, J=21.7 \mathrm{~Hz}),-13.38(d, J=18.1 \mathrm{~Hz}),-24.20$ (dd, $J=21.7 \mathrm{~Hz}, J=18.1 \mathrm{~Hz}$ ); IR: 2,923, 1,760, 1,689, 1,248 $\mathrm{cm}^{-1}$; MALDI-MS $(\mathrm{m} / \mathrm{z}):[\mathrm{M}-\mathrm{H}]^{-}$calcd. for $\mathrm{C}_{50} \mathrm{H}_{75} \mathrm{~N}_{2} \mathrm{O}_{19} \mathrm{P}_{3}, 1099.410$; found, 1099.083 .

\section{$\gamma$-Bis-(4-(butyl-ethane-1,2-diylbis(methylcarbamate))-oxybenzyl)-d4TTP 30} (ammonium salt). General procedure D with $75 \mathrm{mg}$ d4TDP 6 ( $87 \mu \mathrm{mol}, 1.0$ eq.), $0.12 \mathrm{~g} 5 \mathbf{0}(0.15 \mathrm{mmol}, 1.7 \mathrm{eq}),. 0.45 \mathrm{ml} 0.25 \mathrm{M}$ solution of DCI in acetonitrile $(0.11 \mathrm{mmol}, 1.3 \mathrm{eq}),. 32 \mu \mathrm{l} 5.5 \mathrm{M}$ solution of $t$ - $\mathrm{BuOOH}$ in $n$-decane $(0.18 \mathrm{mmol}$, 2.1 eq.) in $1.5 \mathrm{ml}$ acetonitrile. The crude product was purified using automatic RP-18 chromatography (water/acetonitrile gradient). Yield: $68 \mathrm{mg}(60 \mu \mathrm{mol}, 69 \%)$ colourless solid. UV (HPLC): $\lambda_{\max }=265 \mathrm{~nm}$; HPLC: $t_{\mathrm{R}}=12.88 \mathrm{~min}(\operatorname{method} \mathrm{A})$; ${ }^{1} \mathrm{H}-\mathrm{NMR}\left(400 \mathrm{MHz}, \mathrm{CD}_{3} \mathrm{OD}\right): \delta 7.68(d, J=1.0 \mathrm{~Hz}, 1 \mathrm{H}), 7.48-7.42(m, 4 \mathrm{H})$, 7.15-7.09 $(m, 4 \mathrm{H}$, rotamers), $6.96(\mathrm{dt}, J=3.5 \mathrm{~Hz}, J=1.7 \mathrm{~Hz}, 1 \mathrm{H}), 6.49$ $(\mathrm{dt}, J=6.1 \mathrm{~Hz}, J=1.7 \mathrm{~Hz}, 1 \mathrm{H}), 5.86-5.82(m, 1 \mathrm{H}), 5.22-5.16(m, 4 \mathrm{H}), 5.00-4.96$ ( $m, 1 \mathrm{H}), 4.34-4.19(m, 2 \mathrm{H}), 4.17-4.05(m, 4 \mathrm{H}), 3.71-3.53$ ( $m, 8 \mathrm{H}$, rotamers), $3.15-2.96(m, 12 \mathrm{H}), 1.93(d, J=1.0 \mathrm{~Hz}, 3 \mathrm{H}), 1.72-1.56(m, 4 \mathrm{H}$, rotamers), $1.50-1.34$ ( $m, 4 \mathrm{H}$, rotamers), $0.96,0.90\left(t, J=7.4 \mathrm{~Hz}, 6 \mathrm{H}\right.$, rotamers); ${ }^{13} \mathrm{C}-\mathrm{NMR}$ $\left(101 \mathrm{MHz}, \mathrm{CD}_{3} \mathrm{OD}\right): \delta 166.5,158.3,156.4,152.8,152.7,138.6,135.7,134.6,130.4$ $(d, J=2.7 \mathrm{~Hz}), 127.2,123.1+122.9$ (rotamers), $112.0(\mathrm{C}-5), 90.8\left(\mathrm{C}-1^{\prime}\right), 87.2$ $(d, J=9.1 \mathrm{~Hz}), 70.4(\mathrm{dd}, J=5.4 \mathrm{~Hz}, J=2.5 \mathrm{~Hz}), 67.9(d, J=5.8 \mathrm{~Hz}), 66.8+66.6$ (rotamers), $48.1+47.8$ (rotamers), $47.6+47.3$ (rotamers), $35.5+35.0$ (rotamers), $32.2+32.2$ (rotamers), 20.2, $14.1+14.1$ (rotamers), $12.5 ;{ }^{31} \mathrm{P}-\mathrm{NMR}(162 \mathrm{MHz}$, $\left.\mathrm{CD}_{3} \mathrm{OD}\right): \delta-11.72(\mathrm{~d}, J=19.5 \mathrm{~Hz}),-13.16(d, J=17.8 \mathrm{~Hz}),-23.55$ $(t, J=18.1 \mathrm{~Hz})$; IR: $3,191,1,959,1,687,1,204 \mathrm{~cm}^{-1}$; MALDI-MS $(\mathrm{m} / \mathrm{z})$ : $[\mathrm{M}-\mathrm{H}]$ calcd. for $\mathrm{C}_{44} \mathrm{H}_{63} \mathrm{~N}_{6} \mathrm{O}_{21} \mathrm{P}_{3}, 1103.319$; found, 1103.383.

$\gamma$-Bis-(4-(octyl-ethane-1,2-diylbis(methylcarbamate))-oxybenzyl)-d4TTP 3p (ammonium salt). General procedure D with $80 \mathrm{mg}$ d4TDP 6 ( $92 \mu \mathrm{mol}, 1.0$ eq.), $0.15 \mathrm{~g} 5 \mathbf{p}(0.16 \mathrm{mmol}, 1.7 \mathrm{eq}),. 0.48 \mathrm{ml} 0.25 \mathrm{M}$ solution of DCI in acetonitrile $(0.12 \mathrm{mmol}, 1.3 \mathrm{eq}),. 37 \mu \mathrm{l} 5.5 \mathrm{M}$ solution of $t-\mathrm{BuOOH}$ in $n$-decane $(0.20 \mathrm{mmol}$, 2.2 eq.) in $0.8 \mathrm{ml}$ acetonitrile. The crude product was purified using automatic RP-18 chromatography (water/acetonitrile gradient). Yield: $73 \mathrm{mg}(58 \mu \mathrm{mol}, 63 \%)$ colourless solid. UV (HPLC): $\lambda_{\max }=265 \mathrm{~nm}$; HPLC: $t_{\mathrm{R}}=15.98 \mathrm{~min}$ (method A); ${ }^{1} \mathrm{H}-\mathrm{NMR}\left(400 \mathrm{MHz}, \mathrm{CD}_{3} \mathrm{OD}\right): \delta 7.69$ (br.s, $\left.1 \mathrm{H}\right), 7.47-7.42(m, 4 \mathrm{H}), 7.15-7.08$ ( $m, 4 \mathrm{H}$, rotamers), $6.96(\mathrm{dt}, J=3.5 \mathrm{~Hz}, J=1.6 \mathrm{~Hz}, 1 \mathrm{H}), 6.49(\mathrm{dt}, J=6.0 \mathrm{~Hz}$, $J=1.7 \mathrm{~Hz}, 1 \mathrm{H}), 5.83(\mathrm{dt}, J=6.0 \mathrm{~Hz}, J=1.7 \mathrm{~Hz}, 1 \mathrm{H}), 5.22-5.16(m, 4 \mathrm{H}), 5.00-4.96$ $(m, 1 \mathrm{H}), 4.34-4.19(m, 2 \mathrm{H}), 4.15-4.05(m, 4 \mathrm{H}), 3.72-3.53(m, 8 \mathrm{H}$, rotamers), $3.18-2.96(m, 12 \mathrm{H}), 1.93(s, 3 \mathrm{H}, \mathrm{H}-7), 1.74-1.59(m, 4 \mathrm{H}$, rotamers $), 1.47-1.22$
( $m, 20 \mathrm{H}), 0.92(t, J=6.2 \mathrm{~Hz}, 6 \mathrm{H}) ;{ }^{13} \mathrm{C}-\mathrm{NMR}\left(101 \mathrm{MHz}, \mathrm{CD}_{3} \mathrm{OD}\right): \delta 166.3,158.4$, $156.5,152.8,152.8,138.6,135.7,134.6,130.4(d, J=2.7 \mathrm{~Hz}), 127.2,123.2+123.0$ (rotamers), 112.0, 90.8, 87.2 $(d, J=9.2 \mathrm{~Hz}), 70.5-70.3(m), 67.9(d, J=5.9 \mathrm{~Hz})$, $67.1+66.9$ (rotamers), $48.2+47.9$ (rotamers), $47.6+47.3$ (rotamers), $35.5+35.4$ (rotamers), $35.2+35.0$ (rotamers), $32.9,30.3,30.3,30.2+30.1$ (rotamers), 27.0, $23.7,14.5,12.5 ;{ }^{31} \mathrm{P}-\mathrm{NMR}\left(162 \mathrm{MHz}, \mathrm{CD}_{3} \mathrm{OD}\right): \delta-11.71(d, J=19.2 \mathrm{~Hz}),-13.16$ $(d, J=16.7 \mathrm{~Hz}),-3.54$ (br.s, $J=17.2 \mathrm{~Hz})$; IR: $3,190,2,925,0,693,1,205 \mathrm{~cm}^{-1}$; MALDI-MS (m/z): [M-H] ${ }^{-}$calcd. for $\mathrm{C}_{52} \mathrm{H}_{79} \mathrm{~N}_{6} \mathrm{O}_{21} \mathrm{P}_{3}, 1215.444$; found, 1215.630 .

\section{$\gamma$-Bis-(4-(dodecyl-ethane-1,2-diylbis(methylcarbamate))-oxybenzyl)-d4TTP} 3q (ammonium salt). General procedure D with $78 \mathrm{mg}$ d4TDP $6(90 \mu \mathrm{mol}$, 1.0 eq.), $0.22 \mathrm{~g} 5 \mathbf{q}(0.15 \mathrm{mmol}, 1.7$ eq. $), 0.47 \mathrm{ml} 0.25 \mathrm{M}$ solution of DCI in acetonitrile $(0.12 \mathrm{mmol}, 1.3 \mathrm{eq}$.), $36 \mu \mathrm{l} 5.5 \mathrm{M}$ solution of $t$-BuOOH in $n$-decane $(0.20 \mathrm{mmol}, 2.2 \mathrm{eq}$.) in $3.0 \mathrm{ml}$ acetonitrile. The crude product was purified using automatic RP-18 chromatography (water/acetonitrile gradient). Yield: $36 \mathrm{mg}$ $(26 \mu \mathrm{mol}, 29 \%)$ colourless solid. UV (HPLC): $\lambda_{\max }=265 \mathrm{~nm}$; HPLC: $t_{\mathrm{R}}=19.04$ $\min (\operatorname{method} \mathrm{A}) ;{ }^{1} \mathrm{H}-\mathrm{NMR}\left(400 \mathrm{MHz}, \mathrm{CD}_{3} \mathrm{OD}\right): \delta 7.66$ (br.s, $1 \mathrm{H}$ ), 7.46-7.39 $(m, 4 \mathrm{H}), 7.13-7.06(m, 4 \mathrm{H}$, rotamers), $6.95-6.92(m, 1 \mathrm{H}), 6.47(\mathrm{dt}, J=6.1 \mathrm{~Hz}$, $J=1.7 \mathrm{~Hz}, 1 \mathrm{H}), 5.83-5.79(m, 1 \mathrm{H}), 5.20-5.13(m, 4 \mathrm{H}), 4.98-4.93(m, 1 \mathrm{H})$, $4.33-4.16(m, 2 \mathrm{H}), 4.14-4.01(m, 4 \mathrm{H}), 3.71-3.53(m, 8 \mathrm{H}$, rotamers), 3.17-2.93 ( $m, 12 \mathrm{H}), 1.91(s, 3 \mathrm{H}), 1.72-1.55(m, 4 \mathrm{H}$, rotamers), $1.45-1.21(m, 36 \mathrm{H}), 0.91$ $(t, J=6.6 \mathrm{~Hz}, 6 \mathrm{H}) ;{ }^{13} \mathrm{C}-\mathrm{NMR}\left(101 \mathrm{MHz}, \mathrm{CD}_{3} \mathrm{OD}\right): \delta 166.4,158.3,156.4,152.8$, $152.7,138.6,135.7,134.7-134.4(m), 130.4(d, J=2.5 \mathrm{~Hz}), 127.2,123.2+123.0$ (rotamers), 112.5, 90.8, $87.2(d, J=9.2 \mathrm{~Hz}), 70.4(\mathrm{dd}, J=5.3 \mathrm{~Hz}, J=2.2 \mathrm{~Hz}), 67.9$ $(d, J=5.0 \mathrm{~Hz}), 67.1+66.9$ (rotamers), $48.2+47.9$ (rotamers), $47.6+47.3$ (rotamers), $35.5+35.4$ (rotamers), $35.2+34.9$ (rotamers), 33.1, 30.7, 30.7, 30.6, $30.5,30.4,30.3,30.2+30.1$ (rotamers), 27.0, 23.7, 14.5, 12.5; ${ }^{31}$ P-NMR (162 MHz, $\left.\mathrm{CD}_{3} \mathrm{OD}\right): \delta-11.74$ (br.s), $-13.10(d, J=16.1 \mathrm{~Hz}),-23.51$ (br.s); IR: 3,191 , 2,922, 1,697, $1,205 \mathrm{~cm}^{-1}$; MALDI-MS $(\mathrm{m} / z):[\mathrm{M}-\mathrm{H}]^{-}$calcd. for $\mathrm{C}_{60} \mathrm{H}_{95} \mathrm{~N}_{6} \mathrm{O}_{21} \mathrm{P}_{3}$, 1327.569; found, 1327.607 .

General procedure E: preparation of 5-Nitro-cycloSal-(4-alkanoyloxybenzyl)monophosphates 17. Corresponding 4-alkanoyloxybenzyl alcohol 9 (1.0 eq.) and 2.2 eq. diisopropylethylamine were dissolved in acetonitrile or THF and cooled to $-20^{\circ} \mathrm{C}$. After dropwise addition of 2.0 eq., 5-nitrosaligenylchlorophosphite 18, dissolved in acetonitrile or THF, the reaction mixture was allowed to warm to rt. The solution was kept at this temperature for $2 \mathrm{~h}$. For oxidation, oxone ( $4.0 \mathrm{eq}$.) dissolved in water was added. The mixture was stirred for $15 \mathrm{~min}$ and immediately extracted with ethyl acetate. The organic phase was dried over $\mathrm{Na}_{2} \mathrm{SO}_{4}$, filtered and the solvent was removed by evaporation. The crude products were purified using preparative TLC (chromatotron).

5-Nitro-cycloSal-(4-acetyloxybenzyl)-monophosphate 17a. General procedure E with a solution of $0.11 \mathrm{~g} 4$-(hydroxymethyl)phenylacetate $9 \mathrm{a}(0.67 \mathrm{mmol}, 1.0 \mathrm{eq}$.) and $0.25 \mathrm{ml}$ diisopropylethylamine $(0.19 \mathrm{~g}, 1.5 \mathrm{mmol}, 2.2 \mathrm{eq}$.) dissolved in $12 \mathrm{ml}$ acetonitrile, $0.31 \mathrm{~g} 5$-nitrosaligenylchlorophosphite 18 ( $1.3 \mathrm{mmol}, 2.0 \mathrm{eq}$.) dissolved in $15 \mathrm{ml}$ acetonitrile. For oxidation $1.7 \mathrm{~g}$ oxone $(2.7 \mathrm{mmol}, 4.0$ eq. $)$ were used. The crude product was purified using preparative TLC $\left(\mathrm{CH}_{2} \mathrm{Cl}_{2} / \mathrm{MeOH} 19: 1 \mathrm{v} / \mathrm{v}+0.1 \%\right.$ HOAc). Yield: $0.12 \mathrm{~g}(0.31 \mathrm{mmol}, 46 \%)$ yellowish oil. TLC (PE/EE 1:1 v/v $+0.1 \%$ HOAc): $R_{\mathrm{f}}=0.45 ;{ }^{1} \mathrm{H}-\mathrm{NMR}\left(300 \mathrm{MHz}, \mathrm{CDCl}_{3}\right): \delta 8.15-8.05(m, 1 \mathrm{H}), 7.99-7.94$ $(m, 1 \mathrm{H}), 7.38-7.29(m, 2 \mathrm{H}), 7.08-6.95(m, 3 \mathrm{H}), 5.42-5.27(m, 2 \mathrm{H}), 5.18$ $(d, J=10.1 \mathrm{~Hz}, 2 \mathrm{H}), 2.25(s, 3 \mathrm{H}) ;{ }^{13} \mathrm{C}-\mathrm{NMR}\left(75 \mathrm{MHz}, \mathrm{CDCl}_{3}\right): \delta 172.2,154.3$ $(d, J=6.8 \mathrm{~Hz}), 151.2,143.8,132.2(d, J=5.6 \mathrm{~Hz}), 129.6,125.4,122.0,121.4,121.4$, $119.7(d, J=9.2 \mathrm{~Hz}), 70.2(d, J=6.0 \mathrm{~Hz}), 67.9(d, J=7.1 \mathrm{~Hz}), 21.0 ;{ }^{31} \mathrm{P}-\mathrm{NMR}$ $\left(162 \mathrm{MHz}, \mathrm{CDCl}_{3}\right): \delta-10.30$; IR: $3,075,1,753,1,193 \mathrm{~cm}^{-1}$; $\left.\mathrm{HRMS}_{(\mathrm{ESI}}{ }^{+}, \mathrm{m} / z\right)$ : $[\mathrm{M}+\mathrm{Na}]^{+}$calcd. for $\mathrm{C}_{16} \mathrm{H}_{14} \mathrm{NO}_{8} \mathrm{P}, 402.0349$; found, 402.0306 .

\section{5-Nitro-cycloSal-(4-nonanoyloxybenzyl)-monophosphate 17e. General} procedure E with a solution of $0.39 \mathrm{~g}$ 4-(hydroxymethyl)phenylnonanoate $9 \mathrm{e}$ ( $1.5 \mathrm{mmol}, 1.0 \mathrm{eq}$.$) and 0.55 \mathrm{ml}$ diisopropylethylamine $(0.42 \mathrm{~g}, 3.3 \mathrm{mmol}, 2.2 \mathrm{eq}$.) dissolved in $10 \mathrm{ml}$ acetonitrile, $0.69 \mathrm{~g}$ 5-nitrosaligenylchlorophosphite 18 $(3.0 \mathrm{mmol}, 2.0 \mathrm{eq}$.) dissolved in $20 \mathrm{ml}$ acetonitrile. For oxidation, $3.6 \mathrm{~g}$ oxone ( $5.9 \mathrm{mmol}, 4.0$ eq.) was used. The crude product was purified using preparative TLC $\left(\mathrm{CH}_{2} \mathrm{Cl}_{2} / \mathrm{MeOH} 19: 1 \mathrm{v} / \mathrm{v}+0.1 \%\right.$ HOAc). Yield: $0.57 \mathrm{~g}(1.2 \mathrm{mmol}, 80 \%)$ beige solid. TLC (PE/EE 1:1 v/v + 0.1\% HOAc): $R_{\mathrm{f}}=0.66 ;{ }^{1} \mathrm{H}-\mathrm{NMR}\left(300 \mathrm{MHz}, \mathrm{CDCl}_{3}\right)$ $\delta$ 8.19-8.11 $(m, 1 \mathrm{H}), 8.02-7.95(m, 1 \mathrm{H}), 7.42-7.32(m, 2 \mathrm{H}), 7.12-6.98(m, 3 \mathrm{H})$, 5.45-5.29 $(m, 2 \mathrm{H}), 5.22(d, J=10.3 \mathrm{~Hz}, 2 \mathrm{H}), 2.54(t, J=7.5 \mathrm{~Hz}, 2 \mathrm{H}), 1.74$ (quint, $J=7.5 \mathrm{~Hz}, 2 \mathrm{H}), 1.46-1.17(m, 10 \mathrm{H}), 0.87(t, J=6.8 \mathrm{~Hz}, 3 \mathrm{H}) ;{ }^{13} \mathrm{C}-\mathrm{NMR}(75 \mathrm{MHz}$, $\left.\mathrm{CDCl}_{3}\right): \delta 172.2,154.6(d, J=6.9 \mathrm{~Hz}), 151.5,143.9,132.2(d, J=5.7 \mathrm{~Hz}), 129.8$, $125.6(d, J=1.4 \mathrm{~Hz}), 122.3,121.6,121.4,119.9(d, J=9.1 \mathrm{~Hz}), 70.4(d, J=5.6 \mathrm{~Hz})$, $67.9(d, J=6.8 \mathrm{~Hz}), 34.4,31.9,29.3,29.2,29.2,24.9,22.7,14.2 ;{ }^{31} \mathrm{P}-\mathrm{NMR}(81 \mathrm{MHz}$ $\left.\mathrm{CDCl}_{3}\right): \delta-10.73 ; \mathrm{IR:} 2,921,2,852,1,749 \mathrm{~cm}^{-1}$; $\mathrm{HRMS}\left(\mathrm{ESI}^{+}, \mathrm{m} / z\right):[\mathrm{M}+\mathrm{Na}]^{+}$ calcd. for $\mathrm{C}_{23} \mathrm{H}_{28} \mathrm{NO}_{8} \mathrm{P}, 500.1445$; found, 500.1469.

5-Nitro-cycloSal-(4-octadecanoyloxybenzyl)-monophosphate 17j. General procedure E with a solution of $0.43 \mathrm{~g} 4$-(hydroxymethyl)phenyloctadecanoate $\mathbf{9 j}$ ( $1.1 \mathrm{mmol}, 1.0 \mathrm{eq}$.$) and 0.38 \mathrm{ml}$ diisopropylethylamine $(0.29 \mathrm{~g}, 2.2 \mathrm{mmol}, 2.0 \mathrm{eq}$.) dissolved in $20 \mathrm{ml} \mathrm{THF}, 0.69 \mathrm{~g}$ 5-nitrosaligenylchlorophosphite $18(1.7 \mathrm{mmol}$, 
1.5 eq.) dissolved in $15 \mathrm{ml}$ THF. For oxidation, $2.0 \mathrm{~g}$ oxone $(3.3 \mathrm{mmol}$, 3.0 eq.) was used. The crude product was purified using preparative TLC $\left(\mathrm{CH}_{2} \mathrm{Cl}_{2} / \mathrm{MeOH}\right.$ $30: 1 \mathrm{v} / \mathrm{v}+0.1 \% \mathrm{HOAc})$. Yield: $0.58 \mathrm{~g}(0.96 \mathrm{mmol}, 87 \%)$ yellowish solid. TLC $(\mathrm{PE} / \mathrm{EE} 1: 1 \mathrm{v} / \mathrm{v}+0.1 \% \mathrm{HOAc}): R_{\mathrm{f}}=0.72 ;{ }^{1} \mathrm{H}-\mathrm{NMR}\left(400 \mathrm{MHz}, \mathrm{CDCl}_{3}\right): \delta 8.19-8.14$ $(m, 1 \mathrm{H}), 8.00(d, J=2.7 \mathrm{~Hz}, 1 \mathrm{H}), 7.41-7.35(m, 2 \mathrm{H}), 7.10-7.02(m, 3 \mathrm{H}), 5.43-5.29$ $(m, 2 \mathrm{H}), 5.23(d, J=10.4 \mathrm{~Hz}, 2 \mathrm{H}), 2.55(t, J=7.5 \mathrm{~Hz}, 2 \mathrm{H}), 1.74$ (quint, $J=7.5 \mathrm{~Hz}$, $2 \mathrm{H}), 1.46-1.19(m, 28 \mathrm{H}), 0.87(t, J=6.8 \mathrm{~Hz}, 3 \mathrm{H}) ;{ }^{13} \mathrm{C}-\mathrm{NMR}\left(75 \mathrm{MHz}, \mathrm{CDCl}_{3}\right)$ $\delta 172.2,154.6,151.6,144.0,132.2(d, J=5.5 \mathrm{~Hz}), 129.9,125.7,122.2,121.6,121.3$, $120.0(d, J=9.4 \mathrm{~Hz}), 70.5(d, J=5.8 \mathrm{~Hz}), 68.1(d, J=7.1 \mathrm{~Hz}), 34.5,32.0,29.8,29.8$, 29.7, 29.6, 29.5, 29.4, 29.2, 25.0, 22.8, 14.2; ${ }^{31} \mathrm{P}-\mathrm{NMR}\left(162 \mathrm{MHz}, \mathrm{CDCl}_{3}\right): \delta-10.30$;

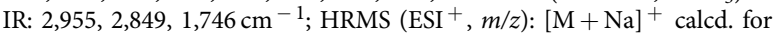
$\mathrm{C}_{32} \mathrm{H}_{46} \mathrm{NO}_{8} \mathrm{P}, 626.2853$; found, 626.2821 .

General procedure F: preparation of $\boldsymbol{\gamma}$-mono(4-alkanoyloxybenzyl)-d4TTP 4. d4TDP 6 (1.0 eq.) was co-evaporated with DMF and dried in vacuum for $2 \mathrm{~h}$. Then, 2.0-2.5 eq. of the corresponding 5-nitro-cycloSal-(4-alkanoyloxybenzyl)-monophosphate 17 was dissolved in a minimum of DMF followed by a dropwise addition to the nucleotide $\mathbf{8}$ dissolved in DMF. The reaction was stirred at $\mathrm{rt}$ for $20 \mathrm{~h}$, and the solvent was removed under reduced pressure. The residue was dissolved in $\mathrm{CH}_{2} \mathrm{Cl}_{2}$ /ammonium acetate $(1 \mathrm{M})$. The layers were separated and the aqueous layer was freeze-dried. The crude product thus obtained was purified using automatic RP-18 chromatography (water/acetonitrile gradient). Subsequently, the cations were exchanged to ammonium ions using Dowex 50WX8 (ammonium form) cation exchange resin followed by a second RP-18 chromatography.

$\gamma$-Mono-(4-acetyloxybenzyl)-d4TTP 4a (ammonium salt). General procedure F with $70 \mathrm{mg}$ d4TDP $6(81 \mu \mathrm{mol}, 1.0$ eq. $)$ in $1.0 \mathrm{ml}$ DMF and $77 \mathrm{mg} 5$-nitrocycloSal-(4-acetyloxybenzyl)-monophosphate $17 \mathrm{a}(0.20 \mathrm{mmol}, 2.5$ eq.) in $0.5 \mathrm{ml}$ DMF. Yield: $16 \mathrm{mg}(24 \mu \mathrm{mol}, 30 \%)$ colourless solid. UV (HPLC): $\lambda_{\max }=265 \mathrm{~nm}$; HPLC: $t_{\mathrm{R}}=10.88 \min (\operatorname{method} \mathrm{A}), 5.23 \min (\operatorname{method} \mathrm{B}) ;{ }^{1} \mathrm{H}-\mathrm{NMR}(400 \mathrm{MHz}$, $\left.\mathrm{CD}_{3} \mathrm{OD}\right): \delta 7.69(d, J=1.2 \mathrm{~Hz}, 1 \mathrm{H}), 7.52-7.48(m, 2 \mathrm{H}), 7.10-7.04(m, 2 \mathrm{H}), 6.95$ $(\mathrm{dt}, J=3.5 \mathrm{~Hz}, J=1.6 \mathrm{~Hz}, 1 \mathrm{H}), 6.53(\mathrm{dt}, J=6.0 \mathrm{~Hz}, J=1.7 \mathrm{~Hz}, 1 \mathrm{H}), 5.85(\mathrm{ddd}$, $J=6.1 \mathrm{~Hz}, J=2.4 \mathrm{~Hz}, J=1.7 \mathrm{~Hz}, 1 \mathrm{H}), 5.07(d, J=6.2 \mathrm{~Hz}, 2 \mathrm{H}), 5.02-4.97(m, 1 \mathrm{H})$, $4.32-4.17(m, 2 \mathrm{H}), 2.29(s, 3 \mathrm{H}), 1.93(d, J=1.2 \mathrm{~Hz}, 3 \mathrm{H}) ;{ }^{13} \mathrm{C}-\mathrm{NMR}(101 \mathrm{MHz}$, $\left.\mathrm{CD}_{3} \mathrm{OD}\right): \delta 171.3,166.7,153.0,151.7,138.7,137.4(d, J=8.7 \mathrm{~Hz}), 135.9,129.7$, 127.0, 122.5, 112.0, 90.9, $87.3(d, J=9.1 \mathrm{~Hz}), 68.2(d, J=5.3 \mathrm{~Hz}), 67.8(d, J=6.1$ $\mathrm{Hz}), 20.9,12.5 ;{ }^{31} \mathrm{P}-\mathrm{NMR}\left(162 \mathrm{MHz}, \mathrm{CD}_{3} \mathrm{OD}\right): \delta-10.95(d, J=19.0 \mathrm{~Hz}),-11.27$ $(d, J=18.8 \mathrm{~Hz}),-22.04(t, J=18.8 \mathrm{~Hz})$; IR: $3,190,2,988,1,687,1,663,1,217 \mathrm{~cm}^{-1}$; MALDI-MS (m/z): [M-H] ${ }^{-}$calcd. for $\mathrm{C}_{19} \mathrm{H}_{23} \mathrm{~N}_{2} \mathrm{O}_{15} \mathrm{P}_{3}, 611.024$; found, 611.044 .

$\gamma$-Mono-(4-nonanoyloxybenzyl)-d4TTP 4e (ammonium salt). General procedure F with $57 \mathrm{mg}$ d4TDP $6(66 \mu \mathrm{mol}, 1.0 \mathrm{eq}$.$) in 1.0 \mathrm{ml} \mathrm{DMF}$ and $63 \mathrm{mg} 5$-nitrocycloSal-(4-nonanoyloxybenzyl)-monophosphate $17 \mathrm{e}(0.13 \mathrm{mmol}, 2.0 \mathrm{eq}$.$) in 0.5 \mathrm{ml}$ DMF. Yield: $15 \mathrm{mg}(20 \mu \mathrm{mol}, 30 \%)$ colourless solid. UV (HPLC): $\lambda_{\max }=265 \mathrm{~nm}$; HPLC: $t_{\mathrm{R}}=13.03 \mathrm{~min}(\operatorname{method} \mathrm{A}) ;{ }^{1} \mathrm{H}-\mathrm{NMR}\left(400 \mathrm{MHz}, \mathrm{CD}_{3} \mathrm{OD}\right): \delta 7.70$ $(d, J=1.4 \mathrm{~Hz}, 1 \mathrm{H}), 7.53-7.47(m, 2 \mathrm{H}), 7.08-7.03(m, 2 \mathrm{H}), 6.96(\mathrm{dt}, J=3.4 \mathrm{~Hz}$, $J=1.6 \mathrm{~Hz}, 1 \mathrm{H}), 6.53(\mathrm{dt}, J=5.9 \mathrm{~Hz}, J=1.7 \mathrm{~Hz}, 1 \mathrm{H}), 5.88-5.82(m, 1 \mathrm{H}), 5.08$ $(d, J=6.1 \mathrm{~Hz}, 2 \mathrm{H}), 5.02-4.97(m, 1 \mathrm{H}), 4.34-4.17(m, 2 \mathrm{H}), 2.60(t, J=7.4 \mathrm{~Hz}, 2 \mathrm{H})$, $1.94(s, 3 \mathrm{H}), 1.76$ (quint, $J=7.3 \mathrm{~Hz}, 2 \mathrm{H}), 1.50-1.29(m, 10 \mathrm{H}), 0.94(t, J=6.7 \mathrm{~Hz}$ $3 \mathrm{H}) ;{ }^{13} \mathrm{C}-\mathrm{NMR}\left(101 \mathrm{MHz}, \mathrm{CD}_{3} \mathrm{OD}\right): \delta 173.9,166.5,152.8,151.7,138.7,137.4$, $135.9,129.7,127.0,122.5,112.0,90.9,87.3(d, J=5.2 \mathrm{~Hz}), 68.2(d, J=5.3 \mathrm{~Hz}), 67.8$ $(d, J=5.4 \mathrm{~Hz}), 35.0,33.0,30.4,30.2,30.2,26.0,23.7,14.4,12.5 ;{ }^{31} \mathrm{P}-\mathrm{NMR}$ $\left(162 \mathrm{MHz}, \mathrm{CD}_{3} \mathrm{OD}\right): \delta-10.99(d, J=19.5 \mathrm{~Hz}),-11.31(d, J=18.8 \mathrm{~Hz}),-22.12$ $(t, J=18.7 \mathrm{~Hz})$; IR: $3,258,2,973,1,691,1,066 \mathrm{~cm}^{-1}$; MALDI-MS $(\mathrm{m} / \mathrm{z})$ : $[\mathrm{M}-\mathrm{H}]^{-}$ calcd. for $\mathrm{C}_{26} \mathrm{H}_{37} \mathrm{~N}_{2} \mathrm{O}_{15} \mathrm{P}_{3}$, 709.133; found, 709.238 .

\begin{abstract}
$\gamma$-Mono-(4-octadecanoyloxybenzyl)-d4TTP 4j (ammonium salt). General procedure F with $56 \mathrm{mg}$ d4TDP $6(65 \mu \mathrm{mol}, 1.0$ eq. $)$ in $1.0 \mathrm{ml}$ DMF and $98 \mathrm{mg}$ 5-nitro-cycloSal-(4-octa-decanoyloxybenzyl)-monophosphate $17 \mathbf{j}(0.16 \mathrm{mmol}$, 2.5 eq.) in $0.5 \mathrm{ml} \mathrm{DMF}$. Yield: $15 \mathrm{mg}(17 \mu \mathrm{mol}, 26 \%)$ colourless solid. UV (HPLC): $\lambda_{\max }=265 \mathrm{~nm}$; HPLC: $t_{\mathrm{R}}=14.79 \min (\operatorname{method} \mathrm{A}) ;{ }^{1} \mathrm{H}-\mathrm{NMR}\left(400 \mathrm{MHz}, \mathrm{CD}_{3} \mathrm{OD}\right)$ : $\delta 7.70(d, J=1.3 \mathrm{~Hz}, 1 \mathrm{H}), 7.55-7.47(m, 2 \mathrm{H}), 7.10-7.02(m, 2 \mathrm{H}), 6.96(\mathrm{dt}, J=3.4$ $\mathrm{Hz}, J=1.6 \mathrm{~Hz}, 1 \mathrm{H}), 6.53(\mathrm{dt}, J=6.0 \mathrm{~Hz}, J=1.7 \mathrm{~Hz}, 1 \mathrm{H}), 5.87-5.83(m, 1 \mathrm{H}), 5.09$ $(d, J=5.8 \mathrm{~Hz}, 2 \mathrm{H}), 5.02-4.97(m, 1 \mathrm{H}), 4.36-4.16(m, 2 \mathrm{H}), 2.60(t, J=7.4 \mathrm{~Hz}, 2 \mathrm{H})$, $1.94(d, J=1.3 \mathrm{~Hz}, 3 \mathrm{H}), 1.76$ (quint, $J=7.3 \mathrm{~Hz}, 2 \mathrm{H}), 1.52-1.27(m, 28 \mathrm{H}), 0.93$ $(t, J=6.6 \mathrm{~Hz}, 3 \mathrm{H}) ;{ }^{13} \mathrm{C}-\mathrm{NMR}\left(101 \mathrm{MHz}, \mathrm{CD}_{3} \mathrm{OD}\right): \delta 174.0,166.6,152.8,151.7$, $138.7,137.2(d, J=7.6 \mathrm{~Hz}), 135.9,129.8,127.1,122.5,112.0,90.9,87.2(d, J=8.1$ $\mathrm{Hz}), 68.3,67.8,35.0,33.0,30.8,30.7,30.6,30.5,30.4,30.2,26.0,23.7,14.4,12.5$; ${ }^{31} \mathrm{P}-\mathrm{NMR}\left(162 \mathrm{MHz}, \mathrm{CD}_{3} \mathrm{OD}\right): \delta-11.14(d, J=18.2 \mathrm{~Hz}),-11.44(d, J=19.9 \mathrm{~Hz})$, $-23.82(t, J=18.6 \mathrm{~Hz})$; IR: $3,209,3,066,2,925,1,757,1,704,1,251 \mathrm{~cm}^{-1}$; MALDIMS $(m / z):[\mathrm{M}-\mathrm{H}]^{-}$calcd. for $\mathrm{C}_{35} \mathrm{H}_{55} \mathrm{~N}_{2} \mathrm{O}_{15} \mathrm{P}_{3}, 835.274$; found, 835.398 .
\end{abstract}

\section{3'-0-Acetylthymidine 20. The synthesis was carried out as described} previously ${ }^{53}$

TLC $\left(\mathrm{CH}_{2} \mathrm{Cl}_{2} / \mathrm{MeOH} 9: 1\right): R_{\mathrm{f}}=0.59 ;{ }^{1} \mathrm{H}-\mathrm{NMR}\left(400 \mathrm{MHz}, \mathrm{DMSO}-d_{6}\right): \delta 11.32$ (br.s, $1 \mathrm{H}), 7.73(d, J=1.4 \mathrm{~Hz}, 1 \mathrm{H}), 6.17(\mathrm{dd}, J=8.7 \mathrm{~Hz}, J=5.9 \mathrm{~Hz}, 1 \mathrm{H}), 5.24-5.19$ $(m, 1 \mathrm{H}), 5.20(t, J=5.1 \mathrm{~Hz}, 1 \mathrm{H}), 3.99-3.95(m, 1 \mathrm{H}), 3.62(\mathrm{dd}, J=5.3 \mathrm{~Hz}, J=3.5 \mathrm{~Hz}$, $2 \mathrm{H}), 2.33-2.15(m, 2 \mathrm{H}), 2.06(s, 3 \mathrm{H}), 1.78(d, J=1.4 \mathrm{~Hz}, 3 \mathrm{H}) ;{ }^{13} \mathrm{C}-\mathrm{NMR}(101 \mathrm{MHz}$,
DMSO- $\left.d_{6}\right): \delta 170.0,163.7,150.5,135.8,109.7,84.6,83.7,74.7,61.3,36.5,20.8,12.3$ IR: $3,468,3,181,1,706,1,659 \mathrm{~cm}^{-1}$; HRMS $(\mathrm{m} / \mathrm{z}):[\mathrm{M}+\mathrm{Na}]^{+}$calcd. for $\mathrm{C}_{12} \mathrm{H}_{16} \mathrm{~N}_{2} \mathrm{O}_{5}, 307.0901$; found, 307.0882 .

Thymidine diphosphate 22 (TDP, tetra-n-butylammonium salt). To a suspension of $1.4 \mathrm{~g} 3^{\prime}$-O-acetylthymidine 20 ( $1.8 \mathrm{mmol}, 1.0$ eq.) in $30 \mathrm{ml}$ acetonitrile, $1.3 \mathrm{ml}$ diisopropylethlyamine $(0.98 \mathrm{~g}, 7.6 \mathrm{mmol}, 1.5 \mathrm{eq}$.) was added, followed by $1.4 \mathrm{~g} 5$-chlorosaligenylchlorophosphite $8(6.1 \mathrm{mmol}, 1.2 \mathrm{eq}$.). The reaction mixture was stirred for $3 \mathrm{~h}$ and subsequently cooled to $0^{\circ} \mathrm{C}$. By addition of $1.4 \mathrm{ml}$ of a $5.5-\mathrm{M}$ solution of tert-butylhydroperoxide in $n$-decane $(7.6 \mathrm{mmol}, 1.5 \mathrm{eq}$.) the phosphite was oxidized for $20 \mathrm{~min}$. The solvent was removed in vacuum. The residue was redissolved in $\mathrm{CH}_{2} \mathrm{Cl}_{2}$ and washed with $1 \mathrm{M}$ ammonium acetate solution. The organic phase was dried over $\mathrm{Na}_{2} \mathrm{SO}_{4}$, filtered and the solvent was removed under reduced pressure. The product $\mathbf{2 1}$ (quantitative conversion) was used for further steps without purification.

5-chloro-cycloSal-3'-O-acetyl-thymidinemonophosphate $21(0.51 \mathrm{~g} ; 1.0 \mathrm{mmol}$, 1.0 eq.) was reacted with $0.89 \mathrm{~g}$ mono-(tetra- $n$-butylammonium)-monophosphate $(2.6 \mathrm{mmol}, 2.5 \mathrm{eq}$.) in $10 \mathrm{ml}$ DMF. After being stirred for $20 \mathrm{~h}$, the solvent was removed in vacuum and the residue was redissolved in a mixture of methanol/ water/tetra- $n$-butylammoniumhydroxide solution $(40 \%)$ in water $(7: 3: 1 \mathrm{v} / \mathrm{v} / \mathrm{v})$. The reaction mixture was stirred for $17 \mathrm{~h}$ for deacetylation, followed by removal of the solvent in vacuum. After extraction with water/ethyl acetate, the separated aqueous layer was freeze-dried. The crude product was purified using RP-18 chromatography (water/acetonitrile gradient: 8:1 to $4: 1 \mathrm{v} / \mathrm{v}$ ). Yield: $0.46 \mathrm{~g}$ $\left(0.52 \mathrm{mmol}, 59 \%, 2 \times \mathrm{Bu}_{4} \mathrm{~N}^{+}\right)$colourless solid. TLC (isopropanol/ $\mathrm{NH}_{3} /$ water $4: 1: 2.5 \mathrm{v} / \mathrm{v} / \mathrm{v}): R_{\mathrm{f}}=0.19 ;{ }^{1} \mathrm{H}-\mathrm{NMR}\left(300 \mathrm{MHz}, \mathrm{D}_{2} \mathrm{O}\right): \delta 7.76(d, J=1.4 \mathrm{~Hz}, 1 \mathrm{H}), 6.32$ $(\mathrm{dd}, J=7.6 \mathrm{~Hz}, J=6.4 \mathrm{~Hz}, 1 \mathrm{H}), 4.67-4.58(m, 1 \mathrm{H}), 4.22-4.08(m, 3 \mathrm{H}), 3.30-2.25$ $(m, 16 \mathrm{H}), 2.43-2.24(m, 2 \mathrm{H}), 1.91(d, J=1.4 \mathrm{~Hz}, 3 \mathrm{H}), 1.74-1.51(m, 16 \mathrm{H}), 1.35$ (sext, $J=7.4 \mathrm{~Hz}, 16 \mathrm{H}), 0.93(t, J=7.3 \mathrm{~Hz}, 24 \mathrm{H}) ;{ }^{13} \mathrm{C}-\mathrm{NMR}\left(75 \mathrm{MHz}, \mathrm{D}_{2} \mathrm{O}\right): \delta 166.3$, 151.6, 137.3, 111.7, 85.5, 84.9, 71.0, 65.3, 58.1, 38.6, 23.1, 19.1, 12.8, 11.6; ${ }^{31} \mathrm{P}-\mathrm{NMR}$ $\left(162 \mathrm{MHz}, \mathrm{D}_{2} \mathrm{O}\right): \delta-10.89(d, J=20.0 \mathrm{~Hz}),-11.53(d, J=20.0 \mathrm{~Hz})$; IR: 3,165 , 2,960, 2,875, 1,683 $\mathrm{cm}^{-1}$; HRMS $\left(\mathrm{ESI}^{+}, \mathrm{m} / z\right):[\mathrm{M}+\mathrm{H}]^{+}$calcd. for $\mathrm{C}_{10} \mathrm{H}_{16} \mathrm{~N}_{2} \mathrm{O}_{11} \mathrm{P}_{2}, 401.016$; found, 400.789 .

$\boldsymbol{\gamma}$-Bis-(4-nonanoyloxybenzyl)-TTP 3r (ammonium salt). General procedure D with $0.11 \mathrm{~g}$ TDP $22(0.13 \mathrm{mmol}, 1.0 \mathrm{eq}$ ) $), 0.17 \mathrm{~g} 5 \mathrm{e}(0.25 \mathrm{mmol}, 2.0 \mathrm{eq}$. $), 0.66 \mathrm{ml}$ $0.25 \mathrm{M}$ DCI solution $(0.17 \mathrm{mmol}, 1.3 \mathrm{eq}),. 46 \mu \mathrm{l} 5.5 \mathrm{M}$ solution of $t-\mathrm{BuOOH}$ in $n$-decane $(0.25 \mathrm{mmol}, 2.0 \mathrm{eq}$.) in $0.7 \mathrm{ml}$ acetonitrile. The crude product was purified using automatic RP-18 chromatography (water/acetonitrile gradient). Yield: $95 \mathrm{mg}$ ( $94 \mu \mathrm{mol}, 74 \%)$ colourless solid. UV (HPLC): $\lambda_{\max }=266 \mathrm{~nm}$; HPLC: $t_{\mathrm{R}}=16.56$ min (method A); ${ }^{1} \mathrm{H}-\mathrm{NMR}\left(300 \mathrm{MHz}, \mathrm{CD}_{3} \mathrm{OD}\right): \delta 7.83(d, J=1.3 \mathrm{~Hz}, 1 \mathrm{H})$, $7.42-7.33(m, 4 \mathrm{H}), 7.03-6.96(m, 4 \mathrm{H}), 6.28(\mathrm{dd}, J=7.6 \mathrm{~Hz}, J=6.0 \mathrm{~Hz}, 1 \mathrm{H}), 5.17$ $(d, J=8.0 \mathrm{~Hz}, 4 \mathrm{H}), 4.65-4.58(m, 1 \mathrm{H}), 4.30(\mathrm{ddd}, J=11.4 \mathrm{~Hz}, J=5.9 \mathrm{~Hz}, J=2.8 \mathrm{~Hz}$, $1 \mathrm{H}), 4.24-4.14(m, 1 \mathrm{H}), 4.01-3.90(m, 1 \mathrm{H}), 2.54(t, J=7.4 \mathrm{~Hz}, 4 \mathrm{H}), 2.31-2.18$ $(m, 1 \mathrm{H}), 2.12($ ddd, $J=13.5 \mathrm{~Hz}, J=6.1 \mathrm{~Hz}, J=3.3 \mathrm{~Hz}, 1 \mathrm{H}), 1.89(d, J=1.3 \mathrm{~Hz}, 3 \mathrm{H})$, $1.75-1.51(m, 4 \mathrm{H}), 1.47-1.21(m, 20 \mathrm{H}), 0.93(t, J=6.7 \mathrm{~Hz}, 6 \mathrm{H}) ;{ }^{13} \mathrm{C}-\mathrm{NMR}$ (75 MHz, $\left.\mathrm{CD}_{3} \mathrm{OD}\right): \delta 173.7,166.7,152.4,152.2,138.3,135.2(d, J=7.1 \mathrm{~Hz}), 130.5$, $122.8,112.0,87.6,85.8,72.2,70.2(d, J=5.4 \mathrm{~Hz}), 67.0,40.5,35.0,33.0,30.4$, $30.3,30.2,26.0,23.7,14.5,12.7 ;{ }^{31} \mathrm{P}-\mathrm{NMR}\left(162 \mathrm{MHz}, \mathrm{CD}_{3} \mathrm{OD}\right): \delta-13.62$ $(d, J=22.0 \mathrm{~Hz}),-15.17(d, J=17.8 \mathrm{~Hz}),-23.67(d, J=20.0 \mathrm{~Hz}) ; \mathrm{IR}: 3,182$, $2,924,1,755,1,688 \mathrm{~cm}^{-1}$; MALDI-MS $(\mathrm{m} / z)$ : $[\mathrm{M}-\mathrm{H}]^{-}$calcd. for $\mathrm{C}_{42} \mathrm{H}_{61} \mathrm{~N}_{2} \mathrm{O}_{18} \mathrm{P}_{3}$, 973.306; found, 973.491 .

Chemical hydrolysis of TriPPPro-d4TTP compounds 3a-q and intermediates $\mathbf{4 a}, \mathbf{e}, \mathbf{j}$. Stock solutions ( $50 \mathrm{mM}$ in DMSO- $d_{6}$ ) of the appropriate compounds were prepared. After dilution of $11 \mu \mathrm{l}$ with $100 \mu \mathrm{l}$ Millipore water and $189 \mu \mathrm{l}$ DMSO- $d_{6}$ to $1.9 \mathrm{mM}$ hydrolysis solutions the reaction was started by the addition of $300 \mu \mathrm{l}$ PBS (50 mM, pH 7.3). The solution was incubated at $37^{\circ} \mathrm{C}$ in a thermomixer. An initial aliquot $(25 \mu \mathrm{l})$ was taken directly and analysed by analytical HPLC at 265-266 nm. Further aliquots were taken for monitoring the kinetic hydrolysis. The exponential decay curves (pseudo-first order) based on absolute integral values were calculated with commercially available software (OriginPro 9.0G) and yielded the half-lives $t_{1 / 2}(1)$ and $t_{1 / 2}(2)$ of the prodrugs via one determination.

Enzymatic hydrolysis of TriPPPro-d4TTP compounds 3a-n and intermediates $\mathbf{4 a}, \mathbf{e}, \mathbf{j}$ with PLE. Overall, $20 \mu$ of the appropriate $50 \mathrm{mM}$ DMSO- $d_{6}$ stock solution were diluted to $6.0 \mathrm{mM}$ by addition of $83.3 \mu \mathrm{l} \mathrm{DMSO}-d_{6}$ as well as $83.3 \mu \mathrm{l}$ Millipore water. Furthermore, $140 \mu \mathrm{l}$ of the $6.0 \mathrm{mM}$ solution was diluted with $105 \mu \mathrm{l}$ DMSO$d_{6}$ and $700 \mu 150 \mathrm{mM}$ PBS buffer. The reaction was started by addition of $52.5 \mu \mathrm{l}$ of PLE in PBS buffer $\left(3 \mathrm{mg} \mathrm{ml}^{-1}\right)$ and the mixture was incubated at $37^{\circ} \mathrm{C}$ in a thermomixer. At different times, aliquots $(125 \mu \mathrm{l})$ were taken and treated as fol-

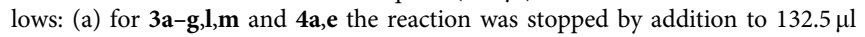
$\mathrm{MeOH}$. The mixture was kept for $5 \mathrm{~min}$ on ice followed by centrifugation for $5 \mathrm{~min}$ (13,000 r.p.m.). The supernatant was filtered (Chromafil RC-20/15 MS, $0.2 \mu \mathrm{m}$ ) and stored in liquid nitrogen. (b) For $\mathbf{3 h}, \mathbf{i}, \mathbf{k}, \mathbf{n}$ and $\mathbf{4 j}$, the sample was directly frozen in liquid nitrogen. The solution was defrosted followed by ultrasonication for $10 \mathrm{~min}$ After centrifugation for $5 \mathrm{~min}$, the supernatant was filtered (Chromafil AO-20/3, $0.2 \mu \mathrm{m}$ ) and stored at $-196^{\circ} \mathrm{C}$. (c) For $3 \mathbf{j}$, the mixture was diluted with $70 \mu \mathrm{l} \mathrm{THF}$ 
(HPLC grade) and frozen in liquid nitrogen followed by defrosting, ultrasonication, centrifugation, filtration and stored as described for (b).

Samples were defrosted and 50-80 $\mu \mathrm{l}$ were subjected to HPLC analysis. The calculation of $t_{1 / 2}$ was performed analogously to that for the chemical hydrolysis studies.

\section{Enzyme-catalysed hydrolysis of TriPPPro-d4TTP compounds 3a-n and}

intermediates $4 a, e, j$ in CEM cell extracts. A volume of $10 \mu \mathrm{l}$ of the appropriate $50 \mathrm{mM}$ DMSO- $d_{6}$ stock solution was diluted to $6.0 \mathrm{mM}$ hydrolysis solution by addition of $73.3 \mu \mathrm{l}$ DMSO- $d_{6}$. Seven different samples including $10 \mu \mathrm{l}$ water and $10 \mu \mathrm{l}$ hydrolysis solution were prepared. The reaction was started by addition of $50 \mu \mathrm{l}$ human CEM cell extract and the mixture was incubated at $37^{\circ} \mathrm{C}$ for different time periods of hydrolysis. The work-up depended on the particular compound: (a)

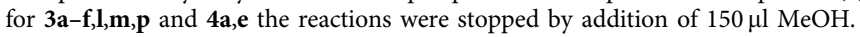
The solution was kept on ice for $5 \mathrm{~min}$ followed by centrifugation for $5 \mathrm{~min}$ (13,000 r.p.m.). The supernatants were filtered (Chromafil RC-20/15 MS, $0.2 \mu \mathrm{m}$ ) and stored in liquid nitrogen. (b) For $\mathbf{3} \mathbf{g}-\mathbf{i}, \mathbf{k}, \mathbf{n}$ and $\mathbf{4 j}$, the samples were directly frozen in liquid nitrogen. The solution was defrosted followed by ultrasonication for $10 \mathrm{~min}$. After centrifugation for $5 \mathrm{~min}$ the supernatants were filtered (Chromafil AO-20/3, $0.2 \mu \mathrm{m}$ ) and stored at $-196^{\circ} \mathrm{C}$. (c) For $3 \mathbf{j}$ the mixture was diluted with $70 \mu \mathrm{l}$ THF (HPLC grade) and frozen in liquid nitrogen followed by defrosting, ultrasonication, centrifugation, filtration and stored as described for (b). Samples were defrosted and 50-80 $\mu \mathrm{l}$ were subjected to HPLC analysis. The calculation of $t_{1 / 2}$ was performed analogously to that for the chemical hydrolysis studies.

Preparation of cell extracts. Human $\mathrm{CD}_{4}^{+} \mathrm{T}$-lymphocyte CEM cells were grown in RPMI-1640-based cell culture medium to a final density of $\sim 3 \cdot 10^{6} \mathrm{cells} \mathrm{ml}^{-1}$. Then, cells were centrifuged for $10 \mathrm{~min}$ at 1,250 r.p.m. at $4{ }^{\circ} \mathrm{C}$, washed twice with cold PBS and the pellet was resuspended at $10^{8}$ cells $\mathrm{ml}^{-1}$ and sonicated (Hielscher Ultrasound Techn., $100 \%$ amplitude, three · times for $10 \mathrm{~s}$ ) to destroy cell integrity. The resulting cell suspension was then centrifuged at 10,000 r.p.m. to remove cell debris, and the supernatant divided into aliquots before being frozen at $-80^{\circ} \mathrm{C}$ and used.

Anti-HIV activity assay. Inhibition of HIV-1(III $\mathrm{B}_{\mathrm{B}}$ )- and HIV-2(ROD)-induced cytopathicity in wild-type CEM/ 0 and TK-deficient $\mathrm{CEM} / \mathrm{TK}^{-}$cell cultures was measured in microtitre 96 -well plates containing $\sim 3 \times 10^{5} \mathrm{CEM}_{\text {cells }} \mathrm{ml}^{-1}$ infected with $100 \mathrm{CCID}_{50}$ of HIV per millilitre and containing appropriate dilutions of the test compounds. After $4-5$ days of incubation at $37^{\circ} \mathrm{C}$ in a $\mathrm{CO}_{2}$-controlled humidified atmosphere, CEM giant (syncytium) cell formation was examined microscopically. The $\mathrm{EC}_{50}$ ( $50 \%$ effective concentration) was defined as the compound concentration required to inhibit HIV-induced giant cell formation by $50 \%$.

Primer extension reactions. The used polymerase HIV RT was obtained from Roboklon. The primer and template were purchased from Life Technologies.

Primer sequence:

5'-TTGGATAGGAGGAAGTCCTGGTTGC-3'

Template sequence:

5'-AGACAAACCTATCCTCCTTCAGGACCAACG- $3^{\prime}$

The primer extension assays were performed under the following conditions:

The primer was labelled using $\left[\gamma^{32} \mathrm{P}\right]$-ATP according to standard techniques. After 5-min incubation at $95^{\circ} \mathrm{C}$ in $20 \mathrm{mM}$ Tris- $\mathrm{HCl}(\mathrm{pH} 7.6)$ and $50 \mathrm{mM} \mathrm{NaCl}$, the hybridization/annealing of the primer to the template strand was achieved by a cooling phase from 95 to $20^{\circ} \mathrm{C}$ over $3 \mathrm{~h}$. The final assay solution $(20 \mu \mathrm{l})$ consists of $2.5 \mu \mathrm{M}$ dNTPs or hydrolysate, $1 \times$ reaction buffer $(50 \mathrm{mM}$ Tris- $\mathrm{HCl}(\mathrm{pH} 8.6)$, $10 \mathrm{mM} \mathrm{MgCl}_{2}$ and $40 \mathrm{mM} \mathrm{KCl}$ ), $0.02 \mu \mathrm{M}$ of hybridization and 0.2 units of the enzyme, which was incubated at $37^{\circ} \mathrm{C}$ for $10 \mathrm{~min}$. The reaction was stopped by heating up to $80^{\circ} \mathrm{C}$ for $3 \mathrm{~min}$. The assays were separated using a denaturating PAGE (15\%). The results were visualized by phosphorimaging.

\section{References}

1. Jordheim, L. P., Durantel, D., Zoulim, F. \& Dumontet, C. Advances in the development of nucleoside and nucleotide analogues for cancer and viral diseases. Nat. Rev. Drug Discov. 12, 447-464 (2013).

2. Deval, J. Antimicrobial strategies: inhibition of viral polymerases by 3'-hydroxyl nucleosides. Drugs 69, 151-166 (2009).

3. Chilar, T. \& Ray, A. S. Nucleoside and nucleotide HIV reverse transcriptase inhibitors: 25 years after zidovudine. Antiviral Res. 85, 39-58 (2010).

4. El Safadi, Y., Vivet-Boudou, V. \& Marquet, R. HIV-1 reverse transcriptase inhibitors. Microbiol. Biotechnol. 75, 723-737 (2007).

5. Burton, J. R. \& Everson, G. T. HCV NS5B polymerase inhibitors. Clin. Liver Dis. 13, 453-465 (2009).

6. De Clercq, E. Antiviral drugs in current clinical use. J. Clin. Virol. 30, 115-133 (2004).

7. Schader, S. M. \& Wainberg, M. A. Insights into HIV-1 pathogenesis through drug discovery: 30 years of basic research and concerns for the future. HIV AIDS Rev. 10, 91-98 (2011).
8. Balzarini, J., Herdewijn, P. \& De Clercq, E. Differential patterns of intracellular metabolism of 2',3'-didehydro-2',3'-dideoxythymidine and 3'-azido-2',3'dideoxythymidine, two potent anti-human immunodeficiency virus compounds. J. Biol. Chem. 264, 6127-6133 (1989).

9. Ho, H.-T. \& Hitchcock, M. J. M. Cellular pharmacology of $2^{\prime}, 3^{\prime}$-Dideoxy- $2^{\prime}$, $3^{\prime}$-didehydrothymidine, a nucleoside analog active against human immunodeficiency virus. Antimicrob. Agents Chemother. 33, 344-349 (1987).

10. Balzarini, J. et al. The in vitro and in vivo anti-retrovirus activity, and intracellular metabolism of $3^{\prime}$-azido-2', $3^{\prime}$-dideoxythymidine are highly dependent on the cell species. Biochem. Pharmacol. 37, 2065-2068 (1988).

11. McKenna, C. E., Kashemirov, B. A., Peterson, L. W. \& Goodman, M. F. Modifications to the dNTP triphosphate moiety: from mechanistic probes for DNA polymerases to antiviral and anti-cancer drug design. Biochim. Biophys. Acta 1804, 1223-1230 (2010).

12. Freeman, S. \& Ross, K. C. Prodrug design for phosphates and phosphonates. Prog. Med. Chem. 34, 112-142 (1997).

13. Van Rompay, A. R., Johansson, M. \& Karlsson, A. Phosphorylation of nucleosides and nucleoside analogs by mammalian nucleoside monophosphate kinases. Pharmacol. Ther. 87, 189-198 (2000).

14. Meier, C., Knispel, T., De Clercq, E. \& Balzarini, J. CycloSal-Pro-nucleotides (cycloSal-NMP) of $2^{\prime}, 3^{\prime}$-dideoxyadenosine (ddA) and $2^{\prime}, 3^{\prime}$-dideoxy- $2^{\prime}$, $3^{\prime}$-didehydroadenosine $(\mathrm{d} 4 \mathrm{~A})$ : synthesis and antiviral evaluation of a highly efficient delivery system. J. Med. Chem. 42, 1604-1614 (1999).

15. Meier, C., Lomp, A., Meerbach, A. \& Wutzler, P. CycloSal-BVDUMP pronucleotides: how to convert an antiviral-inactive nucleoside analogue into a bioactive compound against EBV. J. Med. Chem. 45, 5157-5172 (2002).

16. Wagner, C. R., Iyer, V. V. \& McIntee, E. J. Pronucleotides: toward the in vivo delivery of antiviral and anticancer nucleotides. Med. Res. Rev. 20, 417-451 (2000).

17. Mutahir, Z. et al. Thymidine kinase 1 regulatory fine-tuning through tetramer formation. FEBS J. 280, 1531-1541 (2013).

18. Hecker, S. J. \& Erion, M. D. Prodrugs of phosphates and phosphonates. J. Med. Chem. 51, 2328-2345 (2008).

19. Pradere, U., Garnier-Amblard, E. C., Coats, S. J., Amblard, F. \& Schinazi, R. F. Synthesis of nucleoside phosphate and phosphonate prodrugs. Chem. Rev. 114, 9154-9218 (2014).

20. Ho, H.-T. \& Hitchcock, J. M. Cellular pharmacology of 2',3'-dideoxy-2', 3'-didehydrothymidine, a nucleoside analog active against human immunodeficiency virus. Antimicrob. Agents Chemother. 33, 844-849 (1989).

21. Zhang, Y., Gao, Y., Wen, X. \& Ma, H. Current strategies for improving oral absorption of nucleoside analogues. Asian J. Pharm. Sci. 9, 65-74 (2014).

22. Cahard, D., McGuigan, C. \& J. Balzarini, J. Aryloxyphosphoramidate triesters as pro-tides. Mini Rev. Med. Chem. 4, 371-381 (2004).

23. Meier, C. \& Balzarini, J. Application of the cycloSal-prodrug approach for improving the biological potential of phosphorylated biomolecules. Antiviral Res. 71, 282-292 (2006).

24. Meier, C. CycloSal phosphates as chemical trojan horses for intracellular nucleotide and glycosylmonophosphate delivery-chemistry meets biology. Eur. J. Org. Chem. 5, 1081-1102 (2006).

25. Meier, C., Lorey, M., De Clercq, E. \& Balzarini, J. CycloSal-2',3'-dideoxy-2', 3'-didehydrothymidine monophosphate (cycloSal-d4TMP): synthesis and antiviral evaluation of a new d4TMP delivery system. J. Med. Chem. 41, 1417-1427 (1998).

26. Jessen, H. J., Balzarini, J. \& Meier, C. Intracellular trapping of cycloSalpronucleotides: modification of prodrugs with amino acid esters. J. Med. Chem. 51, 6592-6598 (2008).

27. Gisch, N., Balzarini, J. \& Meier, C. Doubly loaded cycloSaligenylpronucleotides. 5,5'-Bis (cycloSaligenyl-2',3'-dideoxy-2',3'-didehydrothymidine monophosphates). J. Med. Chem. 52, 3464-3473 (2009).

28. Krylov, I. S., Kashemirov, B. A., Hilfinger, J. M. \& McKenna, C. E. Evolution of an amino acid based prodrug approach: stay tuned. Mol. Pharm. 10, 445-458 (2013).

29. Furman, P. A. et al. Phosphorylation of 3 '-azido-3'-deoxythymidine and selective interaction of the 5'-triphosphate with human immunodeficiency virus reverse transcriptase. Proc. Natl Acad. Sci. USA 83, 8333-8337 (1986).

30. Törnevik, Y., Ullman, B., Balzarini, J., Wahren, B. \& Eriksson, S. Cytotoxicity of $3^{\prime}$-azido- $3^{\prime}$-deoxythymidine correlates with $3^{\prime}$-azidothymidine- $5^{\prime}$ monophosphate (AZTMP) levels, whereas antihuman immunodeficiency virus (HIV) activity correlates with $3^{\prime}$-azidothymidine- $5^{\prime}$-triphosphate (AZTTP) levels in cultured CEM T-lymphoblastoid cells. Biochem. Pharmacol. 49, 829-837 (1995).

31. Mackman, R. L. et al. Synthesis and anti-HIV activity of cyclic pyrimidine phosphonomethoxy nucleosides and their prodrugs: a comparison of phosphonates and corresponding nucleosides. Nucleosides Nucleotides Nucleic Acids 26, 573-577 (2007).

32. Jessen, H. J., Schulz, T., Balzarini, J. \& Meier, C. Bioreversible protection of nucleoside diphosphates. Angew. Chem. Int. Ed. Engl. 47, 8719-8722 (2008).

33. Schulz, T., Balzarini, J. \& Meier, C. The DiPPro approach: synthesis, hydrolysis, and antiviral activity of lipophilic $\mathrm{d} 4 \mathrm{~T}$ diphosphate prodrugs. ChemMedChem. 9, $762-775$ (2014). 
34. Pertenbreiter, F., Balzarini, J. \& Meier, C. Nucleoside mono- and diphosphate prodrugs of $2^{\prime}, 3^{\prime}$-dideoxyuridine and $2^{\prime}, 3^{\prime}$-dideoxy- $2^{\prime}, 3^{\prime}$-didehydrouridine. ChemMedChem. 10, 94-106 (2015).

35. Weinschenk, L., Schols, D., Balzarini, J. \& Meier, C. Nucleoside diphosphate prodrugs: non-symmetric DiPPro-nucleotides. J. Med. Chem. 58, 6114-6130 (2015).

36. Sienaert, R. et al. Specific recognition of the bicyclic pyrimidine nucleoside analogs, a new class of highly potent and selective inhibitors of varicella-zoster virus (VZV), by the VZV-encoded thymidine kinase. Mol. Pharmacol. 61, 249-254 (2002)

37. Tan, X., Chu, C. K. \& Boudinot, F. D. Development and optimization of antiHIV nucleoside analogs and prodrugs: a review of their cellular pharmacology, structure-activity relationships and pharmacokinetics. Adv. Drug Deliv. Rev. 39, 117-151 (1999).

38. Bonnaffé, D., Dupraz, B., Ughetto-Monfrin, J., Namane, A. \& Dinh, T. H. Synthesis of acyl pyrophosphates - application to the synthesis of nucleotide lipophilic prodrugs. Tetrahedron Lett. 36, 531-534 (1995).

39. Kreimeyer, A., Andrè, F., Gouyette, C. \& Dinh, T. H. Transmembrane transport of adenosine 5 '-triphosphate using a lipophilic cholesteryl derivative. Angew. Chem. Int. Ed. Engl. 37, 2853-2855 (1998).

40. Kumar, S. et al. Terminal phosphate labeled nucleotides: synthesis, applications, and linker effect on incorporation by DNA polymerases. Nucleosides Nucleotides Nucleic Acids 24, 401-408 (2005).

41. Sood, A. et al. Terminal phosphate-labeled nucleotides with improved substrate properties for homogeneous nucleic acid assays. J. Am. Chem. Soc. 127, 2394-2395 (2005).

42. Vinogradov, S. V., Kohli, E. \& Zeman, A. D. Comparison of nanogel drug carriers and their formulations with nucleoside $5^{\prime}$-triphosphates. Pharm. Res 23, 920-930 (2006).

43. Galmarini, C. M. et al. Polymeric nanogels containing the triphosphate form of cytotoxic nucleoside analogues show antitumor activity against breast and colorectal cancer cell lines. Mol. Cancer Ther. 7, 3373-3380 (2008).

44. Peters, G. J., Adema, A. D., Bijnsdorp, I. V. \& Sandvold, M. L. Lipophilic prodrugs and formulations of conventional (deoxy)nucleoside and fluoropyrimidine analogs in cancer. Nucleosides Nucleotides Nucleic Acids 30, 1168-1180 (2011).

45. Menger, F. M., Guo, Y. \& Lee, A. S. Synthesis of a lipid peptide drug conjugateN-4-(acylpeptidyl)-ara-C. Bioconjugate Chem. 5, 162-166 (1994).

46. Ibrahim, S. S., Boudinot, F. D., Schinazi, R. F. \& Chu, C. K. Physicochemical properties, bioconversion and disposition of lipophilic prodrugs of 2',3'dideoxycytidine. Antiviral Chem. Chemother. 7, 167-172 (1996).

47. Horwitz, J. P., Chua, J., Da Rooge, M. A., Noel, M. \& Klundt, I. L. Nucleosides. IX. The formation of 2',2'- unsaturated pyrimidine nucleosides via a novel betaelimination reaction. J. Org. Chem. 31, 205-211 (1966).

48. Warnecke, S. \& Meier, C. Synthesis of nucleoside di- and triphosphates and dinucleoside polyphosphates with cycloSal-nucleotides. J. Org. Chem. 74, 3024-3030 (2009)
49. DeWit, M. W. \& Gillies, E. R. A cascade biodegradable polymer based on alternating cyclization and elimination reactions. J. Am. Chem. Soc. 131, 18327-18334 (2009).

50. Bonnaffé, D., Dupraz, B., Ughetto-Monfrin, J., Namane, A. \& Dinh, T. H. Potential lipophilic nucleotide prodrugs- synthesis, hydrolysis and antiviral activity of AZT and d4T acyl nucleotides. J. Org. Chem. 61, 895-902 (1996).

51. Sarac, I. \& Meier, C. Efficient automated solid-phase synthesis of DNA and RNA 5'-triphosphates. Chem. Eur. J. 21, 1-7 (2015).

52. Tonn, V. C. \& Meier, C. Solid-phase synthesis of (Poly)phosphorylated Nucleosides and conjugates. Chem. Eur. J. 17, 9832-9842 (2011).

53. Wolf, S., Zismann, T., Lunau, N. \& Meier, C. Reliable synthesis of various nucleoside diphosphate glycopyranoses. Chem. Eur. J 15, 7656-7664 (2009).

\section{Acknowledgements}

We are grateful to Lizette van Berckelaer, Ria Van Berwaer, Kristien Minner, Sandra Claes and Evelyne Van Kerckhove for excellent technical assistance. The work conducted by C.M. has been supported by the Deutsche Forschungsgemeinschaft (DFG; Me1161/13-1) and that of D.S. and J.B. has been supported by the KU Leuven (GOA 15/19 TBA).

\section{Author contributions}

C.M. headed the project; T.G. performed the chemical synthesis; T.D.d.O. contributed with the biochemical assays and D.S. and J.B. carried out the antiviral testing of the synthesized compounds. All authors were involved in the preparation of the manuscript.

\section{Additional information}

Supplementary Information accompanies this paper at http://www.nature.com/ naturecommunications

Competing financial interests: The authors declare no competing financial interests.

Reprints and permission information is available online at http://npg.nature.com/ reprintsandpermissions/

How to cite this article: Gollnest, T. et al. Lipophilic prodrugs of nucleoside triphosphates as biochemical probes and potential antivirals. Nat. Commun. 6:8716 doi: 10.1038 /ncomms9716 (2015).

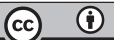

This work is licensed under a Creative Commons Attribution 4.0 International License. The images or other third party material in this article are included in the article's Creative Commons license, unless indicated otherwise in the credit line; if the material is not included under the Creative Commons license, users will need to obtain permission from the license holder to reproduce the material. To view a copy of this license, visit http://creativecommons.org/licenses/by/4.0/ 